UNIVERSIDAD NACIONAL DEL CENTRO DEL PERÚ ESCUELA DE POST GRADO MAESTRÍA EN EDUCACIÓN

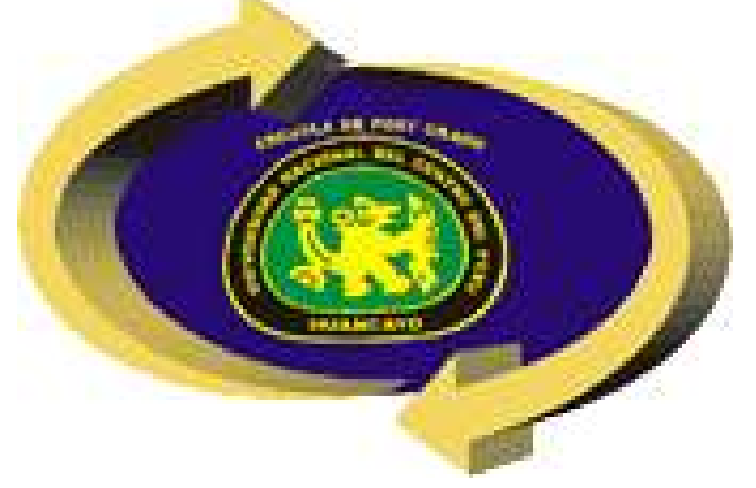

\title{
COACHING Y DESEMPEÑO DOCENTE EN LA PROVINCIA DE HUANCAYO
}

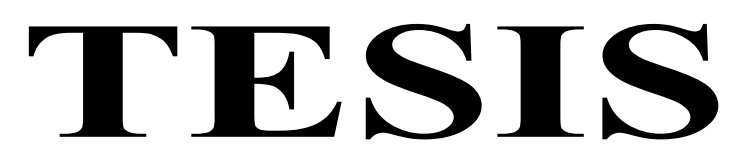

PRESENTADA POR:

CÁRDENAS VALVERDE, JUAN CARLOS

PARA OPTAR EL GRADO ACADÉMICO DE MAGÍSTER EN EDUCACIÓN MENCIÓN GESTIÓN EDUCATIVA

HUANCAYO - PERÚ 


\section{TUTOR:}

Doctor Nicanor Moya Rojas 
A los sueños de Jean Edward y Kimberly Johana:

¿Ya ven?, los míos; como los vuestros, se van cristalizando ...

A la compañia eterna de Irina Giovanna.

Decirte gracias, será siempre insuficiente...

A la perseverancia de Carolina, Cristina y Susan.

Todo lo que hacen por crecer, siempre las hará grandes...

A los ejemplos de vida de: Ibán, Elí y Abel.

Miren, los sueños, sueños son y siguen siendo gratis ...

A los 50 años de casados de: Juan e Isidora.

Eternamente gracias, por darme la vida.

Juan Carlos. 


\section{AGRADECIMIENTO}

Al R.P. Padre Fernando Luis Rodríguez Montes SDB, Director de la IEP Salesiano Santa Rosa por el apoyo incondicional e inconmensurable en la cristalización de mis estudios de post grado.

Al Dr. Nicanor Moya Rojas, por su asesoramiento constante y estricto de la presente investigación.

A los iniciadores de "CASA" de la IEP Salesiano de Huancayo: Marco Antonio Sarmiento Cornejo, Humberto Simón Limache Chale, Julio Eduardo León Cámac, Josué Taype Obregón, Juan Tito Tenorio Romero; Marcos Andrés García Rodríguez; por sus orientaciones y aliento permanente.

A Giovanna, Jean y Kimberly por su tolerancia, por esos días de ausencia; estando en casa, desaparecido, investigando.

Juan Carlos. 


\section{COACHING Y DESEMPEÑO DOCENTE EN LA PROVINCIA DE HUANCAYO}

\section{RESUMEN}

La tesis comienza con la interrogante: ¿Cuál es la influencia de la aplicación del coaching en el desarrollo del desempeño docente en la provincia de Huancayo? Objetivo: Determinar la influencia de la aplicación del coaching en el desarrollo del desempeño docente en la provincia de Huancayo. Hipótesis: La aplicación del coaching tiene influencia positiva en el desarrollo del desempeño docente en la provincia de Huancayo. La tesis es aplicada. Los métodos empleados fueron: científico, experimental, descriptivo y estadístico con un diseño cuasi experimental. La población la conformaron docentes de las IIEE secundarias de la provincia de Huancayo y la muestra, docentes Salesiano Santa Rosa y Salesiano Técnico Don Bosco de Huancayo. Las técnicas empleadas: Observación, fichaje y encuesta. Se aplicó la estadística descriptiva e inferencial. Conclusión: La aplicación del coaching tiene influencia positiva en el desarrollo del desempeño docente en la provincia de Huancayo.

Palabras clave: Coaching, Desempeño Docente, Huancayo. 


\section{PERFORMANCE COACHING AND TEACHING IN THE PROVINCE OF HUANCAYO}

\section{SUMARY}

The thesis begins with the question: What is the influence of the application of coaching in the development of teaching performance in the province of Huancayo? Objective: To determine the influence of the application of coaching in the development of teaching performance in the province of Huancayo. Hypothesis: The application of coaching has a positive influence on the development of teaching performance in the province of Huancayo. The thesis is applied. The methods used were: scientific, experimental, descriptive and statistical with a quasiexperimental design. The population was made up of teachers from secondary Secondary Education in the province of Huancayo and the sample, teachers Salesiano Santa Rosa and Salesian Technical Don Bosco de Huancayo. The techniques used: Observation, signing and survey. Descriptive and inferential statistics were applied. Conclusion: The application of coaching has a positive influence on the development of teaching performance in the province of Huancayo.

Keywords: Coaching, Teaching Performance, Huancayo. 


\section{Í N D I C E}

Portada.

Tutor.

Dedicado a. $\quad$ iii

Gracias a. iv

Resumen. $\quad \mathrm{V}$

Sumary. $\quad$ vi

Índice del documento. vii

Tablas estadísticas. $\quad$ xi

Gráficos y figuras xii

Introducción. xiii

I

PLANTEAMIENTO DEL PROBLEMA

1.1. Caracterización. 16

1.2. Formulación. 21

1.3. Objetivos. 22

1.3.1. General. $\quad 22$

1.3.2. Específicos. 22

1.4. Importancia y justificación de la investigación. 23

1.4.1. Importancia. 24

1.4.2. Justificación. 23

1.5. Limitaciones. 25

1.5.1. Limitaciones teóricas. 25

1.5.2. Limitaciones metodológicas. 25 


\section{II \\ MARCO TEÓRICO}

2.1. Antecedentes. 27

2.1.1. Internacionales. 27

2.1.2. Nacionales. 28

2.1.3. Locales. 29

2.2. Bases teóricas. 31

2.3. Bases conceptuales. 32

2.3.1. El coaching. $\quad 32$

2.3.1.1. ¿Qué es el coaching? 32

2.3.1.2. ¿Cuándo dar coaching? 33

2.3.1.3. ¿Cómo funciona el coaching? 34

2.3.1.4. ¿Quién es el coach? 35

2.3.1.5. Características del coaching. $\quad 39$

2.3.1.6. Elementos del coaching. $\quad 41$

2.3.1.7. Modalidades del coaching. $\quad 42$

2.3.2. Desempeño docente. 45

2.3.2.1. ¿Qué debe conocer el docente? 49

2.3.2.2. Actuación del buen docente? 50

2.3.2.3. Resultados del buen docente en su práctica profesional? 52

2.3.2.4. Indicadores del desempeño docente. 54

2.3.2.5. Criterios para evaluar el desempeño docente. $\quad 60$

2.3.2.6. Propósito de evaluación del desempeño docente. 61

2.3.2.7. Procedimientos de evaluación del desempeño docente. 62

2.3.2.8. Funciones de la evaluación 66

2.4. Hipótesis. $\quad 67$

2.4.1. General. $\quad 67$ 
2.4.2. Específicas.

2.5. Variables e indicadores. 69

2.5.1. Variables. 69

2.5.2. Operacionalización de las variables. 69

2.5.3. Escala de medición. 72

\section{III \\ METODOLOGÍA DE LA INVESTIGACIÓN}

3.1. Tipo.

3.2. Nivel.

3.3. Métodos.

3.3.1. General. $\quad 73$

3.3.2. Particulares. $\quad 74$

3.4. Diseño.

3.5. Población y muestra. $\quad 76$

3.5.1. Población. $\quad 76$

3.5.2. Muestra. $\quad 76$

3.6. Técnicas e instrumentos de recolección de datos. 77

3.6.1. Técnicas. $\quad 77$

3.6.2. Instrumentos. $\quad 77$

3.6.3. Validación del instrumento. 78

3.7. Recolección de datos (procedimientos). 80

3.8. Procesamiento y análisis de resultados. 81

IV

RESULTADOS

4.1. Presentación de resultados. 82

4.1.1. Resultados del grupo control. 82

4.1.2. Resultados del grupo experimental. 97 
4.2. Prueba de hipótesis.

\section{V APORTES DE LA INVESTIGACIÓN}

5.1. Teóricos. 119

5.2. Institucionales o adopción de decisiones. 121

CONCLUSIÓN. 122

SUGERENCIA. 124

BIBLIOGRAFÍA.

ANEXOS. 130

- Programa de aplicación del coaching y el desempeño docente en la provincia de Huancayo.

- Ficha de evaluación por juicio de expertos del desempeño docente.

- Ficha Evaluación del Desempeño Docente.

- Tabulación de resultados. (Excel) 


\section{ÍNDICE DE TABLAS ESTADÍSTICAS}

Tabla 01: Matriz de consistencia de la variable independiente. $\quad 70$

Tabla 02: Matriz de consistencia.

Tabla 03: Resumen. 76

Cuadro $\mathrm{N}^{\circ}$ 01: Validez de la ficha de evaluación de

Desempeño docente (Datos generales) 79

Cuadro $\mathrm{N}^{\circ}$ 02: Validez de la ficha de evaluación de desempeño docente (Resumen). 80

Cuadro $N^{\circ}$ 03: Datos obtenidos del grupo control. 83

Cuadro N 04: Resumen estadístico del grupo control. 84

Cuadro N 05: Resultados por sexo del grupo control. 85

Cuadro N 06: Resultados por edad del grupo control. 86

Cuadro N07: Resultados por institución educativa grupo control. $\quad 88$

Cuadro $N^{\circ}$ 08: Resultados por nivel educativo del grupo control. 89

Cuadro N 09: Resultados por área del grupo control. 90

Cuadro $N^{\circ} 10$ : Resultados por observación de entrada

$\begin{array}{ll}\text { grupo control. } & 92\end{array}$

Cuadro $N^{\circ}$ 11: Resultados por observación de salida grupo control. 94

Cuadro N¹2: Resumen de los resultados - grupo control. 96

Cuadro $\mathrm{N}^{\circ}$ 13: Datos obtenidos del grupo experimental. 97

Cuadro N¹4: Resumen estadístico del grupo experimental. 99

Cuadro N 15: Resultados por sexo del grupo experimental. 100

Cuadro N 16: Resultados por edad del grupo experimental. 101

Cuadro N 17: Resultados por IE del grupo experimental. 103

Cuadro N 18: Resultados por nivel educativo grupo experimental. 104

Cuadro N¹9: Resultados por área. 105

Cuadro $N^{\circ} 20$ : Resultados de la observación de entrada del GE. 
Cuadro $N^{\circ} 21$ : Resultados de la observación de salida del

GE.

Cuadro $\mathrm{N}^{\circ}$ 22: Resumen de los resultados del

GE.

\section{ÍNDICE DE GRÁFICOS}

Gráfico N 01 Resultados por sexo del grupo control. 85

Gráfico N ${ }^{\circ} 02$ Resultados por edad del grupo control. 87

Gráfico Nº3 Resultados por institución educativa grupo control. 88

Gráfico N 04 Resultados por nivel educativo grupo control. 89

Gráfico Nº5 Resultados por área del grupo control. 91

Gráfico Nº6 Resultados por observación de entrada grupo control. 93

Gráfico N 07 Resultados por observación de salida grupo control. 95

Gráfico Nº8 Resultados por sexo del grupo experimental. 100

Gráfico Nº9 Resultados por edad del grupo experimental. 102

Gráfico N 10 Resultados por institución educativa del

grupo experimental. 103

Gráfico N 11 Resultados por nivel educativo grupo experimental. 104

Gráfico N 12 Resultados por área del grupo experimental. 106

Gráfico N 13 Resultados por observación de entrada del grupo experimental.

Gráfico N 14 Resultados por observación de salida del grupo experimental. 


\section{INTRODUCCIÓN}

Excelentísimo señor presidente,

Miembros del jurado.

Presento la tesis: COACHING Y DESEMPEÑO DOCENTE EN LA PROVINCIA DE HUANCAYO, cuyo objetivo es obtener el grado de Magíster en Gestión educativa.

La educación es un fenómeno de contacto; es decir, el docente está en permanente contacto con sus estudiantes. Los estudiantes con sus padres, los padres de familia con la sociedad; esto, es un total contacto interminable.

Hacia el centro educativo también surgen contactos, el profesor no sólo está en contacto con sus estudiantes, sino también con sus pares (otros docentes) que conversan e interactúan para compartir conocimiento y estrategias en aras de mejorar el rendimiento académico de sus alumnos. 
El profesor también está en contacto con los coordinadores de área, subdirector, tutor y director.

Este contacto le permite a los docentes compartir experiencias. A veces, no se da ese contacto como debiera darse.

El director es el llamado a dar asesoría en las diferentes dificultades que hacia el centro educativo pueda surgir, en especial al director y este acercamiento le permitirá aplicar una estrategia interesante llamada coaching.

La tesis comienza con la interrogante: ¿Cuál es la influencia de la aplicación del coaching en el desarrollo del desempeño docente en la provincia de Huancayo? Objetivo: Determinar la influencia de la aplicación del coaching en el desarrollo del desempeño docente en la provincia de Huancayo. Hipótesis: La aplicación del coaching tiene influencia positiva en el desarrollo del desempeño docente en la provincia de Huancayo. La tesis es aplicada. Los métodos empleados fueron: científico, experimental, descriptivo y estadístico con un diseño cuasi experimental. La población la conformaron docentes de las IIEE secundarias de la provincia de Huancayo y la muestra, docentes Salesiano Santa Rosa y Salesiano Técnico Don Bosco de Huancayo. Las técnicas empleadas: Observación, fichaje y encuesta. Se aplicó la estadística descriptiva e inferencial. Conclusión: La aplicación del coaching tiene influencia positiva en el desarrollo del desempeño docente en la provincia de Huancayo.

Para lograr un adecuado entendimiento y comprensión del mismo, la tesis tiene cinco capítulos:

1) Planteamiento del problema, 2) Marco teórico, 3) Metodología de la investigación, 4) Análisis e interpretación de resultados y 5) Aportes de la investigación. 
Además de la conclusión, sugerencia y anexos correspondientes. Sin olvidar la bibliografía.

MI gratitud eterna al Dr. Nicanor Moya Rojas por sus reiteradas charlas nocturnas para llegar al éxito en la redacción del presente informe final. 


\section{1 PLANTEAMIENTO DEL ESTUDIO}

\subsection{CARACTERIZACIÓN DEL PROBLEMA.}

El desempeño docente de los profesores de Educación Básica Regular en los niveles inicial, primaria y secundaria de la provincia de Huancayo está venido a menos, por un sinfín de acciones que no realizan para beneficiar al alumno en su verídica formación integral, desarrollando sus capacidades, destrezas y habilidades. Esto lo podemos comprobar con el informe de evaluación de la postulación a la carrera pública magisterial región Junín que al $80 \%$ han desaprobado o alcanzado notas desaprobatorias, menos de 14. MINEDU -REGIÓN JUNíN (2009).

Ante ello el gobierno peruano propone la inserción de los docentes a la carrera pública magisterial MINEDU (2009); donde explican que sus sueldos (como una motivación al desarrollo y logro de desempeño docente); eso hará que, los docentes se animen a mejorar su desempeño laboral. Sin embargo la mayoría de profesores tienen deficiencias en el logro académico cuando culmina el año escolar; la formación integral de sus alumnos no es la que se espera, pues, a pesar de muchos esfuerzos, 
en las pruebas internacionales Perú muestra un resultado nada alentador, ubicándose en los puestos finales de los diferentes informes de evaluación. Existen para ello muchos factores, uno en especial, el que Perú es grupo control en estas evaluaciones y no grupo experimental, lo que significaría revertir de alguna manera estas deficiencias. INFORMES PISA - UNESCO (2002, 2006 y 2009).

El año 2010, nuevamente se tuvo resultados mínimos, a pesar de lograr 14 de nota aprobatoria y el ministerio de educación publicó comunicados que los docentes en un $70 \%$ aprobaron. Esto es una verdad a medias, pues no mencionan, que solo el $15 \%$ ha pasado la valla de tener la posibilidad de nombrarse al alcanzar un promedio de 14. MINEDU (2010). Estas calificaciones tampoco alcanzan al engrandecimiento de al menos un punto porcentual en lo que corresponde evaluación escrita a los alumnos y docentes respectivamente. Esto dificulta aún más la autoestima de los padres de familia, las familias completas.

El año 2011, sí se logró un avance respecto al examen de nombramiento, pues los resultados mejoraron al $18 \%$.

En la provincia de Huancayo, en especial los centros educativos estatales; existe una característica permanente en los docentes (llegar tarde, faltar) a pesar de que no existe tráfico y que puedan seguir mejorando sus alumnos. Ya que existen denuncias en CADER de la Unidad de Gestión Educativa Local de Huancayo de lo mencionado. Además de que su trabajo y desempeño docente no es el que se espera; pareciera que van a cumplir su permanencia en el plantel y no realmente alcanzar las metas en el cumplimiento de los propósitos de la educación y 
menos de los perfiles ideales que cada centro educativo propone en la formación y desarrollo integral de sus alumnos. Los docentes cumplen su hora de trabajo y se retiran a otras labores y/o responsabilidades, haciendo que el problema presentado no mejore y se siga manteniendo en un círculo interminable. Consultando con alguno de ellos (profesores de la provincia de Huancayo), mencionan que esto no sucedería si los sueldos fueran los adecuados y la canasta básica familiar pueda ser copado y cubierto por nuestros sueldos.

Con todo esto, los alumnos junto a los padres de familia terminan en la encrucijada de no confiar en los docentes, sus profesores que deben darle ejemplo para ser grande académicamente.

Además, preguntando a los Directivos (aprovechando, la coyuntura de las capacitaciones de PRONAFCAP y otras que se organizan en nuestro medio), manifiestan que sus docentes tienen serios problemas de identidad para con la institución en especial en la ejecución y evaluación del desempeño docente, en especial del monitoreo, supervisión y acompañamiento real que debe realizársele; pero, solo queda en papeles y no se avanza realmente. Inclusive, la Gerencia Regional de Educación Junín (GRE-J) o la Unidad de Gestión Educativa Local de Huancayo (UGEL-H), no hacen efecto multiplicador de un real y confiable monitoreo al docente. Esto porque, por razones políticas (y es conocido por todos) se cambian a los especialistas permanentemente, quizás, a lo mucho cada 3 ó 6 meses. Apenas comienzan a conocer la problemática y la realidad de la UGEL respectiva, los cambian. 
Por lo presentado líneas arriba, el gobierno peruano debe y tiene que plasmar una propuesta que permita revertir esta situación caótica para el magisterio peruano.

Por una parte tenemos docentes que sólo cumplen su labor de clase (en el nivel secundario), lo cual hace que al toque del timbre, se retiren de la institución educativa y no planifican y dejan de lado aspectos que puedan servir para mejorar y revertir las diferentes dificultades que se encuentra en un plantel cualquiera.

Esto permitiría que el gobierno planifique un continente de propuestas, en especial de capacitación permanente y continua para que el profesor aplique estrategias adecuadas, metodología acorde a las expectativas internacionales; ya que, muchos de los estudiantes, salen de nuestras fronteras para conseguir un bienestar y mejora auténtica. Algunos otros se enfrentar a trabajos inmediatos en los que los jefes solicitan que estén preparados para enfrentar de una vez, un arte y oficio que haga las veces de tener al empleado efectivo ahora mismo.

Otro contingente de personas, en especial los padres de familia quieren y desean que sus hijos logren las habilidades, destrezas y competencias que les permita trabajar y así ayudar a la alicaída magra economía familiar y pueda traer al menos un pan más para la casa a diario. El sentir de los padres de familia, los profesores y en especial de los alumnos es justamente ello. Ahora, nos encontramos también ante un panorama desconcertante, el $60 \%$ de los docentes a nivel nacional con contratados. Debe existir una norma que les permita darle seguridad a cada docente con la finalidad de que trabaje identificándose de la mejor 
manera posible ante sus jefes y subordinados. Esta política de nombramiento debe comenzar con revalorar el buen desempeño del docente, pero, con costumbres todavía arraigadas de retirarse del plantel, no apostar por algunas horas adicionales y lograr los resultados esperados (por el centro educativo y por el ministerio de educación).

Debe existir también una política institucional en la que todos los docentes y actores educativos involucrados deban de identificarse con el contexto en el que viven y así poder establecer metas que ayuden a mejorar a diario como personas y como integrante importante de nuestra sociedad, pues si un docente no conoce un contexto determinado experimentará algún tipo de estrategia, método, técnica, procedimiento u otro arte para enseñar y no para que sus alumnos aprendan. Esta política debe ser interna, en cada centro educativo se debe y tiene que mejorar de manera sustancial el conocimiento del lugar a donde irán a trabajar.

Además, el gobierno debe establecer políticas de reconocimiento a los docentes que sin lugar a dudas, viajan hasta tres días de canino (a pie o en acémilas) para llegar a dictar a los estudiantes y lograr resultados significativos. Debemos rescatar los artículos que establece el Proyecto Educativo Regional (PER), Diseño Curricular Regional (DCR), Diseño Curricular Nacional (DCN) y Proyecto Educativo Nacional (PEN), pues incentivan y reconocen la labor del docente que conoce y se identifica con el contexto al que irá a trabajar y si es oriundo del lugar (el docente) con mayor razón debe de identificarse y valorar lo rico de sus tradiciones y mostrar al mundo ese algo que se puede mejorar y corregir. Esto se mejoraría a través del coaching. 
No hay coaching si no hay acción del participante. El coach nos ofrece mucho más que una conversación interesante, puesto que el proceso se va completando con la realización de distintos hitos que le ayudan a avanzar por su camino. El coaching logra resultados favorables y sorprendentes si en realidad lo aplicamos con la vehemencia y consistencia posible. Los docentes que tienen dificultades deben y tienen que tener un coach a su lado y de esta manera en la provincia de Huancayo se podrán mejorar los resultados académicos y serán significativos, ya que depende de muchos factores y hoy, al menos pretendemos y presentamos uno: el coaching.

\subsection{FORMULACIÓN DEL PROBLEMA.}

\subsubsection{Problema general.}

¿Cuál es la influencia del coaching en el desarrollo del desempeño docente en la provincia de Huancayo?

\subsubsection{Problemas específicos.}

Este problema, tarea consigo, un sinfín de posibilidades, y los objetivos específicos que proponemos son;

¿Existe un programa de coaching para el desarrollo del desempeño docente en la provincia de Huancayo?

¿Qué características tiene el coaching?

¿Cuáles son las ventajas y desventajas del coaching? 
¿Cuál es el nivel de desempeño docente antes y después del experimento?

¿Cuáles son los indicadores del desempeño docente?

¿Cuáles son los resultados al aplicar el coaching en los grupos control y experimental?

\subsection{OBJETIVOS.}

\subsubsection{General.}

Establecer la influencia del del coaching en el desarrollo del desempeño en la provincia de Huancayo.

\subsubsection{Específicos.}

1. Proponer y experimentar un programa de coaching en el desarrollo del desempeño docente en la provincia de Huancayo.

2. Establecer características que tiene el coaching.

3. Identificar las ventajas y desventajas del coaching.

4. Establecer el nivel de desempeño docente en la provincia de Huancayo antes y después del experimento. 
5. Identificar los indicadores del desempeño docente.

6. Analizar, comparar e interpretar los resultados en los grupos control y experimental.

\subsection{IMPORTANCIA Y JUSTIFICACIÓN.}

Todo trabajo muestra y manifiesta un cambio cualitativo y significativo en aras de lograr la mejora de los estudiantes, esta mejora, ayudará y permitirá ser líder en su centro educativo y abanderar el cambio que todos queremos.

Lo importante para la investigación es que dará a conocer a los directores que mediante el coaching (interacción entre personas; una que conoce y sabe más que la otra) sus docentes pueden encontrar un avance significativo en el logro de resultados que todos esperan. Los padres de familia conocerán y entenderán que pueden apoyar esta propuesta (el coaching) y puedan colaborar para que las capacitaciones fluyan de inicio a final.

\subsubsection{Importancia.}

- Práctica. La ejecución de la variable independiente (coaching) en los profesores está supeditada a su correcta aplicación y permanente uso con los docentes de la provincia de Huancayo. 
- Teórica. La información presentada sobre las variables dependiente e independiente, permitirá conocer de manera contextualizada estos datos y así beneficiar a otros investigadores acerca del tema.

- Social. Esta información será compartida, por diferentes medios, a todos los docentes que se interesen y puedan valorar el aporte significativo que hemos encontrado. Además permitirá saber que la interacción entre estudiante-docente, docente-directivo, es muy importante.

- Metodológica. Permite a los directores de las Instituciones Educativas de la Provincia de Huancayo adecuar su trabajo de Gestión Docente a la orientación permanente, ya que cada director es potencialmente el coach del centro educativo en el que lidera la educación.

\subsubsection{Justificación.}

La presente investigación sirve para que los directivos de las instituciones educativas (primero de la provincia de Huancayo y luego a nivel nacional) mejoren sus aspiraciones, metas y objetivos institucionales de manera sustantiva y significativa, mediante la aplicación del coaching con los docentes. 


\subsection{LIMITACIONES DE LA INVESTIGACIÓN.}

\subsubsection{Limitaciones teóricas.}

- De acuerdo al diseño de investigación se trabajó con dos grupos establecidos (I.E.P. Salesiano Santa Rosa de Huancayo: Grupo Experimental) e (I.E.P. Salesiano Técnico Don Bosco: Grupo control) lo que permite determinar dar los resultados para la población elegida solamente.

- La falta de bibliografía especializada y otros estudios iniciales respecto al tema a nivel de post grado, principalmente.

- A nivel del instrumento, para la validez y confiabilidad se empleó el juicio de expertos.

\subsubsection{Limitaciones metodológicas.}

- Confortantes de la muestra: para los fines del estudio se seleccionaron a los profesores de las IE: Salesiano Santa Rosa y Técnico Don Bosco.

- Variables intervinientes: Se ha establecido para la investigación las variables intervinientes: edad, sexo y nivel educativo.

- Del instrumento de investigación: El instrumento de investigación utilizado evalúa únicamente las dimensiones de: Planificación, Ejecución, Verificación y Evaluación de la sesión de clase. 
- Del tiempo de aplicación: La investigación se realizó los años 2010 y 2011. 


\section{II \\ MARCO TEÓRICO}

\subsection{ANTECEDENTES.}

\subsubsection{Internacionales.}

Palma (2000) Plantea que las condiciones laborales deben ser consideradas dentro de un modelo de diagnóstico desde la psicología organizacional.

Ello implica que, si queremos tener resultados favorables; como resultado de un trabajo adecuado y pertinente, éste debe partir de qué condiciones la empresa le está brindando al trabajador, empleado u otro, pues de ello dependerá la satisfacción laboral que el empleado podrá asumir y el resultado será el que todos esperamos, un trabajo de calidad.

Cedeño (2008) En la investigación sobre El coaching como herramienta gerencial para optimizar el desempeño laboral del docente de la UNEFA.

Manifiesta que para lograr un resultado favorable y que el desempeño del docente sea el que la universidad espera, éste tiene 
y debe partir de elementos que sólo la universidad pueda brindar, como tener un director líder, cuyo liderazgo enamore e inspire a los seguidores, además de tecnologías que permitan su aplicación. Justamente el coaching permite que se pueda transformar en política organizacional cuando éste sea aplicado teniendo una cultura de apertura, al cambio y seguir demostrando que la gerencia y el desempeño docente van de la mano pues el coaching es una herramienta en las manos del líder y el decano, rector y el mismo docente es el líder que la organización esperaba.

\subsubsection{Nacionales.}

Mendoza (2009) en la investigación: Coaching y su aplicación en la IE 14344-Piura, concluye que: a) El coaching, ayuda a los docentes a mejorar sus destrezas de trabajo a través de elogios y retroalimentación positiva basado en observación. Esto se puede evidenciar rescatando los aspectos teóricos que tiene el coaching. Es decir, se basa fundamentalmente en el acompañamiento que tiene de parte de un entrenador que es el coach hacia un alumno que domina poco y tiene una experiencia básica o desconocida, entonces el coaching entra a tallar mediante la escucha atenta, la determinación de estrategias que le permiten finalmente al líder que maneja y conoce al alumno, la estrategia a tratar. Además, el coaching permite que el mismo entrenante, pueda dar la solución él mismo, es decir, el mismo interesado en mejorar puede plantear una estrategia tal que le permite mejorar de manera significativa. 
Adriano (2007) En la investigación "Clima organizacional y satisfacción laboral en las instituciones educativas del distrito de Satipo", concluye que a un mejor nivel de satisfacción laboral existirá siempre un clima institucional, organizacional estructura y planificado. Es de vital importancia llevarse bien en el trabajo, sin digresiones, sin envía, sin egoísmo, esto permitirá y determinará que los empleados y todos los involucrados con el quehacer organizacional tengan como resultado, una correcta y buena satisfacción laboral, por lo que los empleadores y líderes que tienen a cargo la empresa podrán decir misión cumplida. Además existe una relación directa entre el clima organizacional y la satisfacción laboral, el líder debe conocer a los empleados de tal manera que puedan sentirse identificados con cada uno de ellos en el campo de acción. En los centros educativos, sucede lo mismo, el director o directora debe planear un plan de manejo de clima laboral organizacional para que los resultados en la satisfacción laboral sea la esperada.

\subsubsection{Locales.}

De La Cruz (2009) en la tesis: Clima laboral y Desempeño Docente concluyen que de existir un adecuado clima laboral el desempeño, será eficiente y efecto en cada docente que integra la institución educativa; es por ello que los docentes motivados tendrán un desempeño favorable.

Montalvo (2008) en la investigación: Motivación y Desempeño Docente, dan a conocer la conclusión categórica que es la de 
proporcionar al docente de estrategias de motivación, aspectos psicológicos que éste debe y tiene que manejar y hacerlas propias frente a los estudiantes y así mejorar su aspecto moral, económico y político; sin olvidar aspectos importantes como el social y ético, pues mejorará su entusiasmo, y anímicamente se desempeñará mejor. Dentro de las diferentes esferas de la motivación encontramos la más importante que es la afectiva, pues el director es el encargado de proporcionarla.

Salomé (2008), en la investigación: El liderazgo estratégico del director y su relación entre el desempeño docente, menciona claramente que el director debe tener una metodología adecuada para cada uno de los docentes con quienes trabaja; es decir, debe conocer a cada integrante de su personal docente y saber qué estrategia sería la que ayude a este profesional a ser mejor y diferente. Esto lo comprobamos en las IE de San Agustín de Cajas, donde fue aplicado este experimento.

Calderón (2007). En la tesis Autoestima y liderazgo en directores de las IE de Huancayo, concluye que los docentes cuya autoestima es elevada, pueden mejorar su relación laboral y por ende manifestar la práctica efectiva del liderazgo; esto se evidencia porque la persona con autoestima elevada, tendrá la posibilidad de dirigir mejor aspectos de su emocionalidad y los resultados laborales serán diferentes, mejores a los que tienen la autoestima baja, además, ellos ejecutarán la aplicación del liderazgo de manera oportuna, adecuada y en especial pensando en los resultados que 
todos esperan, que ganen los estudiantes de las instituciones educativas a las que pertenecen. Ellos mismos (los docentes) serán los responsables de un cambio cualitativo. El director ayudará mucho en este aspecto, ya que él, si no conoce a sus docentes, los resultados serán uno más y no el que pretende la investigación.

\subsection{BASES TEÓRICAS QUE FUNDAMENTAN LA INVESTIGACIÓN}

La presente investigación: Coaching y desempeño docente, tiene fundamentos en la psicología cognitiva, debido a que el ser es un ente pensante, con sentimientos, graduable, plástico, moldeable y ello permite que se adapte a normas, reglas y esquemas fijos, además se permite analizar información y datos pertinentes del complejo mundo humano. Su emoción está controlada, aunque debe plantear alternativas de mejora y construcción de un resultado adaptable a lo que se requiere y desea emplear.

Gardner (1988) brinda sus características:

1. Requiere de la aplicación de un estudio cooperativo e interdisciplinario; es decir, necesita de otras ciencias para que pueda funcionar de manera óptima, tal como la lingüística (manera adecuada de comunicarnos), psicología (estudio de los procesos mentales del ser humano), antropología (estudio del hombre), cibernética (estudio de la interacción del hombre con las tecnologías), matemática (estudio del cálculo), entre otras. 
2. Proporciona el empleo de un esquema computacional de la mente humana es su total y verídica funcionalidad partiendo desde tres perspectivas: a) permite simular procesos; b) es un modelo de pensamiento y c) analizar información (datos) proporcionados por los medios externos y procesos por el individuo.

3. Establece el nivel de representación ya que funciona a partir de reglas, símbolos, esquemas, imágenes e ideas; además de otras y diferentes maneras de representación de la mente. Esto permite que el cerebro funciona y aprenda aspectos relacionados con lo que se desea conocer en un sentido libre, amplio y diferente,

4. Tiene poca importancia por las emociones o afectos debido a que el conocimiento es el que prevalece dentro en su formación.

Es por ello que la psicología cognitiva permite adentrarnos con mayor fortuna en el dominio y conocimiento del coaching.

\subsection{BASES CONCEPTUALES (Definición de términos).}

\subsubsection{EL COACHING.}

\subsubsection{1. ¿Qué es el Coaching?}

O'connor (2005) manifiesta que es un método de entrenamiento individual a través de la comunicación. Esto se podrá lograr gracias a que una persona con mayor conocimiento y 
mayor experiencia, pueda comunicarse con otra que necesita y desea aprender y mejorar aspectos relacionados a su trabajo, persona y esto se realiza gracias a la comunicación e interacción que ambos podrán tener y manifestar. Es una ayuda mutua, el entrenador ayudará a su discípulo y éste a su vez obtendrá mayores potenciales de sí mismo mediante respuestas que proporcionará.

Whitmore (2010) incluye instrumentos de medición, procesos, conceptos, herramientas de trabajo y estructuras. Como vemos se incluyen aspectos variados para la mejora de la personalidad del coachee, es decir, la persona que necesita ser asesorada debe y tiene que recurrir a una persona que le ayudará mediante instrumentos diferentes de medición a mejorar su personalidad, metodología, aspectos que sólo él desea y sabe, como también aprenderá conceptos y procesos que esta teoría trae consigo. Sin duda el coaching ayuda a ser mejor persona, a ser mejor cada día, se alimenta de un desarrollo evolutivo y personalizado, esta estrategias no podrá ser empleada por otro entrenador ni en otro entrenante porque las personas somos única y capaces de mejorar por cuenta propia y apropiación de elementos nuevos.

\subsubsection{2.¿Cuándo dar coaching?}

O'connor (2005) indica que: 
- Cuando un profesor pretende mejorar alguna destreza personal en su trabajo.

- Cuando un docente merece ser felicitado por su aporte al centro educativo.

- Cuando alguno de los involucrados pueda brindar retroalimentación.

Como vemos, existe la necesidad de aplicar coaching en estas circunstancias y esto puede ampliarse de manera diferente en aspectos todavía no presentados o estudiados.

\subsubsection{3. ¿Cómo funciona el coaching?}

Whitmore (2010) manifiesta que funciona en un diálogo entre coach (entrenador) y coachee (entrenante, discípulo).

- El entrenador tiene un compromiso con los resultados que proporcionará; su honestidad, su verídico esfuerzo para ser grande.

- De parte del entrenante hay un compromiso de proponer un resultado favorable del que todos esperan. Este logro será el logro de todos.

A todo esto debemos incluir que el entrenador (coach) es la persona que desarrolla bien y mejor los oídos, pues tendrá una forma única de escuchar a sus discípulos y podrá proporcionarle un método o técnica adecuada para mejorar y sobresalir. 
También el coach sabe, de acuerdo a Flores (2006), que la mejor forma de dar a conocer un enfoque, estrategias o práctica es a través del lenguaje que expresa, la manera adecuada de comunicarse.

Cabe mencionar que los entrenadores trabajar, de manera fundamental, con los estados de ánimo; es decir, captan lo que el entrenante o discípulo anhela y desea, a partir de la coyuntura social, contextual u otra, el coach opta por manejar los estados de ánimo de manera favorable y los resultados son óptimos y no porque uno despertó con el pie derecho. Todo esto se hace posible, sin embargo con disciplina, normas, reglas que ambos (entrenante y entrenador) han establecido para la consecusión de dichos resultados que ambos aspiraban y esperaban. Esto determina en que el trabajo el coordinado y mancomunado.

\subsubsection{4. ¿Quién es un entrenador?}

O'connor (2005) manifiesta que es una persona que se ha especializado entre muchos aspectos en dar consejería partiendo de la experiencia propia del entrenante. Aprovecha como ninguno su conocimiento y grandeza de persona que es para dar consejería a los discípulos y alumnos.

\section{a) Particularidades:}

Hendricks (1996) da a conocer dichas particularidades: siendo estas: 1) Respeto, 2) Claridad, 3) Construcción de 
confianza, 4) Perspectiva, 5) Apoyo, 6) Riesgo, 7) Paciencia, 8) Confidencialidad y 9) Mutualidad.

En este aspecto es muy importante entender que el respeto se da de manera horizontal, todos respetan a todos, desde el director hasta el último empleado.

La claridad se evidencia en la manera de cómo manifiesta sus ideas a través del diálogo entre todos los que se involucran cuando se efectúa el coaching; es decir, el director debe tener claras sus ideas para comunicar a sus pares y estos a su vez expresarlo y recibirlo de la forma más humilde que se pueda aceptar una comunicación.

La comunicación aterrizará en la consecución de la confianza que todos deben inspirarse. El coach es la primera persona en dar confianza a todos y gracias a ello se logrará lo que todos aspiramos: confianza.

Respetar el punto de vista de los integrantes en este proceso se denomina perspectiva, pues, todos trabajan en función a un mismo objetivo, de manera clara y bien puesta.

Además el apoyo es sinónimo natural al aplicar el coaching entre los docentes de una institución educativa, pues, el entrenador apoya y ayuda de manera seguida y personalizada las ideas y claridad de todos los entrenantes.

Pero, ¿qué ocurre cuando existen errores? Pues, significa que estamos avanzando, ya que nuestros errores ayudarán a mejorar aspectos como errores se puedan presentar. El riesgo que 
se asume es porque estamos seguros que también debemos atravernos.

La paciencia es otra característica que se manifiesta en cada uno de los coach, debido a que no todo lo que se pretenda lograr se hará en un instante inmediato, la paciencia es asumida con tranquilidad, pues los entrenantes, no tienen el ritmo del coach y viceversa.

¿Qué sucede con lo platicado entre coach y entrenantes? Se queda entre ellos, no se divulga, se propone que el entrenante mejore y a pesar de tener errores, estos errores se quedarán en el proceso del diálogo, ya que, alguno puede ser susceptible de emociones y se arruinaría el trabajo.

Finalmente, una característica del coach es la mutualidad, es decir, la manera de compartir la misma idea, la misma visión entre todos, esas metas comunes nos harán crecer de manera sencilla.

\section{b) Conducta del Coach.}

Hendricke (1996) indica que los valores mencionados anteriormente relacionados al coach serán plasmados gracias a las conductas evidenciables que éste tendrá que demostrar.

Entre estas conductas están las siguientes: 1) Afirmar, 2) Disciplina, 3) Reflejar, 4) Atención, 5) Indagar.

La afirmación expresa estar de acuerdo con las ideas del coach, sin dudas, relajos ni murmuraciones, debido a que se tiene 
una confianza plena y segura respecto a la fe ciega que se debe tener al líder.

La disciplina, es otra de las conductas que se evidencia en el diario vivir del coach, debido a que el líder es una persona ordenada, organizada y tiene todo previsto y normado. Además brinda la posibilidad de estar bien ante todos los ojos que los observan a diario.

Una conducta especial que tiene el coach es sin duda, la de establecer un orden importante para obtener la información que será vertida luego ante sus entrenantes; se trata del reflejo, es decir, reflejar la misma información de calidad, que tiene que buscar el líder a diario para dar a sus discípulos de manera clara, el reflejo que él busca se otorga sin problemas a los demás. Aunque le cueste recopilar dicha información días y meses. Igual el reflejo será entregado sin quitar nada.

Otra conducta expresada por el coach es la atención, que se refiere al instante en el que él tendrá que prestar a los discípulos con el ánimo de ayudarlos porteriormente. Estar atento implica que sus cinco sentidos deben estar acorde a lo que el coach necesita para poder expresar a sus entrenantes. Estar atento también implica que le presten atención sus alumnos cuando él interviene en preguntas y las posteriores respuestas que en suma, ayudarán al producto que todos esperan en el centro educativo. El rendimiento académico, el desarrollo de una conducta, la consecución de ideas para formar y lograr un objetivo común. 
Sin duda, la conducta que le ayuda a trascender al coach es la indagación, debido a que él debe buscar la información adecuada, necesaria y pertinente en todos los rincones y bibliotecas existentes. Actualmente se cuenta con la red de redes internet para que puedan ser consultadas varias fuentes que permitirán facilitar el trabajo adecuado, organizado por el coach para que sus discípulos consigan la meta planeada.

Esta conducta debe ser coherente de manera diaria, es decir, permanente, debido a que si queremos sincerar la actitud de un líder, ésta actitud y comportamiento debe manifestarse de manera diaria, pues, sin duda será el sello personal de aquel que trabaja y utiliza el coaching en su trabajo diario.

\subsubsection{Características del coaching.}

Whitmore (2010) aclara que son: 1) Responsabilidad compartida, 2) Interactiva, 3) Respeto, 4) Concreta y 5) Forma específica.

Describiendo cada una de ellas manifestamos que para lograr la responsabilidad compartida, todos los involucrados en el sistema de aplicación del coaching tendrán que estas involucrados de manera inmediata, permanente y total, pues cada uno aporta con mucha calidad el trabajo que esperan; lo único que aspiran y esperan será que si uno cumple, es porque la meta ha sido planificada y comunicada y si alguno falla, será porque no desea 
participar ni permanecer en el sistema de aplicación del coaching que pueda beneficiar a todos los integrantes.

Lo mencionado permite saber también que otra característica es la interacción que tienen todos los involucrados en el proceso de aplicación del coaching para el ogro de un objetivo o meta a seguir. Esto lo evidenciamos cuando interactúan tanto el coach con el entrenante a favor de un mismo y único objetivo. Ambos son forjadores de cambio para el beneficio de la meta planteada.

La característica elemental por naturaleza es el respeto que todos se tienen, debido a que sin ella el trabajo será uno mediocre. No queremos lograr trabajos a media agua o a media caña, se pretende lograr el cien por ciento de éxito y esto se logrará gracias al respeto. El respeto es la madre de todas las propuestas que se han tenido en cuenta. Se persigue con mucho anhelo estas finezas de la conducta humana a través de la característica que inspirará a todos los integrantes.

La característica pequeñita y no menos importante es que las actividades sean concretas. Claras, pues sin un objetivo claro y concreto, sólo se conseguirá un resultado más y no el que esperamos.

Lo antes mencionado no es más que el reflejo de que lo que queremos lograr con eficacia es el forma concreta, es decir, de manera específica, debido a que no deben perderse más tiempo ni 
esfuerzo para decir que se ha logrado algo más, se debe lograr lo que realmente se ha establecido.

\subsubsection{Elementos.}

O'connor (2005) indica que el coaching tienen los elementos que a continuación se indican: 1) Resultados, 2) Disciplina, 3) Valores, 4) Entrenamiento.

No hay coaching sin resultados, debido a que el objetivo principal del coaching es haber planificado, organizado, organizado y ejecutado un resultado previsto.

Sigue como elemento primordial la disciplina, debido a que tanto el coach como el entrenante deben jugar un papel importante que consiste en asumir con creces y bastante humildad, la de crecer junto y eso se logra con apoyo mutuo y disciplina permanente pues ello lo llevarán al logro de un resultado esperado.

Los valores es otro elemento en el coach, pues sin valores las personas no son nada ni logran objetivos ni nada.

Finalmente el entrenamiento es un elemento primordial, pues la práctica contínua y constante será la que evidencia que se ha planificado y logrado un objetivo en común,

Estos elementos aplicados de manera conjunta ayuda a lograr los resultados que se esperan y se han planificado. Los elementos pueden aplicarse de manera indistinta, es decir, en un orden diferente, debido a la plasticidad que tendrán tanto el coach como el entrenante. 


\subsubsection{Modalidades del coaching.}

Whitmore (2010) manifiesta que las modalidades del coaching son: 1) Redes o asociaciones de coaching, 2) integral, 3) Co-active, 4) Autocoaching, 5) De la variedad, 6) de vida, 7) ejecutivo, 8) Estructural, 9) coercitivo, 10) filosófico, 11) sistémico.

Una modalidad natural que se evidencia en nuestro diario vivir son las redes o asociaciones de coaching, debido a que gracias a las redes sociales, Facebook y otra red, permite que los involucrados estarán involucrados de manera permanente. Hay facilidad en la actualidad, pues un buen grupo de intelectuales, alumnos y padres de familia cuentan con una computadora conectada a internet y le pueden sacar el máximo provecho. Además existen asociaciones, grupos, clubes de coaching donde pueden compartir experiencias y ser mejor cada día. Lo único que se necesita son las ganas de querer interactuar con las demás personas para alcanzar el objetivo deseado de ese anhelo que deben haberse planteado.

La modalidad principal del coaching es que este sea integral, integral para lograr aspectos relacionados a una programación, a un plan, a un objetivo que se tiene planeado, debido a que sin un plan, o una visión en la mente de antemano se logrará los resultados que se esperan. La situación integral en una actividad planificada viene a ser esa organización pormenorizada, específica que el coach planificó el coach. El entrenante también trabaja de manera integral, pues, sabe y tiene que luchar, eliminando taras, 
errores, trabas, inconvenientes que impiden el logro de las metas o resultados. El entrenante es responsable para que estos resultados sean alcanzados por él. La integralidad se pone de acuerdo con los integrantes del coach, pues, poco a poco, se van integrando las líneas de trabajo de querer conseguir un resultado esperado. Esta situación sólo depende de la rigurosidad por lograr un verdadero logro.

La modalidad co-active permite brindar a los involucrados la co participación en los resultados que se esperan; es decir, primero se logra establecer la meta, el objetivo, la finalidad; luego, las estrategias, la metodología que se debe aplicar en la experiencia; además de la ejecución de la misma, está en función a los lineamientos que se esperaba lograr. La co participación resulta, luego de establecer responsabilidades que tanto coach como entrenante deben y tienen que conseguir. Este tipo de práctica viene, actualmente, siendo utilizada por las redes sociales, los correos electrónicos que ayudan a mejorar e interactuar de manera inmediata entre más de dos participantes.

El autocoaching es otra modalidad. El aprendizaje autónomo, individual, que pueda ayudar a crecer a su propio ritmo, buscando la información que uno mismo desea y quiere lograr. Esta modalidad ayuda y facilita a los coach que realmente desean cumplir metas, sin tener ningún temor a equivocarse pues deben y tienen que lograr de manera inmediata los resultados que se esperan. El interesado debe buscar información luego de haber 
establecido su propia meta, además de ello debe establecer la metodología que empleará en la consecución de los logros que él mismo ha establecido. La verificación de los resultados están inmersos en el tiempo en que el coach ha establecido. Normalmente los resultados son los que se esperan desarrollar de manera rápida, en un corto tiempo, pues, la mayoría de resultados están en función a los hechos inmediatos. En Educación los resultados se le conoce como plan de acción, pues, la metodología será siempre de manera inmediata. El cronograma será revisado de manera estricta por el mismo sujeto que ha planeado y ejecutado la actividad.

El coaching de la variedad permite aprovechar todos los recursos con que se dispone a nivel local, distrital, provincial, regional, nacional e internacional; pues, en la página web que está en la red de redes internet, se encuentran muchos vínculos relacionados a las actividades que se pretende, y desea aprovechar de manera inmediata. La información es tan reciente que se puede opinar de manera inmediata, en vivo. Existen respuestas ante una opinión determinada, ante un proceso y empleo de recursos que se están utilizando, en todos los idiomas, y los traductores de google se encargan de transformarlos en la lengua natal, oriunda para que pueda beneficiar en lograr la meta prevista. Los recursos son variados, la variada literatura especializada que se encuentra en las bibliotecas, ayudan a escoger, lo mejor que se quiere y pretende. 
EL coaching de vida, es una de las modalidades más usuales en las redes y en la realidad. En las librerías las podemos encontrar como biografías, personas que destacan en los diferentes ámbitos de la vida humana. En nuestro caso, nos interesan los resultados que se han opinado y establecido relacionados a la educación, también tenemos profesores, académicos o intelectuales que parten de su realidad y hacen que podamos seguir mejorando nuestra alicaída sociedad. Vemos y revisamos material e información de la aplicabilidad que se vienen realizando en países vecinos. De otras latitudes y los resultados estratégicos las empleamos de manera inmediata en nuestra realidad.

Otras modalidades del coaching es el ejecutivo, orientado de manera directa a la vida administrativa, empresarial, organizativa. Un colegio es un centro educativo que permite que un gerente (líder-coach) pueda asumir responsablemente los resultados que se pretendan conseguir. Las modalidades también existentes en nuestro medio son: la estructural, el coercitivo, el filosófico y el sistémico.

\subsubsection{DESEMPEÑO DOCENTE}

Miranda y Ragni (2007) manifiestan que una herramienta fundamental para gestionar la calidad docente es la evaluación del desempeño docente. Esto, lo podemos evidenciar en el buen trabajo que proponen educadores, docentes, preceptores, 
enseñantes, instructores, que desean evidenciar que su trabajo reúne las condiciones necesarias de un trabajo adecuado. Entonces, resulta claro y evidente que una herramienta fundamental para evidenciar un correcto y trabajo de calidad es el desempeño docente. Este desempeño será una evidencia y muestra que lo que queremos lograr es un resultado favorable para toda la comunidad educativa en nuestro centro educativo. El docente establece los logros que anhela. Sin embargo, en nuestro medio, esto es una práctica lírica, subjetiva, pues, únicamente en el papel funciona bien y no en la práctica permanente ni diaria. Eso, porque existen diferentes factores para que un docente se desanime y no otorgue un resultado mínimamente alcanzable para las grandes mayorías.

Valdez (2004) pone énfasis en que esta evaluación del desempeño docente es un proceso sistemático; pues, sino se consiguen datos organizados, buenos, confiables y verídicos, como que la evaluación del mismo será nuevamente subjetivo, inalcanzable. Esta evaluación debe estar planificada, debido a que se necesitan prueban contundentes y evidentes de un avance significativo de resultados que se pretende lograr. Es sistemática porque entra en juego un sinfín número de entes que se involucran en la experiencia. Los docentes necesitan evidenciar que los procesos presentados son evolutivos, se deben registrar en algún documento y que éste quede como evidencia física palpable de lo que se quiere y debe observar. Es sistemático porque también 
participan muchas personas; no sólo se involucra al docente, sino a los coordinadores de área, al director de la institución educativa y en especial a los directivos de la Ugel, los especialistas que deben y tienen la obligación de brindar respuestas inmediatas a problemas que se presentan.

Teniendo en cuenta a los autores antes mencionados, diremos que si el desempeño docente puede evidenciarse en una clase, por el desempeño efectivo en el aula, será uno de los tantos motivos de evaluación de dicho desempeño. Otra forma de evidenciar es que puedan filmar la clase.

Los directores solicitan la carpeta pedagógica a todos los docentes que serán evaluados, y esto establece que el docente deba dar el ejemplo con contar con documentos fidedignos que evidencian su trabajo en el aula, aunque la información que tendrá en dicha carpeta no solo muestra un sinnúmero de evidencias palpables de su trabajo actuado. Los directores (a veces, se dejan engañar, pues, evidencian los papeles de la carpeta de trabajo o portafolio, pero no evidencian su aplicación, tal cual fue planificado en el aula. Esto se evidencia en el campo de acción, pues de acuerdo al tamaño de la institución educativa o cantidad docente, el director no se da abasto para poder visitar a los docentes y aun así, si se detectara alguna falencia, nos e hace una retroalimentación adecuada, debido a que muchos directores no son de la misma especialidad que el docente monitoreado o supervisado. 
Un docente que no motive a sus estudiantes a ser mejores personas, que logren el desarrollo de su propia identidad y los objetivos propios del centro educativo, no podría haber logrado un resultado favorable para beneficio del centro educativo, menos para el alumno.

El profesor tiene la responsabilidad de facilitar y promover en el estudiante el desarrollo de una comunicación efectiva, debido a que cuando egrese (el estudiante) debe enfrentar a una sociedad que se comunica de manera permanente y fluida. Si el docente no ha logrado este desarrollo, entonces las condiciones en las que enseñado, no le permiten haber alcanzado los niveles mínimos de comunicación. El aprendizaje que se debe desarrollar de parte de un docente hacia sus estudiantes debe partir de un ejercicio sencillo y práctico que consiste en acompañar al menor en el logro de objetivos que el mismo alumno deba haber propuesto para sí, con ayuda del mismo docente (la autonomía), si la autonomía no se ha logrado, entonces el docente ha fallado, le falta mejorar aspectos profesionales para dicho logro.

Rolf (2006) precisa que un docente sin metodología, no logrará lo que espera. Efectivamente, un docente debe y tiene que establecer una metodología apropiada para cada uno de los alumnos, esto significa que si el docente tiene veinte alumnos, al menos de veinte maneras diferentes debe haber planificado su trabajo en el aula, estos resultados sí serán significativos en el aula y lo que mejor aspirará el docente es conocer a sus alumnos. Nos 
preguntamos ¿cuántos docentes conocen realmente a sus alumnos? Probablemente la respuesta será por más absurda, muchos docentes pretenden conocer a sus estudiantes, sin embargo, no los conocen, a ninguno en toda la magnitud del conocimiento. Se debe precisar que conocer y hablar acerca de ellos, significa que sabrá emplear una estrategia metodológica adecuada.

Brophy (1986) afirma que el docente debe de tenerse un gran dominio de la materia. Sin duda, este es un aporte significativo, pues, un docente que no conoce de manera inmediata su materia no debe estar frente a los estudiantes. Conocer y tener estricto dominio de su área significará que el alumno trabajará de manera pertinente y adecuada a un ritmo que todos esperan.

Woolfolk (1999) precisa que el docente debe tener muchas facetas que lo hacen eficaz en el aula, esto significa que; si conoce bien a sus alumnos y estudiantes, los resultados serán siempre efectivos, pero ¿cuántos docentes conocen a sus estudiantes? Sin duda para lograr los resultados esperados, los docentes deben hacer de todo para mantener concentrado a los estudiantes para un par de horas pedagógicas de clase. Aunque no nos hemos preguntado ¿cuántos alumnos se concentran y tienen interés por dicho curso? La respuesta también es complicada, muchos alumnos no tienen conciencia de por qué están en la escuela. La idea es aprender conocimientos, no repetir contenidos que de manera permanente se da en las instituciones educativas. 


\subsubsection{1. ¿Qué debe saber el correcto profesor?}

Hernández (2000) menciona que afirma el profesor correcto y adecuado, el buen docente, es aquel docente que tiene cuidado milimétrico a diferentes aspectos, entre ellos citamos, que debe conocer a sus estudiantes, debido a que no se puede aprovechar mejor lo que no se conoce. Otro aspecto importante es que debe dominar el curso o área que tiene a cargo, es decir, si el docente no conoce su área sólo será un simple transmisor de discursos o información, es diferente cuando el docente logra cautivar a los alumnos de manera inmediata con el dominio de su área; pero sin duda, se debe tener mayor cuidado es el lenguaje que emplea el docente, es decir, la comunicación es muy importante y el profesor tienen que conocer a la perfección a sus estudiantes, la manera de cómo entienden más rápido y mejor

\subsubsection{2. ¿Cómo debe actuar el correcto profesor?}

Todo docente debe y tiene que lograr aspectos importantes si pretende alcanzar una meta trazada, estos aspectos le permitirán tener una actuación en el aula.

El docente que se respeta comenzará por los resultados que pretende alcanzar.

A partir de estos resultados iniciará la elaboración fehaciente de los instrumentos de evaluación que le permitirán conseguir y evidenciar estos resultados, teniendo en cuenta los documentos oficiales nacionales, regionales, locales e institucionales. 
Entonces ahora puede iniciar su programación, esta planificación le permitirá proyectar los resultados, partiendo; sin embargo, de conocer a cada uno de sus alumnos, o sea, debe conocer el contexto con el que trabaja, su sociedad, el entorno geográfico, cultural, social, económico, físico, biológico, entre otros, pues de esto dependerá que el docente consiga sacar lo mejor de lo mejor en cada estudiante. Para ello, conversará con los padres de familia, se involucrará en la sociedad que le toca trabajar (hasta ahora el docente es autoridad en cualquier sociedad; esto ocurre principalmente en las zonas rurales) para que así logre lo que se debe de lograr.

El lenguaje que emplee en la consecución de dichos resultados le permitirá establecer si la planificación tiene una adecuada metodología. Si el docente debe lograr un desarrollo pleno de aspectos cognitivos, la estrategia a emplear será rica en el desarrollo de aspectos cognitivos, así para cada una de las propuestas que el mismo docente pretende de lograr.

El docente debe de relacionarse con sus pares, o sea, los demás docentes de la institución educativa, esta unidad le permitirá conseguir resultados adecuados y significativos de acuerdo a lo establecido por él. Sin duda, una tarea difícil que entre docentes lo puedan realizar, debido a que existen un sin número de trabas para que los docentes se reúnan y piensen en un objetivo común que es el del centro educativo. Debe conversar mucho con los directivos e interactuar con ellos para que, entre todos ayuden a elaborar el 
proyecto educativo institucional o las metas establecidas en el centro educativo. No todo es gratuito. El estado debe tener en cuenta cómo debe motivar a los docentes para que se comprometan en este compromiso natural.

\subsubsection{3. ¿Qué resultados se espera?}

Lo mencionamos líneas arriba. Tenemos para esta pregunta algunas respuestas.

El Ministerio de Educación, pretende lograr resultados nacionales, en función a resultados internacionales y tratar de formar a los estudiantes con una mirada holística internacional; es decir, a raíz de las experiencias internacionales se establecerán objetivos para nosotros. Sin embargo, se olvida que el papel lo soporta todo, mejor dicho, se toma en cuenta el logro de dicho país, y no las condiciones con la que cuenta dicho país (económicas, geográficas, etc) para que dicho resultado sea evidente y lograble. También se debe tener en cuenta ello.

El Proyecto Educativo Nacional, tiene su propia lógica y mecánica, es decir, los objetivos institucionales ahora se hacen para cada centro educativo, el logro de un objetivo en especial debe alcanzarse en cada centro educativo; sí o sí, pues, de ello depende los resultados que se habían planificado. El Consejo Nacional de la Educación se olvida que también hacia cada región, provincia y distrito se tienen objetivos plenos de cada distrito, no todos los pobladores del Perú anhelan tener las mismas 
condiciones y deseos y aspiraciones. Todos aspiran de acuerdo al medio y contexto en el que los rodea.

Algunos gobiernos regionales han establecido su propio proyecto educativo regional, teniendo en cuenta que su aporte permitirá el logro de su región. Cada provincia que integra dicha región ayudará a establecer estos resultados con el apoyo de cada ciudadano de la región. Sin embargo, también dichos gobiernos regionales, no tienen en cuenta que sus pobladores no todos piensan de la misma manera; es decir, el aspecto geográfico, sociopolítico y económico permite que sus aspiraciones puedan verse truncadas o no. Pareciera que no se tiene en cuenta el aspecto cultural, un pueblo que ha vivido bajo sus propias normas y leyes y costumbres jamás podrá aspirar aspectos que se relacionen con lo que no le corresponde; es decir, los Ashaninkas no podrán pensar ni aspirar aspectos que los citadinos aspiran. Cada cultura tiene su propia dinámica de vida.

Pocas provincias han establecido lineamientos de política para el crecimiento de su localidad, muchas autoridades sólo gobiernan políticamente el municipio pero no así gobiernan los aspectos más importantes de las personas: valores, aspiraciones, proyectos, deseo, anhelos. Algún municipio provincial o distrital se ha preguntado ¿Qué queremos lograr académicamente y por que queremos hacerlo? Sin duda, es una aspiración un poco complicada pero no imposible. 
Las instituciones educativas, sin embargo son las llamadas a establecer los lineamientos de qué queremos lograr en nuestros centros educativos, y en especial como resultado en nuestros estudiantes, las características y cualidades de nuestros docentes. Debemos comenzar a establecer de que cultivar la responsabilidad, el liderazgo el deseo por aprender, sentido de la comunicación y de ser un docente nato, es parte elemental que todo docente debe desarrollar por sí mismo. Pues, está comprobado que ninguna universidad nos da lo que nuestra vocación hace al natural. Ningún instituto superior pedagógico podrá otorgarnos lo que nuestra dedicación natural hace. Sin embargo, no es pedir mucho pero el docente debe reunir cualidades individuales de respeto, liderazgo, metodología, investigación, y que domine su área.

Además este docente debe saber interactuar con sus pares, desenvolverse con los demás colegas y personas con las que se involucran.

Cardó (2010) menciona que si el docente no domina ni desarrolla características propias de un docente por vocación, no podrá desarrollar en él la pasión por enseñar. Estas características son logrables de manera inmediata.

\subsubsection{Indicadores esperados.}

En el Consorcio de Colegios Católicos de la Provincia de Huancayo, han adaptado indicadores para las siguientes dimensiones: 

A) Logros de aprendizaje
B) Contenido del área curricular.
C) Estrategias metodológicas en el desarrollo de la clase.
D) Clima para el aprendizaje.
E) Materiales educativos.
F) Evaluación de los aprendizajes.

Se entiende que para lograr un desempeño adecuado y alturado en el aula, todo docente debe de desempeñarse (de manera evidente) teniendo en cuenta los logros que ha establecido en el aprendizaje de sus estudiantes; es decir, si él puede lograr informar a los alumnos lo que se pretende conseguir a lo largo de la clase, la semana, el mes, la unidad, el bimestre, el semestre, el año, pues, depende de ello para que las aspiraciones planificadas sean evidentes al culminar el año lectivo. Quiere decir que todo docente está en la obligación de comunicar los propósitos diarios de la clase con la finalidad de alcanzar (sumando todas las clases) el resultado deseado en la planificación y programación que se ha anticipado.

Una dimensión muy importante es sin lugar a dudas conocer y dominar el contenido del área que el docente estará a cargo. No podemos atentar con brindar un conocimiento o desarrollar una capacidad, si el docente no está preparado en lo más mínimo.

Lo mencionado anteriormente en este numeral, permite también saber si el docente está preparado para el manejo de una 
metodología en especial; es decir, debe y tiene que conocer al menos cien estrategias metodológicas que implica aplicar y dar a conocer su área. Ello implica que le permitirá conocer, mediante saberes previos, qué aspiran los estudiantes y sabrá relacionar estos conocimientos con los que se darán a conocer. Los docentes están llamados a motivar a los docentes, es decir, desarrollar actividades motivadoras, inspirantes, motivacionales para que los estudiantes se enamoren de manera inmediata de lo que se espera conseguir. Además de ello, se les pide que conozcan a los alumnos a fin de que los resultados que se pretenden lograr sean los que realmente se conocen. El docente además sabrá sacarle provecho al tiempo mediante estrategias que le permitan lograr en el tiempo previsto (cuarenta cinco minutos, noventa minutos o más) el resultado que se había planificado desde siempre. Ello también implica que realizará retroalimentación (en el mismo tiempo, no otro) si se requiere para la clase.

Todo esto funcionará de acuerdo a la manera de tratar a los estudiantes. Todo docente debe tener, no solo tolerancia ni empatía, sino paciencia que le permita saber hasta cuanto se puede conseguir a partir de los recursos con que dispone en el centro educativo y en especial en el aula. El clima del aula también es demostrado a partir de las aspiraciones que los mismos alumnos tienen y desean. No se trata de levantar la voz o disimular que todo está bien, si no se tiene en claro y plano una aspiración adecuada. 
Los materiales educativos también son muy importantes. Se anhela que el gobierno pueda dotar de materiales educativos (de calidad) a los alumnos de los diferentes centros educativos estatales de nuestra patria, con la finalidad de que estos materiales estén su alcance. Aunque parece un sueño, es un deseo fehaciente. A pesar de ello, todo docente debe adaptarse al medio en el que trabaja y debe utilizar y emplear materiales educativos que también los pueda adaptar.

Finalizamos con el cuco que tiene todo docente: la evaluación, en realidad no es terrible de conocer y dominar la evaluación si se ha tenido desde siempre un pensamiento bien establecido y claro. Por ello, en la propuesta se estableció que si el docente ya sabe lo que quiere y desea, el docente podrá proponer y utilizar instrumentos que se amoldan a su propia realidad, es decir, todo docente sabe qué quiere alcanzar y lograr y esto le permitirá conseguir lo planificado para el día, la semana, el mes, el bimestre. No se debe permitir alumnos desaprobados, debido a que él conoce o que quería conseguir. Los instrumentos, además deben ser conocidos por los estudiantes antes de su aplicación, debido a que debe de existir un sinceramiento de información entre docentes y alumnos.

Existen otros indicadores o rasgos del desempeño docente, como en la Universidad Católica Silva Henriquez - Santiago de Chile (2009) manifiestan cuatro dimensiones: 
A. Planificación. Es la preparación para el aprendizajeenseñanza y organización del contenido, capacidades, destrezas y habilidades, de acuerdo a lo que se espera conseguir en el centro educativo.

B. Ejecución. Permite dar la clase a los estudiantes manifestando un clima apropiado, coherente, tolerante, democrático y respetuoso con los alumnos a su cargo.

C. Aprendizaje-Enseñanza. Es el momento propiamente de trabajo en el aula ejecutando toda la metodología a emplear en el proceso aprendizaje-enseñanza de los alumnos.

D. Evaluación. Es la verificación del profesionalismo docente mediante la observación evidente de los resultados propuestos en los estudiantes.

Existen, además de estas propuestas existen las más usuales, instrumentos que serán aplicados partiendo de informes, cuestionarios, etc.

Tejedor (1996) nos manifiesta que el profesor es el principal entre a tener en cuenta.

Y efectivamente no se equivoca, debido a que, si el docente no ha logrado desarrollo en él, los aspectos antes mencionados, sólo se estará realizando un mero proceso de repetición y tener en claro una educación bancaria que desde hace mucho tiempo nos han brindado evolutivamente. Eso ya se acabó, se debe tener en cuenta otros aspectos, realmente significativos. 
Doyle (1975) precisa que debemos tener en cuenta competencias y actitudes en el docente.

Las actitudes del docente deben incluir el trato hacia el alumno y al grupo completo. Manejar grupos en una actividad no complicada, es una tarea sencilla si ha recibido un curso o ha sido capacitado para ello. Además de ser exigente consigo mismo, se capaz de lograr y alcanzar sus metas con un trato adecuado y efectivo.

El docente debe desarrollar habilidades, destrezas y competencias de manera organizada, evolutiva, planificada, en sintonía con los contenidos que se han tenido en cuenta para la clase, para el logro de un resultado que se anhela y espera. Lo planeado debe estar en sintonía con el contexto, es decir, el profesor tiene la obligación de conocer el contexto en el que trabaja para que los resultados se alcancen.

Si se consiguen estos aspectos, se habrá logrado de manera superlativa el logro esperado, pero, ¿el docente conocer lo que realmente quiere lograr? ¿Los directores saben qué quieren para su institución educativa? Sin duda que sí y es por esto este aporte que permitirá dar un poco de luces a los involucrados con la educación con la finalidad de mejorar siempre.

La interacción entre docentes y estudiantes junto a una estrategia adecuada y el uso de instrumentos de evaluación, sin duda, es lo que se espera y debe de conseguir. 
Mateo y otros (1995) precisan el uso de recursos de evaluación que permitirá establecer y conocer el desempeño del docente.

Estos instrumentos deben evaluar el área, las destrezas planeadas, los instrumentos de evaluación y el desempeño propiamente en el aula que el docente debe haber establecido para que sus alumnos lo logren de manera inmediata. El responsable hasta este momento es el docente de los logros que se pretenden alcanzar en el aula. Tarea pendiente a otras investigaciones, la de estudiar la responsabilidad del gobierno, de la colectividad, los directores, los padres de familia y los mismos alumnos.

\subsubsection{5. ¿Cómo evaluar desempeño docente?}

Los aspectos planificados para la evaluación del desempeño docente debe estar enmarcado entre muchos criterios en: el comportamiento y conducta de los docentes; en los resultados que se pretenden lograr (al término de la clase, la semana, el mes, etc.) y las características propias que todo docente ha desarrollado a lo largo de su carrera profesional.

Hay docentes que, a pesar de las distancias que puedan caminar y trasladarse para su centro educativo, llegan, a pesar de todo. No hay camino que impida cumplir con sus aspiraciones pedagógicas, esto se ve reflejado principalmente en los docentes de las zonas rurales. 


\subsubsection{Propósito de dicha evaluación.}

Hay una palabra que se ha escuchado desde el año 2003, que es la meritocracia.

Para que un docente pueda ser nombrado y promovido a un cargo y convertirse en director, especialista, director de unidad de gestión educativa local, dirección regional de educación o especialista del ministerio de educación, debe ser evaluado con permanencia.

No debemos obviar tampoco que esta evaluación permitirá mantenerlo en el trabajo, en el puesto, pues, si no inspira a sus pares, no debería continuar en algo que sólo se realiza por cumplir.

Cada dirección de las diferentes instituciones educativas tendrá la posibilidad de, gracias a la evaluación docente que se realiza, debe establecer y proponer tutores para las secciones que tendrá a cargo el próximo año, sin duda una tarea grande; además de establecer que el docente podrá ser promovido a coordinador de área. Los directivos también tendrán que informar a las instancias superiores para que puedan realizar reconocimientos a los docentes que puedan sobresalir en esta empresa.

Los padres de familia utilizarán la evaluación del desempeño docente con la única intención de saber que sus hijos están en buenas manos y que de ellos (los docentes) sus hijos recibirán la mejor educación.

Las unidades de gestión educativa local, deben de recibir las evaluaciones de los docentes con la finalidad de reconocer y 
felicitar por el trabajo alcanzado y logrado, debido a que es la instancia que promueve de manera inmediata a los docentes.

Las direcciones regionales de educación deben y tendrán la oportunidad de aprovechar a los docentes exitosos que puedan apoyar como docentes líderes (docentes fortaleza) en la mejora frente a otros centros educativos; es decir, podrán realizar pasantías para que puedan observar su trabajo y puedan aprender haciendo.

El Ministerio de Educación debe tener una política de meritocracia para ascender al docente, proponer mejores sueldos y condición de vida acorde a las exigencias y expectativas deseadas. Todo docente exitoso debe desarrollar camino a la excelencia educativa y proponerle como docente que deba recibir las Palmas Magisteriales.

La práctica docente de cada profesor debe ser reconocida por todos los actores de la comunidad y por todos os involucrados, principalmente los estudiantes, que algunos de ellos, no tienen en claro a donde quieren llegar y qué deben conseguir.

El propósito de la evaluación, entonces dependerá de qué instancia pueda utilizar la información que se ha alcanzado y qué vendrá luego.

\subsubsection{Procedimientos de evaluación}

Citaremos a los siguientes a) Autoevaluación, b) Observación de clases, c) Pruebas de conocimientos, d) Carpeta 
Didáctica, e) Encuesta a padres, f) Encuesta a alumnos, g) Evaluación de los pares, h) Resultado académico de los alumnos.

El desempeño docente debe comenzar con la autoevaluación y así el docente será responsable si en él se ha desarrollado la vocación, convicción y pasión por el arte de la educación, debido a que si no se siente motivado a aprender a diario, no podrá ser un excelente profesional. Esta autoevaluación le permitirá mirarse él mismo. El coaching lo ayudará para que verifique si lo que en su cuerpo y mente estaba presente, entonces nació para realizar esta hermosa actividad que es ser profesional de la educación.

El docente se mueve en el aula, como los peces en el mar; se debe realizar una exigente observación de clase debido a que es el campo de acción y pasa la mayor parte del tiempo junto a los estudiantes. Si se logra a un nivel superior es porque el docente se ha preparado, tanto psicológica, moral y físicamente para ser parte de la formación de los estudiantes. Debe considerar varios aspectos, planear lo que quiere lograr al final de la jornada de trabajo, manejar el clima en el aula, utilizar materiales educativos diversificados y contextualizados, hacer uso de metodología acorde a las exigencias del área y/ curso, como también aplicar y utilizar instrumentos de evaluación acordes a las necesidades y realidad del estudiante; debiendo comunicar y socializar estos documentos con ellos, con la única finalidad de proponer espacios de cambio y desarrollo. 
Las pruebas de conocimientos, no solo deben permitir nombrar docentes, sino también promoverlos para saber cómo vamos avanzando, estas pruebas deben ser comunicadas con antelación para que el docente pueda practicar y prepararse de manera inmediata y adecuada y de esta forma enfrentar las sesenta o cien preguntas que deben establecerse para este fin. Una prueba pedagógica es un indicador de que conoce y puede enfrentar situaciones tal y como lo hacen sus estudiantes. La prueba debe durar no más de tres horas cronológicas para no cansar a los docentes participantes. Además de ello, en las instituciones educativas, los directores deben ser los motivadores para que los docentes crezcan profesionalmente y el desempeño docente sea el que aspiran y quieren.

La carpeta didáctica es el reflejo de lo que sucede en el aula; es decir, este portafolio evidenciará paso a paso, de manera evolutiva, entre muchas cosas que las acciones que el docente realiza están planificadas desde siempre. La metodología que utiliza se evidencia y aplica de acuerdo al contexto y a los intereses del centro educativo (que hará la planificación del proyecto educativo institucional junto a sus colegas). Este portafolio además debe contener las evidencias del trabajo de los estudiantes; es decir, debe al menos, contener, como muestra, los trabajos exitosos de los estudiantes.

La encuesta de los padres de familia es otra forma de evaluar el desempeño docente, pues, se entiende que la buena y 
correcta opinión de los docentes que harán y darán a conocer los padres de familia es una evidencia que se quiere recuperar y desarrollar a lo largo del trabajo que se enfrenta a diario el docente en el colegio. El padre de familia debe estar seguro que el docente cumple metas y objetivos comunicados en una sesión que permita la interacción con ellos y se pueda mejorar y apoyar en la consecución de resultados que beneficiarán a todos. Esta información será corroborada con los resultados de los estudiantes y qué decir y mejor todavía si en dichas reuniones participan los directivos y el director en especial, no solo para respaldar el buen y correcto trabajo de los docentes, sino para comunicar que el trabajo es planificado, mancomunado.

Una encuesta a los estudiantes permitirá saber la opinión que tienen ellos respecto a sus docentes, la manera de cómo los trata, si conoce y domina o no su materia, la manera apropiada de evaluación y la exigencia que éste debe mostrar hacia los estudiantes. Todo ello si está planificado se realizará de manera apropiada, pero si no ha sido planificado ni comunicado a los estudiantes, ellos tendrán una opinión sesgada de sus docentes. Anticipo que, por la exigencia que el docente tendrá hacia sus alumnos, algunos de ellos quizá opinen en contra, debido a que no les gusta o no encaja en ellos dicha exigencia. Una encuesta bien preparada, honesta permitirá saber con qué tipo de docentes dejamos a nuestros menores hijos. 
La evaluación por pares es importante (aunque no tenemos una cultura de evaluación) esta práctica podría ayudar mucho a nuestros docentes debido a que un docente entiende y comprende mejor el trabajo de otro docente. La manera de cómo enfrenta a los estudiantes, la dinámica que tiene para con ellos, el trato, los instrumentos de evaluación utilizados; solo son entendidos por otros docentes. Aunque también advierto que no existe una cultura de evaluación y no hemos superado todavía la cultura de la envidia, el celo que tendría un docente frente a otro que viene consiguiendo mejores resultados en el aula.

Finalmente, la más importante es la que debe responder por el buen desempeño de los docentes en el aula, el rendimiento académico final que debe evaluarse en diferentes momentos: al inicio de la clase, durante la clase y al finalizar la clase. Este resultado debe ser evidenciado mediante evaluaciones ajenas al docente, quizá aplicadas por el director, otro docente, la unidad de gestión educativa local o la dirección regional de educación.

\subsubsection{Funciones}

La evaluación del desempeño docente tiene entre muchas funciones, de acuerdo a Cardó (2010) las siguientes: a) Diagnóstica, b) Instructiva, c) Educativa y d) Desarrolladora.

La evaluación cuya función es la diagnóstica permitirá conocer que el docente se encuentra en un nivel de desarrollo 
magisterial y este nos permitirá ayudarlo a mejorar y crecer como profesional.

La función instructiva, a partir de la anterior; la diagnóstica, nos ayudará a dar capacitación y desarrollo permanente a los docentes que lo requieran en las instituciones educativas públicas y/o privadas que lo ayuden a sobresalir.

La evaluación del desempeño docente debe de brindar una función especial a todo docente; la educativa, debido a que el ministerio de educación tiene la obligación de brindar (gracias a sus entes descentralizados) capacitación continua, acorde a lo que se necesite en su contexto y realidad. No todos necesitan lo mismo. Lo que si se hace necesario y se solicita al MINEDU es dar a conocer estrategias de trato a las personas, pues los docentes que han sido graduados el milenio pasado, hacen poco o nada para ser mejores. Se debe desarrollar de acuerdo a las necesidades del contexto.

Finalmente la desarrolladora. Todo docente desarrolla varios aspectos en él, si se capacita.

\subsection{HIPÓTESIS DE INVESTIGACIÓN.}

\subsubsection{Hipótesis general.}

El coaching tiene influencia positiva en el desarrollo del desempeño docente en la Provincia de Huancayo. 


\subsubsection{Hipótesis específicas:}

a) Si existe un programa de aplicación del coaching en el desarrollo del desempeño docente en la provincia de Huancayo.

b) Las características que tiene el coaching está supeditada al desarrollo personal y profesional del docente.

c) Las ventajas que tiene el coaching ayuda a crecer al docente de manera personal y profesional; y las desventajas hacen que el coaching se convierta en una actividad repetitiva.

d) El nivel de desempeño docente es deficiente y después alto luego de aplicar el experimento.

e) Los indicadores de desarrollo del desempeño docente están en función a las dimensiones que se pretende evaluar.

f) Los resultados obtenidos del desempeño docente son más favorables en el grupo experimental que en el grupo control antes y después del experimento. 


\subsection{VARIABLES E INDICADORES.}

\subsubsection{Variables.}

a) Independiente:

- Aplicación del Coaching

b) Dependiente:

- Desarrollo del Desempeño Docente en la provincia de Huancayo.

\subsubsection{Operacionalización}

\section{a) Independiente: Coaching}

(Ver anexo $\left.\mathrm{N}^{\circ} 01\right)$

Anticipamos que las dimensiones son tres: metodológico, funcional y pedagógico. En el anexo podemos observar cada uno de los indicadores que tiene esta variable con la finalidad de establecer los lineamientos de aplicación en la presente investigación.

b) Dependiente: Desempeño docente en la provincia de Huancayo

(Ver anexo $\mathrm{N}^{\circ}$ 01)

Anticipamos que son seis dimensiones: logros, contenido, metodología, clima, recursos y evaluación. Los correspondientes indicadores serán evidenciados en el 
anexo mencionado y tiene la intención de aplicarlos en el experimento en mención.

\subsubsection{Escala de medida.}

Es 0 a 4 (nominal). 


\section{III \\ METODOLOGÍA DE LA INVESTIGACIÓN}

3.1. TIPO.

El presente trabajo fue de tipo APLICADO, pues se aplicó la variable independiente (coaching) para lograr un desarrollo en la variable dependiente (desempeño docente en profesores de la provincia de Huancayo).

3.2. NIVEL.

Fue el EXPLICATIVO, pues, luego de la aplicación del experimento en los grupos control y experimental, se explicó el porqué de los resultados en cada uno de los casos que se informan en el capítulo siguiente.

\subsection{MÉTODOS.}

\subsubsection{General.}

Fue el científico, teniendo en cuenta cada uno de sus pasos. 


\subsubsection{Específicos.}

En la presente tesis se aplicaron los métodos particulares siguientes: descriptivo, experimental, estadístico y analíticosintético.

Estos métodos fueron utilizados a lo largo de la investigación y se comenzó con la descripción de la problemática, manifestando cada uno de las causas que las motivan; además de la descripción de la teoría científica que fundamenta el estudio, de manera evolutiva y paso a paso; de igual manera se describió los antecedentes del trabajo con investigaciones internacionales, nacionales y locales. Se hizo uso de este método también cuando se describió el marco teórico, indicando los pormenores de cada una de las variables del trabajo.

El método experimental se aplicó en las aulas, junto con los docentes de las instituciones educativas involucradas, a partir de los diferentes instrumentos ejecutados para que el experimento resulte como se planificó al inicio del trabajo.

El método estadístico se aplicó una vez obtenido los datos de los diferentes instrumentos aplicados, gracias a la estadística descriptiva e inferencial este método nos permitió encontrar los pormenores que la investigación provee.

El método analítico sintético se aplicó de manera permanente junto al estadístico se tenía que explicar, analizando los datos y la información propuesta. Los datos se tenían que resumir y presentarlos. 


\subsection{DISEÑO.}

Fue el cuasi-experimental con pre y post test; los grupos fueron evaluados respecto al desarrollo del desempeño docente.

Su esquema es:

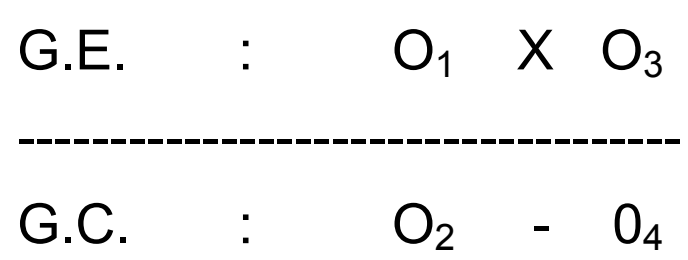

Donde:

G.E. : Grupo experimental (docentes de la I.E.P. Salesiano Santa Rosa de Huancayo).

G.C. : Grupo control (docentes de la I.E.P. Salesiano Técnico Don Bosco de Huancayo.

$0_{1}, 0_{2}$ : Resultados del Pre Test. (Observación de entrada)

$0_{3}, 0_{4}$ : Resultados del Post test. (Observación de salida)

X : Variable experimental (coaching)

-- $\quad$ : No aplicación de la variable experimental

Como vemos, el esquema es el que se ha aplicado en el experimento, para ello se ha contado con un grupo control y otro experimental, en ambos fueron aplicados la prueba de entrada y salida (respectivamente). 


\subsection{POBLACIÓN Y MUESTRA.}

\subsubsection{Población.}

Docentes de los centros educativos secundarios de la provincia de Huancayo.

\subsubsection{Muestra.}

Fueron los docentes de los colegios de varones salesianos presentes en la provincia de Huancayo, nos referimos a Técnico Don Bosco y Santa Rosa. Ambos centros educativos se ubican en el distrito de El Tambo. Cuentan con el mismo carisma y trabajan bajo el sistema preventivo de Don Bosco. Pertenecen además al Consorcio de Colegios Católicos de la Región Junín.

TABLA N ${ }^{\circ} 04$

\section{RESUMEN}

\begin{tabular}{|c|c|c|c|}
\hline Grupo & $\mathbf{N}^{\circ}$ sujetos & Sexo & Edad \\
\hline Control & \multirow{2}{*}{34} & Masculino & 29 \\
\cline { 3 - 4 } IEP Salesiano Técnico Don Bosco & \multirow{2}{*}{ Femenino } & 05 \\
\hline $\begin{array}{c}\text { Experimental } \\
\text { IEP Salesiano Santa Rosa }\end{array}$ & \multirow{2}{*}{ Masculino } & 34 \\
\cline { 3 - 4 } & & Femenino & 11 \\
\hline
\end{tabular}

El primer grupo (Grupo control) estuvo constituido por los profesores de la IE Técnico Don Bosco de Huancayo. El segundo grupo (Grupo experimental) estuvo constituido por los docentes de la IE Santa Rosa de Huancayo. Ambos colegios salesianos. 


\subsubsection{Tipo de muestra.}

- La intencionalidad fue aplicada para esta investigación, debido a que las características que reúnen estos centros educativos eran parecidas. En especial el hecho de que ambos colegios sean eminentemente de varones $y$ pertenecen a la familia Salesiana. Cabe indicar que se hicieron coordinadores con ambos padres directores para que la aplicación del experimento se ejecute sin dificultad alguna.

\subsection{TÉCNICAS DE RECOLECCIÓN DE INFORMACIÓN.}

\subsubsection{Técnicas.}

Las técnicas utilizadas en la investigación fueron:

- Fichaje. Al inicio para poder establecer la problemática que se evidenciaba en los centros educativos de la investigación, se utiliza un cuadernito que fue reemplazado por ficha, es así que, en las fichas se enumeraban las diferentes problemáticas que se podían enumerar, además de aplicarlos en la redacción del capítulo número dos (marco teórico) del presente informe de tesis, debido a que teníamos que recurrir a las ideas principales con las que dispone un autor, la palabra fuerza, la idea fuerza que ayudó de manera importante la selección y elección del término apropiado y el autor que 
teníamos que realizar la cita correspondiente. El fichaje es importante para estos casos.

- Interrogación: El empleo que se realizó de esta técnica, partió desde el instante en que visitamos las diferentes instituciones educativas, a los docentes de la muestra. Ayudó de manera significativa en el logro de la recopilación de datos que se esperaba y tenía estimado. Fueron muchas preguntas que se generaron a partir de la experiencia.

\subsubsection{Instrumentos.}

Estos fueron:

* Ficha de desempeño docente. Fue elaborado teniendo en cuenta las dimensiones que se explican y dan a conocer en el anexo número 1 (ver anexos) a los diferentes docentes del experimento. Se partió evidenciando un trabajo de evaluación y visita a los docentes citados.

* Sesiones de Aprendizaje. Fueron presentados a los directivos de las instituciones involucradas para que pueda aplicarse en el aula y observar a los docentes de la muestra. Su preparación, planificación e ideación previa fue capital para el logro de los resultados que en el capítulo posterior presentaremos. 
* Fichas: Fueron diferentes y se aplicó de manera pormenorizada en el desarrollo del trabajo.

\subsubsection{Validez de los instrumentos.}

Para dar una validez pena y clara se tuvo en cuenta la validación por juicio de expertos.

Los validadores, expertos y conocedores fueron:

Humberto Simón LIMACHE CHALE. Magíster en Educación, Mención Didáctica Universitaria, egresado de la Escuela de Post Grado de la Universidad Nacional Mayor de San Marcos.

Hector Hugo SANCHEZ CARLESSI. Doctor en Psicología por la Universidad Nacional Mayor de San Marcos y catedrático de la Universidad Ricardo Palma.

Nicanor MOYA ROJAS. Doctor en Educación por la Universidad Nacional Del Centro del Perú. Es el actual diretor de la unidad de posgrado de la Facultad de Educación.

Rossana Lucrecia VENTOCILLA PACHECO. Magíster en Gestión Universitaria (UNCP). Licenciada en Computación e Informática, egresada de la Universidad Peruana Los Andes. 
Actualmente docente del Instituto Superior Tecnológico "9 de Diciembre" de Chongos Bajo.

Luis Ernesto TAPIA LUJÁN. Magíster en Educación por la Universidad Nacional Del Centro del Perú.

La Ficha de Evaluación del Desempeño Docente (Entrada y salida) (Ver Anexos) consideraba una calificación para cada ítem de: 0 (Deficiente), 1 (Insatisfactorio), 2 (Suficiente) y 3 (Sobresaliente). En tal sentido, para un total de 30 ítems, se tuvo una puntuación máxima de 120 puntos. Los resultados fueron los siguientes: 


\section{CUADRO N 01}

\section{Validez de instrumentos - Resultado General}

\begin{tabular}{|c|c|c|c|c|c|c|c|c|}
\hline \multirow{2}{*}{ Ítem } & \multicolumn{5}{|c|}{ JUEZ } & \multirow{2}{*}{ Total } & \multirow{2}{*}{ Índice } & \multirow{2}{*}{ Valoración } \\
\hline & 1 & 2 & 3 & 4 & 5 & & & \\
\hline 01 & 03 & 04 & 02 & 04 & 04 & 17 & 0,9 & Muy Bueno \\
\hline 02 & 04 & 04 & 03 & 03 & 04 & 18 & 0,9 & Muy Bueno \\
\hline 03 & 02 & 03 & 03 & 03 & 03 & 14 & 0,7 & Bueno \\
\hline 04 & 02 & 04 & 04 & 03 & 04 & 17 & 0,9 & Muy Bueno \\
\hline 05 & 02 & 03 & 03 & 03 & 04 & 15 & 0,8 & Bueno \\
\hline 06 & 02 & 03 & 02 & 01 & 03 & 11 & 0,5 & Bueno \\
\hline 07 & 04 & 04 & 04 & 04 & 04 & 20 & 1,0 & Muy Buenc \\
\hline 08 & 03 & 04 & 03 & 04 & 04 & 18 & 0,9 & luy Bueno \\
\hline 09 & 04 & 04 & 04 & 04 & 04 & 20 & 1,0 & Muy Bueno \\
\hline 10 & 03 & 02 & 03 & 03 & 04 & 15 & 0,7 & Bueno \\
\hline 11 & 03 & 02 & 02 & 03 & 03 & 13 & 0,5 & Bueno \\
\hline 12 & 03 & 04 & 03 & 03 & 04 & 17 & $0, \varepsilon$ & Muy Bueno \\
\hline 13 & 04 & 04 & 04 & 04 & 04 & 20 & 1,0 & Muy Bueno \\
\hline 14 & 04 & 04 & 03 & 04 & 04 & 19 & 1,0 & Muy Bueno \\
\hline 15 & 02 & 03 & 02 & 03 & 02 & 12 & 0,5 & Bueno \\
\hline 16 & 03 & 04 & 03 & 04 & 04 & 18 & 0,9 & Muy Bueno \\
\hline 17 & 03 & 03 & 03 & 03 & 03 & 15 & 0,8 & Bueno \\
\hline 18 & 04 & 04 & 04 & 04 & 03 & 19 & 1,0 & Muy Bueno \\
\hline 19 & 03 & 03 & 03 & 03 & 03 & 15 & 0,8 & Bueno \\
\hline 20 & 04 & 04 & 04 & 04 & 03 & 19 & 1,0 & Muy Bueno \\
\hline 21 & 02 & 03 & 03 & 03 & 04 & 15 & 0,8 & Bueno \\
\hline 22 & 02 & 03 & 02 & 01 & 03 & 11 & 0,5 & Bueno \\
\hline 23 & 04 & 04 & 04 & 04 & 04 & 20 & 1,0 & Muy Bueno \\
\hline 24 & 03 & 04 & 03 & 04 & 04 & 18 & 0,9 & Muy Bueno \\
\hline 25 & 04 & 04 & 04 & 04 & 04 & 20 & 1,0 & Muy Bueno \\
\hline 26 & 03 & 02 & 03 & 03 & 04 & 15 & 0,7 & Bueno \\
\hline 27 & 03 & 02 & 02 & 03 & 03 & 13 & 0,5 & Bueno \\
\hline 28 & 03 & 04 & 03 & 03 & 04 & 17 & 0,8 & Muy Bueno \\
\hline 29 & 04 & 04 & 04 & 04 & 04 & 20 & 1,0 & Muy Bueno \\
\hline 30 & 04 & 04 & 03 & 04 & 04 & 19 & 1,0 & Muy Bueno \\
\hline Total & 94 & 104 & 93 & 100 & 109 & 500 & 0,83 & Bueno \\
\hline
\end{tabular}


El cuadro $\mathrm{N}^{\circ} 01$, presenta de manera detallada las puntuaciones asignadas por cada juez, a cada uno de los factores y/o ítems.

\section{CUADRO N 02}

Validez de instrumentos - Resumen

\begin{tabular}{|c|c|c|c|c|c|c|c|c|c|c|c|c|}
\hline \multicolumn{10}{|c|}{ JUEZ } & \multirow{2}{*}{\multicolumn{2}{|c|}{ Total }} & \multirow{3}{*}{ Valoración } \\
\hline \multicolumn{2}{|c|}{1} & \multicolumn{2}{|c|}{2} & \multicolumn{2}{|c|}{3} & \multicolumn{2}{|c|}{4} & \multicolumn{2}{|c|}{5} & & & \\
\hline Punt & Ind & Punt & Ind & Punt & Ind & Punt & Ind & Punt & Ind & Punt & Ind & \\
\hline 99 & 0,8 & 104 & 0,8 & 93 & 0,7 & 100 & 0,9 & 109 & 0,9 & 500 & 0,8 & BUENO \\
\hline
\end{tabular}

En general, de acuerdo a lo mostrado en el cuadro $\mathrm{N}^{\circ} 2$, la valoración cualitativa otorgada por los cinco jueces a la Ficha de evaluación fue de BUENO, con un total de 500 Puntos sobre 600 . De manera individual, 2 expertos otorgaron el calificativo cuantitativo de 109 y 104 que significa MUY BUENO, en tanto que tres expertos lo calificaron de Bueno, con puntuaciones de 100, 99 y 93.

Entonces, la opinión de los especialistas fue que el programa era bueno y que se constituía en un instrumento que medía lo que pretendía medir, por lo que se aplicó de manera inmediata.

\subsection{PROCEDIMIENTO DE RECOLECCIÓN DE INFORMACIÓN.}

Se realizaron las siguientes etapas: 
* Coordinación con los Reverendos Padres Salesianos (Directores de las instituciones educativas de la muestra) para realizar la aplicación del experimento.

* Planificación del experimento, teniendo en cuenta los pormenores, el contexto, los posibles resultados a tener en cuenta.

* Elaboración de la ficha que tenía que evaluar el desempeño docente de los profesores de la muestra materia de investigación.

* Identificación de los grupos control y experimental.

* Procesamiento de la información.

* Redacción del presente informe de tesis.

* Presentación de ejemplares revisados, corregidos y mejorados, como evidencia de la tesis.

\subsection{TÉCNICAS DE DATOS Y ANÁLISIS.}

Utilizamos la estadística descriptiva e inferencial. 


\section{IV \\ RESULTADOS DE LA INVESTIGACIÓN}

A continuación se presentan los resultados de la aplicación del coaching en el desempeño docente.

Estos datos, fueron elaborados utilizando el programa estadístico SPSS.

4.1. PRESENTACIÓN E INTERPRETACIÓN DE INFORMACIÓN.

4.1.1. Resultados del grupo control. 
CUADRO Nº3

DATOS DEL GRUPO CONTROL, IEP TÉCNICO DON BOSCO

\begin{tabular}{|r|r|r|r|r|r|r|r|}
\hline $\mathbf{N}^{\circ}$ & Sexo & Edad & IEP & Nivel & Área & Entrada & Salida \\
\hline $\mathbf{1}$ & 1 & 44 & 1 & 3 & 2 & 91 & 100 \\
\hline $\mathbf{2}$ & 1 & 36 & 1 & 3 & 2 & 79 & 96 \\
\hline $\mathbf{3}$ & 2 & 36 & 1 & 3 & 1 & 83 & 94 \\
\hline $\mathbf{4}$ & 2 & 61 & 1 & 3 & 7 & 84 & 92 \\
\hline $\mathbf{5}$ & 2 & 41 & 1 & 3 & 8 & 91 & 102 \\
\hline $\mathbf{6}$ & 2 & 28 & 1 & 3 & 9 & 90 & 104 \\
\hline $\mathbf{7}$ & 2 & 53 & 1 & 3 & 1 & 79 & 100 \\
\hline $\mathbf{8}$ & 2 & 26 & 1 & 3 & 6 & 90 & 98 \\
\hline $\mathbf{9}$ & 2 & 49 & 1 & 3 & 1 & 90 & 98 \\
\hline $\mathbf{1 0}$ & 2 & 38 & 1 & 3 & 1 & 80 & 90 \\
\hline $\mathbf{1 1}$ & 2 & 37 & 1 & 3 & 7 & 91 & 96 \\
\hline $\mathbf{1 2}$ & 2 & 45 & 1 & 3 & 11 & 90 & 93 \\
\hline $\mathbf{1 3}$ & 2 & 47 & 1 & 3 & 7 & 78 & 87 \\
\hline $\mathbf{1 4}$ & 2 & 54 & 1 & 3 & 7 & 92 & 94 \\
\hline $\mathbf{1 5}$ & 1 & 37 & 1 & 3 & 3 & 87 & 90 \\
\hline $\mathbf{1 6}$ & 2 & 37 & 1 & 3 & 7 & 91 & 93 \\
\hline $\mathbf{1 7}$ & 2 & 26 & 1 & 3 & 9 & 90 & 94 \\
\hline $\mathbf{1 8}$ & 2 & 35 & 1 & 3 & 9 & 97 & 102 \\
\hline $\mathbf{1 9}$ & 2 & 31 & 1 & 3 & 11 & 96 & 99 \\
\hline $\mathbf{2 0}$ & 2 & 31 & 1 & 3 & 8 & 95 & 94 \\
\hline $\mathbf{2 1}$ & 2 & 38 & 1 & 3 & 10 & 98 & 94 \\
\hline $\mathbf{2 2}$ & 2 & 62 & 1 & 3 & 10 & 85 & 84 \\
\hline $\mathbf{2 3}$ & 2 & 38 & 1 & 3 & 9 & 91 & 98 \\
\hline $\mathbf{2 4}$ & 2 & 54 & 1 & 3 & 11 & 98 & 93 \\
\hline $\mathbf{2 5}$ & 1 & 35 & 1 & 3 & 3 & 91 & 87 \\
\hline $\mathbf{2 6}$ & 2 & 56 & 1 & 3 & 2 & 96 & 88 \\
\hline $\mathbf{2 7}$ & 2 & 67 & 1 & 3 & 7 & 84 & 87 \\
\hline $\mathbf{2 8}$ & 2 & 49 & 1 & 3 & 6 & 85 & 79 \\
\hline $\mathbf{2 9}$ & 2 & 34 & 1 & 3 & 5 & 103 & 101 \\
\hline $\mathbf{3 0}$ & 2 & 52 & 1 & 3 & 11 & 79 & 79 \\
\hline $\mathbf{3 1}$ & 1 & 36 & 1 & 3 & 5 & 100 & 94 \\
\hline $\mathbf{3 2}$ & 2 & 34 & 1 & 3 & 6 & 84 & 90 \\
\hline $\mathbf{3 3}$ & 2 & 62 & 1 & 3 & 10 & 95 & 92 \\
\hline $\mathbf{3 4}$ & 2 & 31 & 1 & 3 & 5 & 94 & 88 \\
\hline
\end{tabular}

Fuente: Información procesada por el autor.

\section{Interpretación:}

Como apreciamos, se muestran los resultados del grupo control respecto a la observación inicial. Se puede apreciar información importante para las 
variables intervinientes: sexo, edad, institución educativa, nivel educativo, área que el docente tiene a cargo. Como se aprecia se tuvo una muestra de 34 profesores.

\section{CUADRO Nº 04 \\ RESUMEN ESTADÍSTICO DEL GRUPO CONTROL DOCENTES DE LA IEP SALESIANO TÉCNICO DON BOSCO}

Estadísticos

\begin{tabular}{|ll|r|r|r|r|r|r|r|}
\hline & & \multicolumn{1}{|c|}{ sexo } & \multicolumn{1}{c|}{ edad } & iep & nivel & area & P_entrada & P_salida \\
\hline $\mathrm{N}$ & Válidos & 34 & 34 & 34 & 34 & 34 & 34 & 34 \\
& Perdidos & 0 & 0 & 0 & 0 & 0 & 0 & 0 \\
Media & & 1,8529 & 42,3529 & 1,0000 & 3,0000 & 6,3824 & 89,6176 & 93,2353 \\
Mediana & 2,0000 & 38,0000 & 1,0000 & 3,0000 & 7,0000 & 90,5000 & 94,0000 \\
Moda & 2,00 & $31,00 \mathrm{a}$ & 1,00 & 3,00 & 7,00 & 91,00 & 94,00 \\
Desv. típ. &, 35949 & 11,21655 &, 00000 &, 00000 & 3,31219 & 6,54131 & 6,12525 \\
Varianza &, 129 & 125,811 &, 000 &, 000 & 10,971 & 42,789 & 37,519 \\
Suma & 63,00 & 1440,00 & 34,00 & 102,00 & 217,00 & 3047,00 & 3170,00 \\
Percentiles & 25 & 2,0000 & 34,7500 & 1,0000 & 3,0000 & 3,0000 & 84,0000 & 89,5000 \\
& 50 & 2,0000 & 38,0000 & 1,0000 & 3,0000 & 7,0000 & 90,5000 & 94,0000 \\
& 75 & 2,0000 & 52,2500 & 1,0000 & 3,0000 & 9,0000 & 95,0000 & 98,0000 \\
\hline
\end{tabular}

Fuente: Información procesada por el autor.

Interpretación:

Los datos que se pueden observar en el cuadro $\mathrm{N}^{\circ} 04$ hacen referencia a la prueba de entrada con los valores que evidenciamos. Se tiene una media aritmética de 89,6176 en la prueba de entrada, frente al 93,2353 de la prueba de salida. 
CUADRO No 05

RESULTADOS POR SEXO DEL GRUPO CONTROL DOCENTES DE LA IEP SALESIANO TÉCNICO DON BOSCO

\begin{tabular}{|c|c|c|c|c|c|}
\hline & & fi & $\%$ & \% válido & $\%$ acumulado \\
\hline \multirow[t]{3}{*}{$\overline{\text { Válidos }}$} & 1,00 & 5 & 14,7 & 14,7 & 14,7 \\
\hline & 2,00 & 29 & 85,3 & 85,3 & 100,0 \\
\hline & Total & 34 & 100,0 & 100,0 & \\
\hline
\end{tabular}

Fuente: Información procesada por el autor.

Interpretación:

En el cuadro podemos identificar que el $14,6 \%$ son damas y 85,3 son varones. Esto se evidencia por la variante de colegios técnicos, el cual es este centro educativo.

Gráficamente observamos:

\section{GRÁFICO Nº1 01}

RESULTADOS POR SEXO DEL GRUPO CONTROL DOCENTES DE LA IEP SALESIANO TÉCNICO DON BOSCO

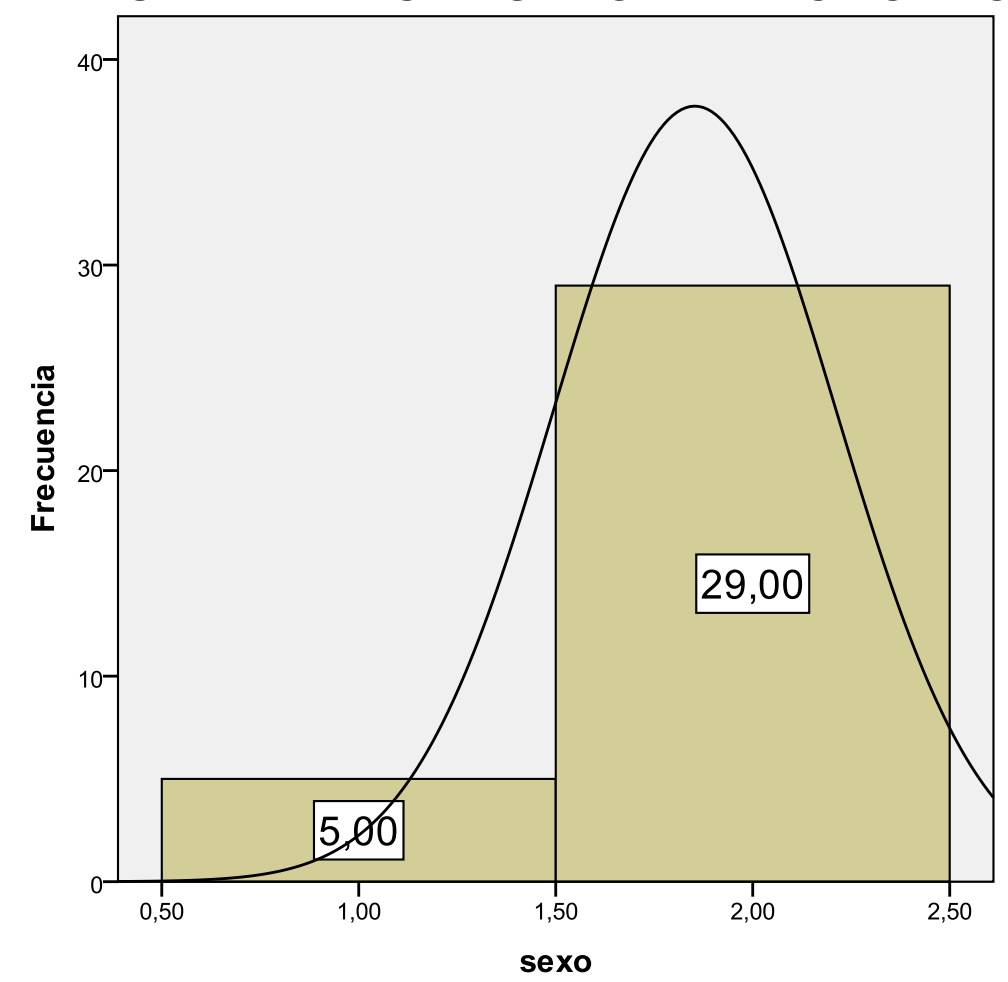


CUADRO No 06

RESULTADOS POR EDAD DEL GRUPO CONTROL DOCENTES DE LA IEP SALESIANO TÉCNICO DON BOSCO

\begin{tabular}{|c|c|c|c|c|c|}
\hline \multicolumn{6}{|c|}{ Edad } \\
\hline & & $\mathrm{fi}$ & $\%$ & \% válido & $\%$ acumulado \\
\hline \multirow[t]{21}{*}{ Válidos } & 26,00 & 2 & 5,9 & 5,9 & 5,9 \\
\hline & 28,00 & 1 & 2,9 & 2,9 & 8,8 \\
\hline & 31,00 & 3 & 8,8 & 8,8 & 17,6 \\
\hline & 34,00 & 2 & 5,9 & 5,9 & 23,5 \\
\hline & 35,00 & 2 & 5,9 & 5,9 & 29,4 \\
\hline & 36,00 & 3 & 8,8 & 8,8 & 38,2 \\
\hline & 37,00 & 3 & 8,8 & 8,8 & 47,1 \\
\hline & 38,00 & 3 & 8,8 & 8,8 & 55,9 \\
\hline & 41,00 & 1 & 2,9 & 2,9 & 58,8 \\
\hline & 44,00 & 1 & 2,9 & 2,9 & 61,8 \\
\hline & 45,00 & 1 & 2,9 & 2,9 & 64,7 \\
\hline & 47,00 & 1 & 2,9 & 2,9 & 67,6 \\
\hline & 49,00 & 2 & 5,9 & 5,9 & 73,5 \\
\hline & 52,00 & 1 & 2,9 & 2,9 & 76,5 \\
\hline & 53,00 & 1 & 2,9 & 2,9 & 79,4 \\
\hline & 54,00 & 2 & 5,9 & 5,9 & 85,3 \\
\hline & 56,00 & 1 & 2,9 & 2,9 & 88,2 \\
\hline & 61,00 & 1 & 2,9 & 2,9 & 91,2 \\
\hline & 62,00 & 2 & 5,9 & 5,9 & 97,1 \\
\hline & 67,00 & 1 & 2,9 & 2,9 & 100,0 \\
\hline & Total & 34 & 100,0 & 100,0 & \\
\hline
\end{tabular}

Fuente: Información procesada por el autor.

Interpretación:

En el presente cuadro se observa que la edad mínima es de 26 años y la edad máxima de 67 años. Además se tiene un promedio de edad de 42 años.

Gráficamente observamos: 
GRÁFICO No 02

RESULTADOS OBTENIDOS POR EDAD DEL GRUPO CONTROL DOCENTES DE LA IEP SALESIANO TÉCNICO DON BOSCO

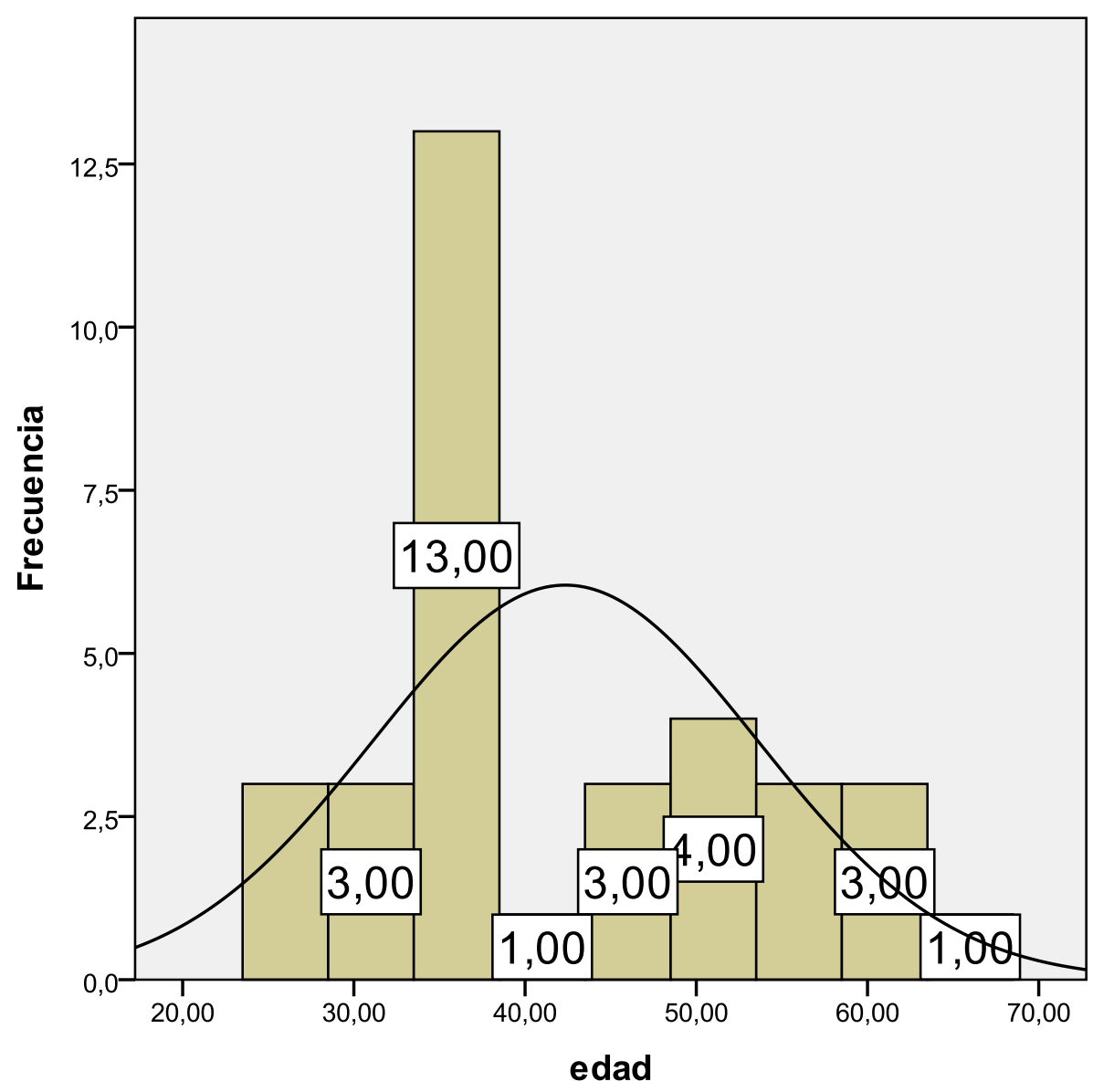


CUADRO № 07

RESULTADOS POR INSTITUCIÓN EDUCATIVA DEL GRUPO

CONTROL

DOCENTES DE LA IEP SALESIANO TÉCNICO DON BOSCO

\begin{tabular}{|lr|r|r|r|r|}
\hline & \multicolumn{2}{|c|}{ lep } \\
\hline Válidos 1,00 & & $\%$ & $\%$ válido & $\%$ acumulado \\
\hline
\end{tabular}

Fuente: Información procesada por el autor.

Interpretación:

Se observa en el presente cuadro que el $100 \%$ de profesores son de la IE Técnico Don Bosco.

Gráficamente observamos:
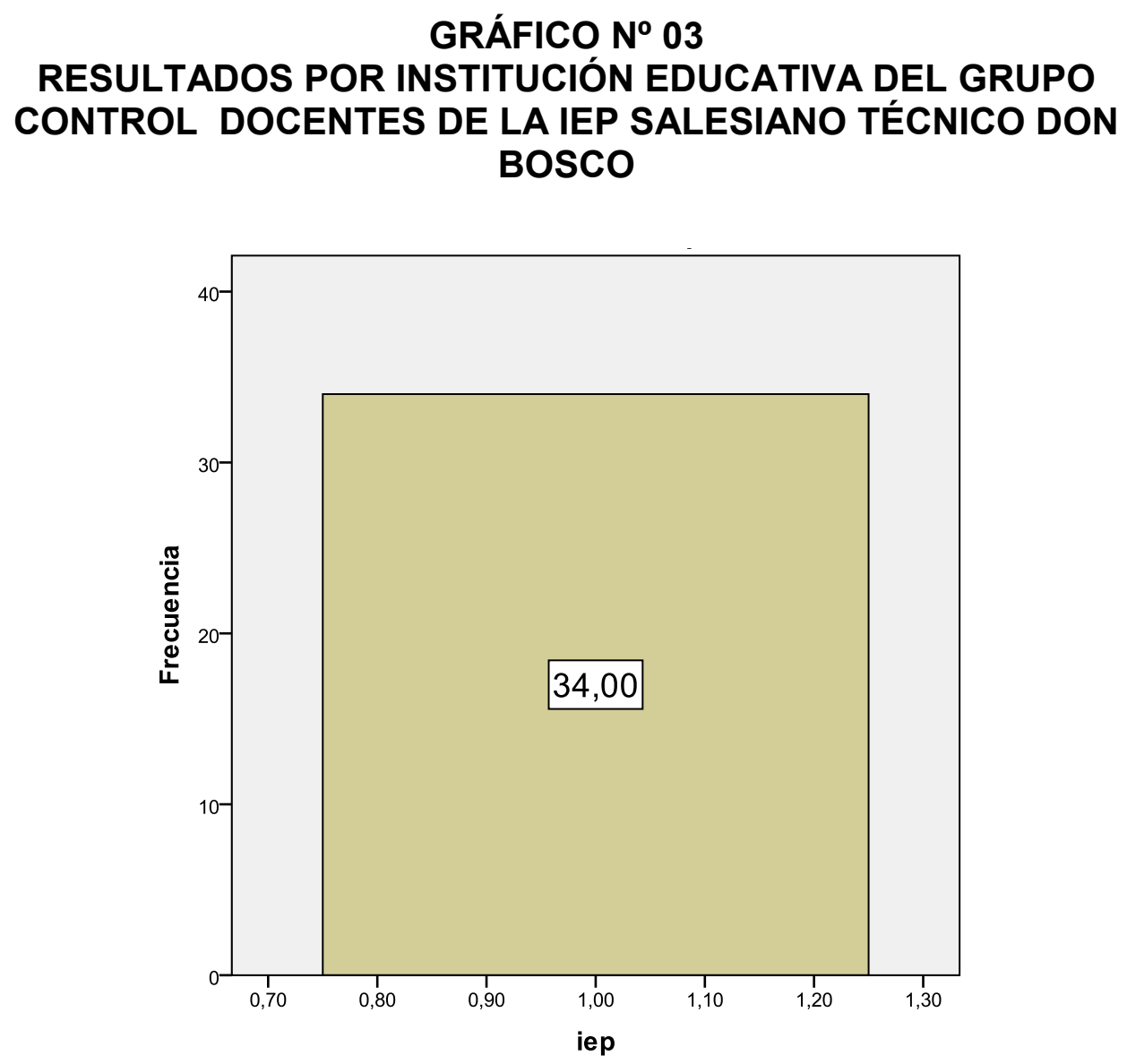


\section{CUADRO N 08}

RESULTADOS POR NIVEL EDUCATIVO DEL GRUPO CONTROL DOCENTES DE LA IEP SALESIANO TÉCNICO DON BOSCO

\begin{tabular}{|l|r|r|r|r|}
\hline & \multicolumn{1}{|c|}{ Nivel } \\
\hline Válidos 3,00 & & $\%$ & $\%$ válido & $\%$ acumulado \\
\hline
\end{tabular}

Fuente: Información procesada por el autor.

Interpretación:

Observamos en el cuadro que el $100 \%$ son del nivel secundario del centro educativo citado anteriormente.

Gráficamente observamos:

GRÁFICO No 04

RESULTADOS POR NIVEL EDUCATIVO DEL GRUPO CONTROL DOCENTES DE LA IEP SALESIANO TÉCNICO DON BOSCO

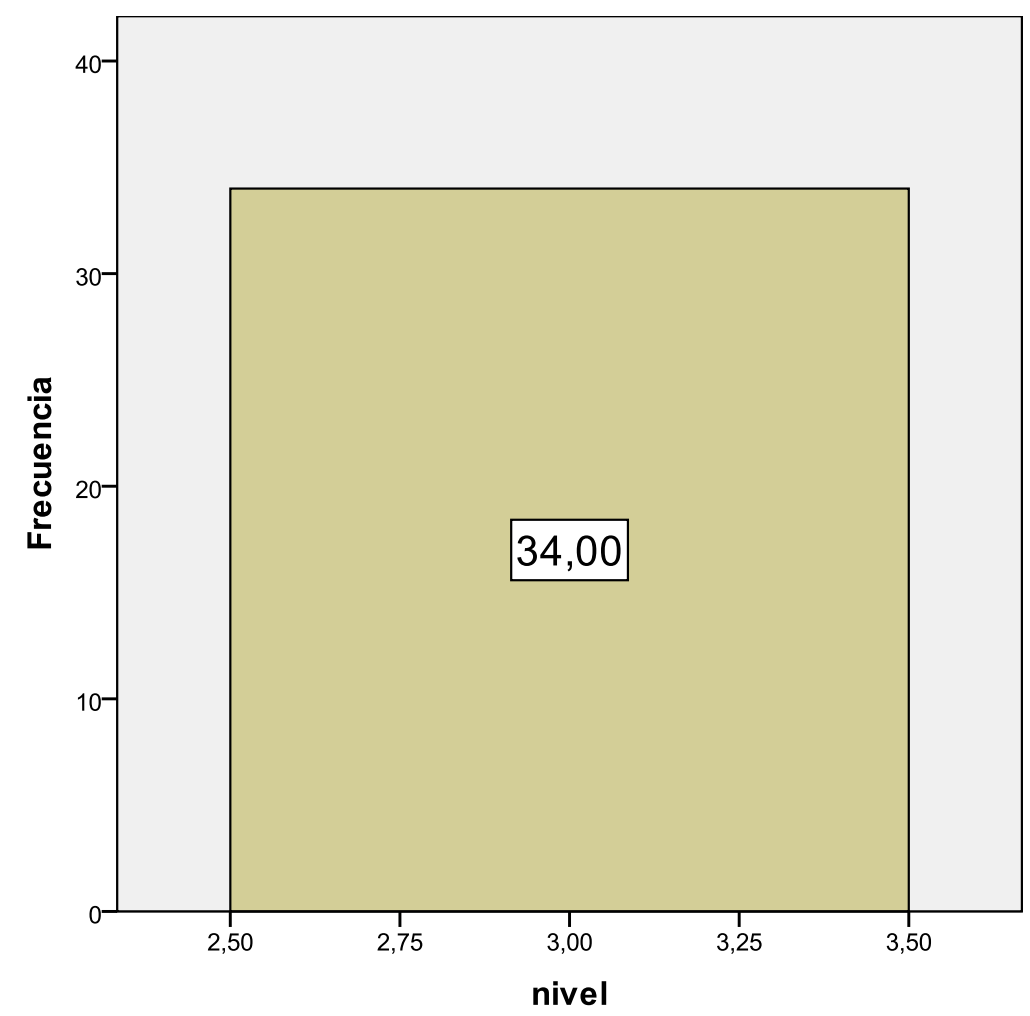




\section{CUADRO N 09}

\section{RESULTADOS POR ÁREA DEL GRUPO CONTROL DOCENTES DE LA IEP SALESIANO TÉCNICO DON BOSCO}

\begin{tabular}{|c|c|c|c|c|c|}
\hline \multicolumn{6}{|c|}{ Area } \\
\hline & & $f i$ & $\%$ & \% válido & $\%$ acumulado \\
\hline \multirow[t]{11}{*}{ Válidos } & 1,00 & 4 & 11,8 & 11,8 & 11,8 \\
\hline & 2,00 & 3 & 8,8 & 8,8 & 20,6 \\
\hline & 3,00 & 2 & 5,9 & 5,9 & 26,5 \\
\hline & 5,00 & 3 & 8,8 & 8,8 & 35,3 \\
\hline & 6,00 & 3 & 8,8 & 8,8 & 44,1 \\
\hline & 7,00 & 6 & 17,6 & 17,6 & 61,8 \\
\hline & 8,00 & 2 & 5,9 & 5,9 & 67,6 \\
\hline & 9,00 & 4 & 11,8 & 11,8 & 79,4 \\
\hline & 10,00 & 3 & 8,8 & 8,8 & 88,2 \\
\hline & 11,00 & 4 & 11,8 & 11,8 & 100,0 \\
\hline & Total & 34 & 100,0 & 100,0 & \\
\hline
\end{tabular}

Fuente: Información procesada por el autor.

\section{Leyenda:}

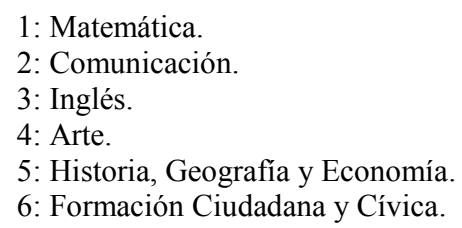

7: Persona Familia y Relaciones Humanas.

8: Educación Física.

9: Educación Religiosa.

10: Ciencia, Tecnología y Ambiente.

11: Educación para el Trabajo.

\section{Interpretación:}

En el cuadro observamos que:

- 4 docentes son del área de Matemática $(11,8 \%)$.

- 3 docentes son del área de Comunicación (8,8 \%).

- 3 docentes son del área de Historia, Geografía y Economía (8,8 \%).

- 3 docentes son del área de Formación Ciudadana y Cívica $(8,8$ \%).

- 6 docentes son del área de Persona, Familia y Relaciones Humanas $(17,6 \%)$.

- 2 docentes son del área de Educación Física (5,9 \%).

- 4 docentes son del área de Educación Religiosa (11,8 \%). 
- 3 docentes son del área de Ciencia, Tecnología y Ambiente (8,8 \%)

- 4 docentes son del área de Educación para el Trabajo (11,8 \%).

Gráficamente observamos:

\section{GRÁFICO Nº5}

RESULTADOS POR ÁREA DEL GRUPO CONTROL DOCENTES DE LA IEP SALESIANO TÉCNICO DON BOSCO

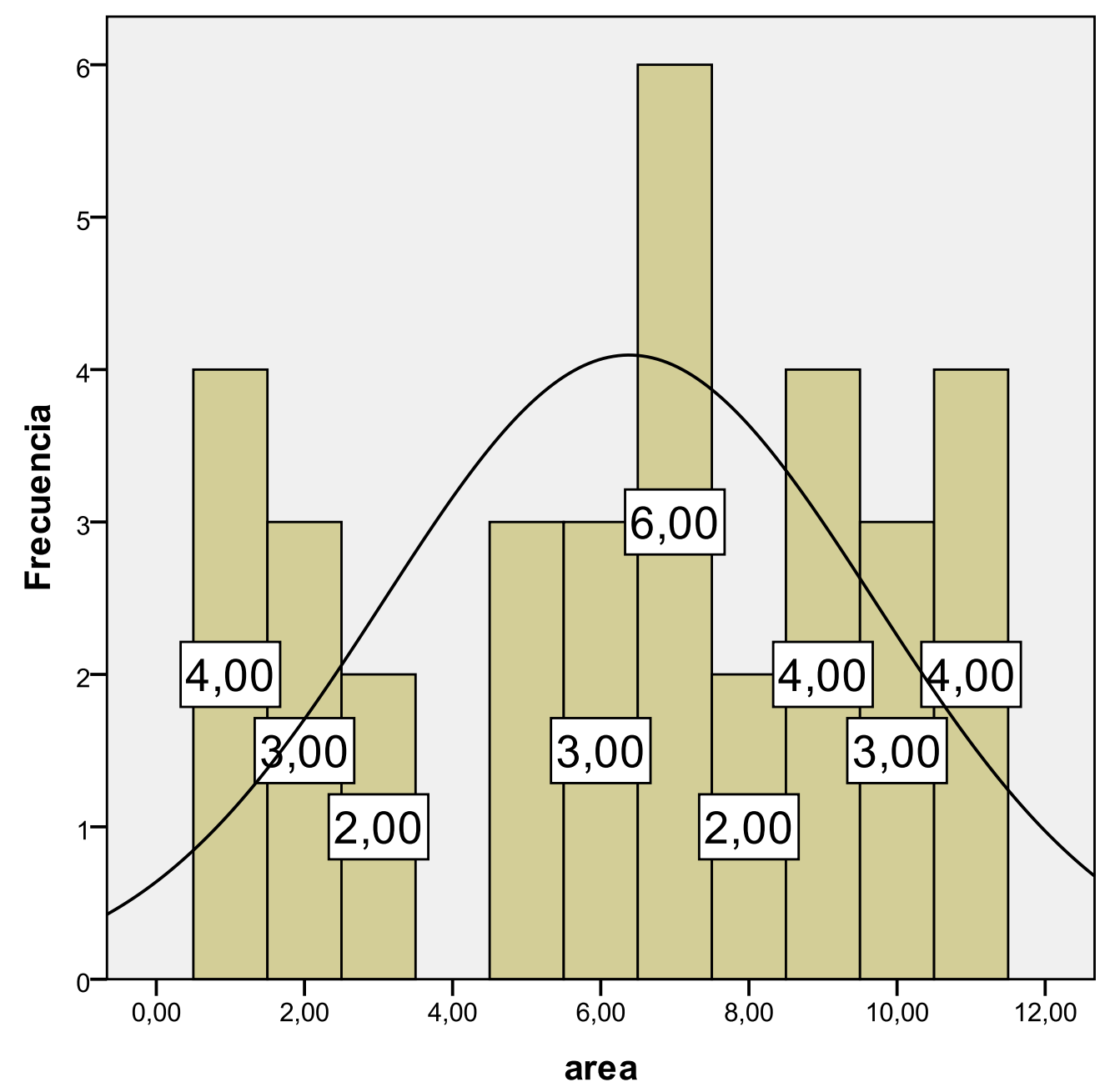


CUADRO No 10

RESULTADOS POR LA OBSERVACIÓN DE ENTRADA DEL GRUPO CONTROL DOCENTES DE LA IEP SALESIANO TÉCNICO DON BOSCO

\begin{tabular}{|c|c|c|c|c|c|}
\hline \multicolumn{6}{|c|}{ p_entrada } \\
\hline & & $f i$ & $\%$ & \% válido & $\%$ acumulado \\
\hline Válidos & 78,00 & 1 & 2,9 & 2,9 & 2,9 \\
\hline & 79,00 & 3 & 8,8 & 8,8 & 11,8 \\
\hline & 80,00 & 1 & 2,9 & 2,9 & 14,7 \\
\hline & 83,00 & 1 & 2,9 & 2,9 & 17,6 \\
\hline & 84,00 & 3 & 8,8 & 8,8 & 26,5 \\
\hline & 85,00 & 2 & 5,9 & 5,9 & 32,4 \\
\hline & 87,00 & 1 & 2,9 & 2,9 & 35,3 \\
\hline & 90,00 & 5 & 14,7 & 14,7 & 50,0 \\
\hline & 91,00 & 6 & 17,6 & 17,6 & 67,6 \\
\hline & 92,00 & 1 & 2,9 & 2,9 & 70,6 \\
\hline & 94,00 & 1 & 2,9 & 2,9 & 73,5 \\
\hline & 95,00 & 2 & 5,9 & 5,9 & 79,4 \\
\hline & 96,00 & 2 & 5,9 & 5,9 & 85,3 \\
\hline & 97,00 & 1 & 2,9 & 2,9 & 88,2 \\
\hline & 98,00 & 2 & 5,9 & 5,9 & 94,1 \\
\hline & 100,00 & 1 & 2,9 & 2,9 & 97,1 \\
\hline & 103,00 & 1 & 2,9 & 2,9 & 100,0 \\
\hline & Total & 34 & 100,0 & 100,0 & \\
\hline
\end{tabular}

Fuente: Información procesada por el autor.

Interpretación:

En el presente cuadro se evidencia que:

- El puntaje mínimo o menor logrado es de 76 puntos.

- El puntaje más alto alcanzado es de 103 puntos.

- 91 puntos fue alcanzado por 6 docentes,

Gráficamente observamos: 
GRÁFICO Nº6

OBSERVACIÓN DE ENTRADA DEL GRUPO CONTROL DOCENTES DE LA IEP SALESIANO TÉCNICO DON BOSCO

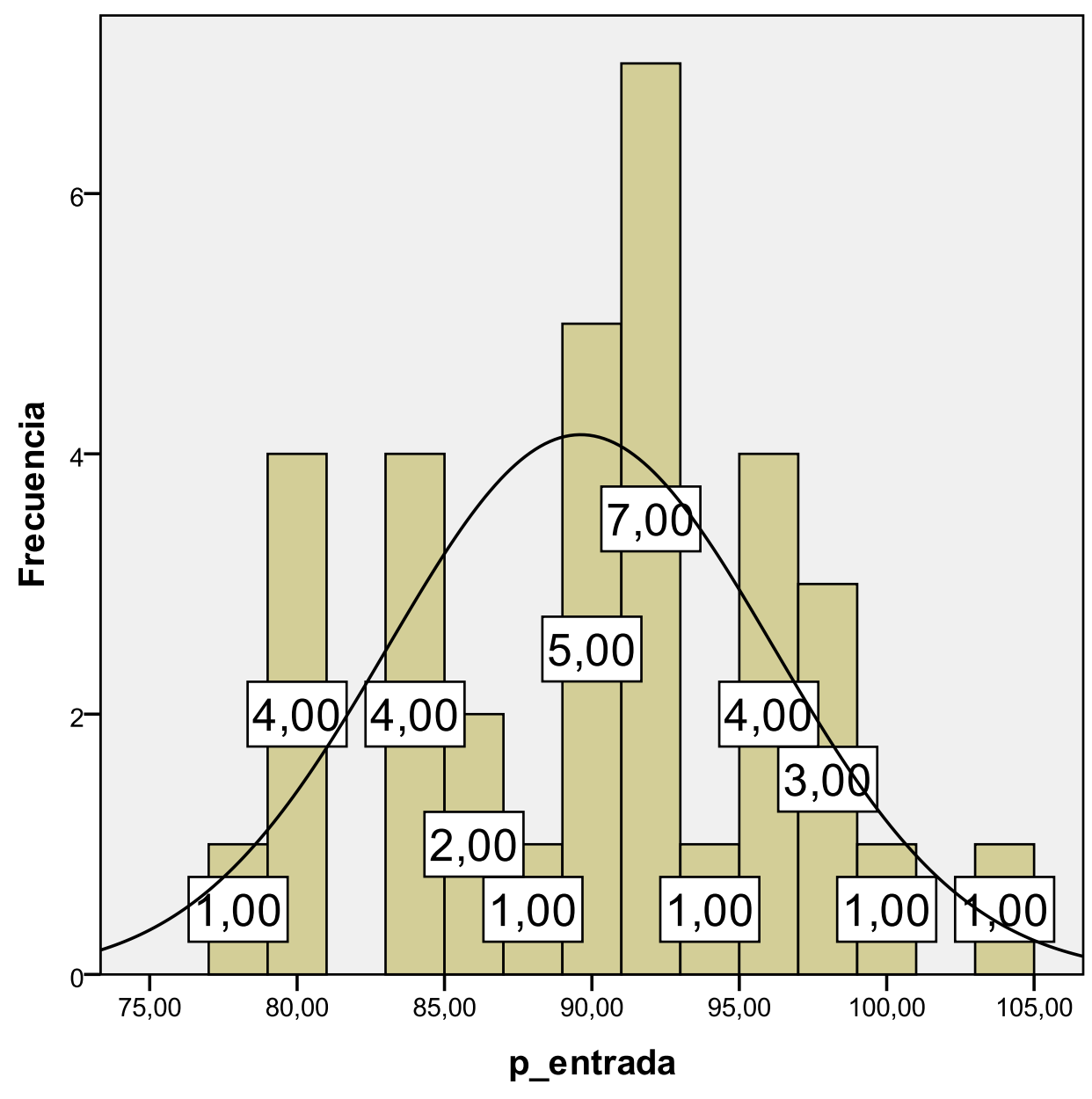


CUADRO No 11

RESULTADOS POR LA OBSERVACIÓN DE SALIDA DEL GRUPO

CONTROL

DOCENTES DE LA IEP SALESIANO TÉCNICO DON BOSCO

\begin{tabular}{|c|c|c|c|c|c|}
\hline \multicolumn{6}{|c|}{ p_salida } \\
\hline & & $\mathrm{fi}$ & $\%$ & $\%$ válido & $\%$ acumulado \\
\hline Válidos & 79,00 & 2 & 5,9 & 5,9 & 5,9 \\
\hline & 84,00 & 1 & 2,9 & 2,9 & 8,8 \\
\hline & 87,00 & 3 & 8,8 & 8,8 & 17,6 \\
\hline & 88,00 & 2 & 5,9 & 5,9 & 23,5 \\
\hline & 90,00 & 3 & 8,8 & 8,8 & 32,4 \\
\hline & 92,00 & 2 & 5,9 & 5,9 & 38,2 \\
\hline & 93,00 & 3 & 8,8 & 8,8 & 47,1 \\
\hline & 94,00 & 6 & 17,6 & 17,6 & 64,7 \\
\hline & 96,00 & 2 & 5,9 & 5,9 & 70,6 \\
\hline & 98,00 & 3 & 8,8 & 8,8 & 79,4 \\
\hline & 99,00 & 1 & 2,9 & 2,9 & 82,4 \\
\hline & 100,00 & 2 & 5,9 & 5,9 & 88,2 \\
\hline & 101,00 & 1 & 2,9 & 2,9 & 91,2 \\
\hline & 102,00 & 2 & 5,9 & 5,9 & 97,1 \\
\hline & 104,00 & 1 & 2,9 & 2,9 & 100,0 \\
\hline & Total & 34 & 100,0 & 100,0 & \\
\hline
\end{tabular}

Fuente: Información procesada por el autor.

Interpretación:

Podemos evidenciar en la prueba de salida los datos siguientes:

- El puntaje mínimo es de 79 puntos.

- El puntaje más alto alcanzado es de 104 puntos.

- Seis docentes alcanzaron un puntaje de 94 puntos.

Gráficamente observamos: 
GRÁFICO No 07

OBSERVACIÓN DE SALIDA DEL GRUPO CONTROL DOCENTES DE LA IEP SALESIANO TÉCNICO DON BOSCO

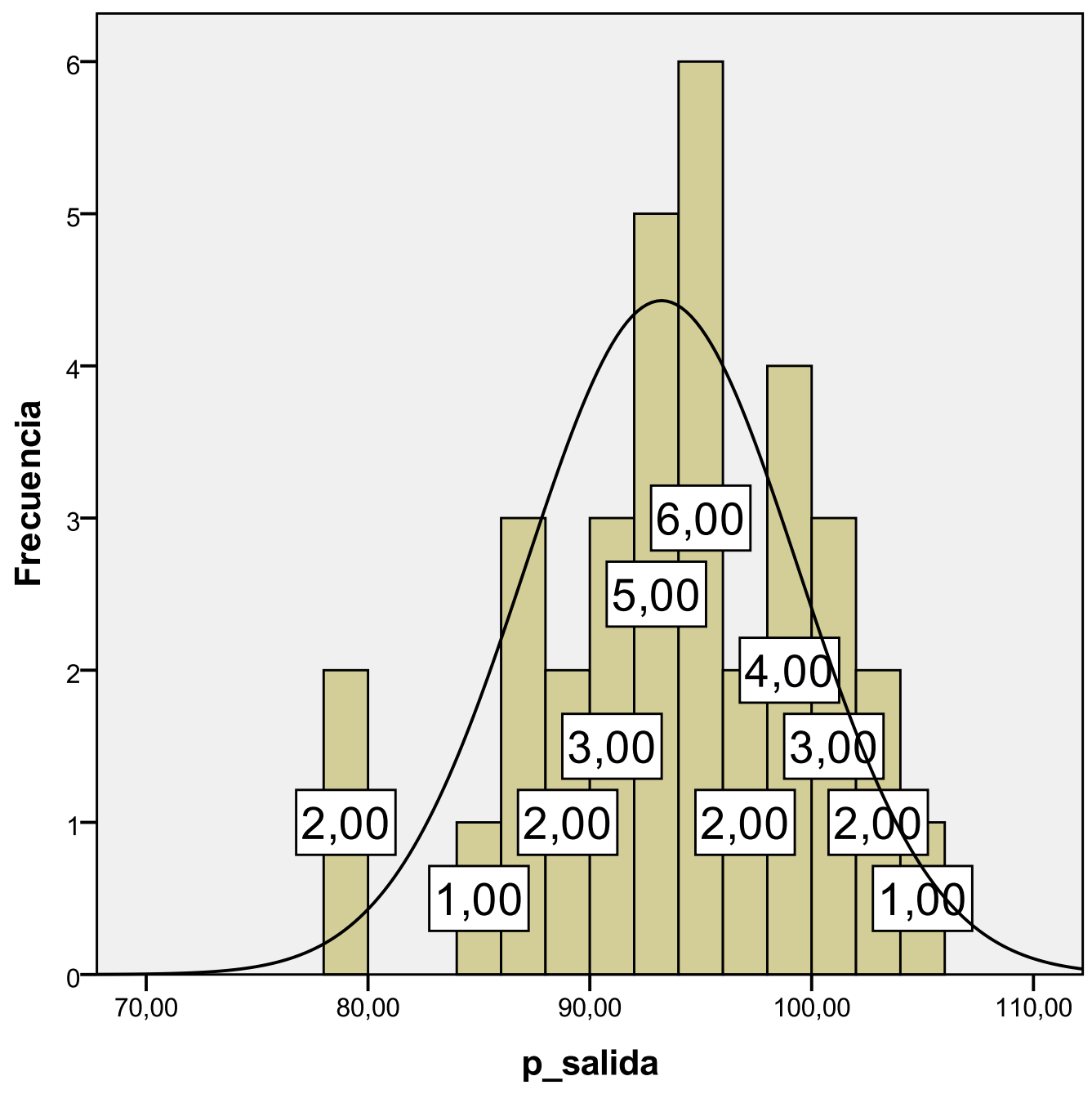




\section{CUADRO N 12}

RESUMEN DE LOS RESULTADOS DEL GRUPO CONTROL OBSERVACIÓN DE ENTRADA Y DE SALIDA DOCENTES DE LA IEP SALESIANO TÉCNICO DON BOSCO

\begin{tabular}{|l|r|r|r|r|r|}
\hline & \# & Min & Máx & X & Desv. típ. \\
\hline p_entrada & 34 & 78,00 & 103,00 & 89,6176 & 6,54131 \\
p_salida & 34 & 79,00 & 104,00 & 93,2353 & 6,12525 \\
N válido (según & 34 & & & & \\
lista) & & & & & \\
\hline
\end{tabular}

Fuente: Información procesada por el autor.

\section{Interpretación:}

En el cuadro $\mathrm{N}^{\circ} 12$ se observa que el número de docentes conformantes de la muestra fueron 34, tanto para la observación de entrada como para el de salida; los puntajes mínimos logrados fueron, 78 y 79 puntos respectivamente; los puntajes máximos son 103 y 104 puntos; la media aritmética al inicio fue de 89,6176 puntos frente a los 93,2353 logrado y también tenemos una desviación típica de 6,54131 y 6,12525 respectivamente. 
4.1.2. Resultados del grupo experimental.

CUADRO No 13

DATOS OBTENIDOS DEL GRUPO EXPERIMENTAL DOCENTES DE LA IEP SALESIANO SANTA ROSA

\begin{tabular}{|r|r|r|r|r|r|r|r|}
\hline $\mathbf{N}^{\circ}$ & Sexo & Edad & IEP & Nivel & Área & Entrada & Salida \\
\hline $\mathbf{1}$ & 1 & 46 & 2 & 1 & 2 & 73 & 92 \\
\hline $\mathbf{2}$ & 1 & 34 & 2 & 2 & 1 & 78 & 97 \\
\hline $\mathbf{3}$ & 1 & 35 & 2 & 2 & 1 & 79 & 96 \\
\hline $\mathbf{4}$ & 1 & 36 & 2 & 2 & 5 & 69 & 90 \\
\hline $\mathbf{5}$ & 1 & 37 & 2 & 2 & 1 & 73 & 99 \\
\hline $\mathbf{6}$ & 1 & 32 & 2 & 2 & 2 & 64 & 92 \\
\hline $\mathbf{7}$ & 1 & 44 & 2 & 2 & 5 & 47 & 88 \\
\hline $\mathbf{8}$ & 2 & 41 & 2 & 2 & 2 & 86 & 111 \\
\hline $\mathbf{9}$ & 2 & 45 & 2 & 2 & 1 & 46 & 91 \\
\hline $\mathbf{1 0}$ & 2 & 28 & 2 & 2 & 5 & 47 & 100 \\
\hline $\mathbf{1 1}$ & 1 & 38 & 2 & 2 & 1 & 90 & 113 \\
\hline $\mathbf{1 2}$ & 2 & 62 & 2 & 2 & 2 & 89 & 112 \\
\hline $\mathbf{1 3}$ & 2 & 40 & 2 & 2 & 1 & 47 & 97 \\
\hline $\mathbf{1 4}$ & 2 & 38 & 2 & 2 & 2 & 79 & 115 \\
\hline $\mathbf{1 5}$ & 2 & 35 & 2 & 2 & 1 & 39 & 75 \\
\hline $\mathbf{1 6}$ & 2 & 41 & 2 & 2 & 10 & 72 & 109 \\
\hline $\mathbf{1 7}$ & 2 & 37 & 2 & 2 & 5 & 86 & 104 \\
\hline $\mathbf{1 8}$ & 1 & 43 & 2 & 2 & 4 & 63 & 110 \\
\hline $\mathbf{1 9}$ & 1 & 35 & 2 & 2 & 3 & 77 & 113 \\
\hline $\mathbf{2 0}$ & 2 & 28 & 2 & 2 & 3 & 36 & 101 \\
\hline $\mathbf{2 1}$ & 2 & 34 & 2 & 2 & 3 & 72 & 109 \\
\hline $\mathbf{2 2}$ & 2 & 38 & 2 & 2 & 8 & 55 & 99 \\
\hline $\mathbf{2 3}$ & 2 & 36 & 2 & 2 & 9 & 41 & 77 \\
\hline $\mathbf{2 4}$ & 2 & 43 & 2 & 2 & 11 & 60 & 90 \\
\hline $\mathbf{2 5}$ & 2 & 29 & 2 & 2 & 8 & 30 & 81 \\
\hline $\mathbf{2 6}$ & 2 & 42 & 2 & 3 & 1 & 42 & 103 \\
\hline $\mathbf{2 7}$ & 2 & 44 & 2 & 3 & 1 & 47 & 102 \\
\hline $\mathbf{2 8}$ & 2 & 47 & 2 & 3 & 1 & 74 & 110 \\
\hline $\mathbf{2 9}$ & 2 & 37 & 2 & 3 & 2 & 95 & 118 \\
\hline $\mathbf{3 0}$ & 1 & 37 & 2 & 3 & 2 & 79 & 105 \\
\hline $\mathbf{3 1}$ & 2 & 26 & 2 & 3 & 3 & 39 & 81 \\
\hline
\end{tabular}




\begin{tabular}{|l|l|l|l|r|r|r|r|}
\hline $\mathbf{3 2}$ & 2 & 25 & 2 & 3 & 3 & 40 & 98 \\
\hline $\mathbf{3 3}$ & 2 & 49 & 2 & 3 & 3 & 96 & 108 \\
\hline $\mathbf{3 4}$ & 2 & 44 & 2 & 3 & 4 & 36 & 56 \\
\hline $\mathbf{3 5}$ & 2 & 37 & 2 & 3 & 5 & 99 & 118 \\
\hline $\mathbf{3 6}$ & 2 & 33 & 2 & 3 & 6 & 54 & 96 \\
\hline $\mathbf{3 7}$ & 2 & 31 & 2 & 3 & 7 & 48 & 104 \\
\hline $\mathbf{3 8}$ & 2 & 43 & 2 & 3 & 9 & 52 & 107 \\
\hline $\mathbf{3 9}$ & 2 & 34 & 2 & 3 & 9 & 82 & 108 \\
\hline $\mathbf{4 0}$ & 2 & 45 & 2 & 3 & 8 & 63 & 97 \\
\hline $\mathbf{4 1}$ & 2 & 43 & 2 & 3 & 10 & 103 & 120 \\
\hline $\mathbf{4 2}$ & 2 & 42 & 2 & 3 & 10 & 98 & 120 \\
\hline $\mathbf{4 3}$ & 2 & 49 & 2 & 3 & 10 & 51 & 99 \\
\hline $\mathbf{4 4}$ & 2 & 52 & 2 & 3 & 10 & 49 & 94 \\
\hline $\mathbf{4 5}$ & 2 & 39 & 2 & 3 & 11 & 46 & 98 \\
\hline
\end{tabular}

Fuente: Información procesada por el autor.

\section{Interpretación:}

Como apreciamos, se muestran los resultados del grupo control respecto a la observación inicial de la Institución Educativa Salesiano Santa Rosa de Huancayo. 


\section{CUADRO No 14}

\section{RESUMEN ESTADÍSTICO DEL GRUPO EXPERIMENTAL DOCENTES DE LA IEP SALESIANO SANTA ROSA}

\section{Estadísticos}

\begin{tabular}{|ll|r|r|r|r|r|r|r|}
\hline & & \multicolumn{1}{|c|}{ sexo } & \multicolumn{1}{c|}{ edad } & \multicolumn{1}{c|}{ iep } & nivel & area & p_entrada & p_salida \\
\hline N & Válidos & 45 & 45 & 45 & 45 & 45 & 45 & 45 \\
& Perdidos & 0 & 0 & 0 & 0 & 0 & 0 & 0 \\
Media & & 1,7556 & 38,9778 & 2,0000 & 2,4222 & 4,6889 & 64,2444 & 100,0667 \\
Mediana & & 2,0000 & 38,0000 & 2,0000 & 2,0000 & 3,0000 & 63,0000 & 100,0000 \\
Moda & 2,00 & 37,00 & 2,00 & 2,00 & 1,00 & 47,00 & $97,00 a$ \\
Desv. típ. &, 43461 & 7,18106 &, 00000 &, 54309 & 3,44319 & 20,38956 & 12,93058 \\
Varianza &, 189 & 51,568 &, 000 &, 295 & 11,856 & 415,734 & 167,200 \\
Suma & & 79,00 & 1754,00 & 90,00 & 109,00 & 211,00 & 2891,00 & 4503,00 \\
Percentiles & 25 & 1,5000 & 34,5000 & 2,0000 & 2,0000 & 2,0000 & 47,0000 & 93,0000 \\
& 50 & 2,0000 & 38,0000 & 2,0000 & 2,0000 & 3,0000 & 63,0000 & 100,0000 \\
& 75 & 2,0000 & 43,5000 & 2,0000 & 3,0000 & 8,0000 & 79,0000 & 109,5000 \\
\hline
\end{tabular}

Fuente: Información procesada por el autor.

\section{Interpretación:}

En el cuadro $\mathrm{N}^{\circ} 14$ se evidencia que existe una media aritmética de 64,2444 puntos en la prueba de entrada y en la de salida tenemos una media aritmética de 100,0667 puntos. 


\section{CUADRO No 15}

RESULTADOS POR SEXO DEL GRUPO EXPERIMENTAL

DOCENTES DE LA IEP SALESIANO SANTA ROSA

\begin{tabular}{|c|c|c|c|c|c|}
\hline \multicolumn{6}{|c|}{ Sexo } \\
\hline & & fi & $\%$ & $\%$ válido & $\%$ acumulado \\
\hline Válidos & 1,00 & 11 & 24,4 & 24,4 & 24,4 \\
\hline & 2,00 & 34 & 75,6 & 75,6 & 100,0 \\
\hline & Total & 45 & 100,0 & 100,0 & \\
\hline
\end{tabular}

Fuente: Información procesada por el autor.

Interpretación:

Apreciamos la información presentada en el cuadro $\mathrm{N}^{\circ} 15$ que el $24,4 \%$ son damas y 75,6 son varones.

Gráficamente observamos:

GRÁFICO No 08

RESULTADOS POR SEXO DEL GRUPO EXPERIMENTAL

DOCENTES DE LA IEP SALESIANO SANTA ROSA

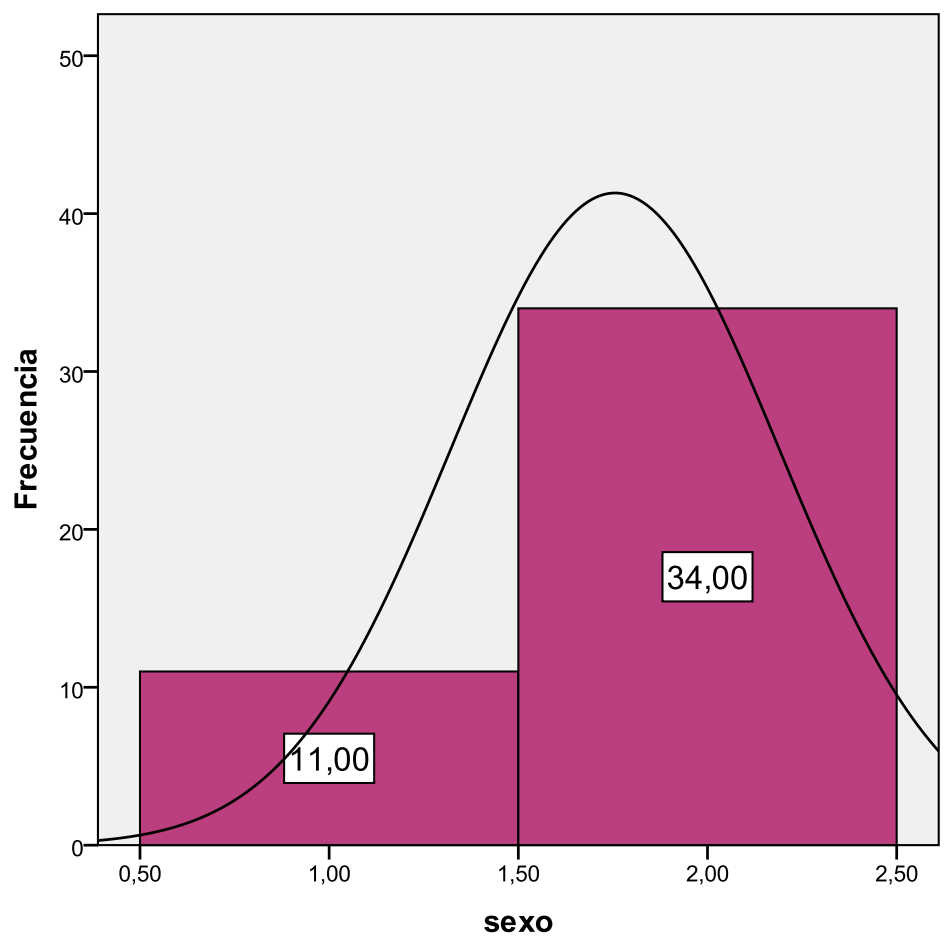




\section{CUADRO N 16}

RESULTADOS POR EDAD DEL GRUPO EXPERIMENTAL DOCENTES DE LA IEP SALESIANO SANTA ROSA

\begin{tabular}{|c|c|c|c|c|c|}
\hline & & Frecuencia & Porcentaje & $\begin{array}{l}\text { Porcentaje } \\
\text { válido }\end{array}$ & $\begin{array}{l}\text { Porcentaje } \\
\text { acumulado }\end{array}$ \\
\hline \multirow[t]{25}{*}{ Válidos } & 25,00 & 1 & 2,2 & 2,2 & 2,2 \\
\hline & 26,00 & 1 & 2,2 & 2,2 & 4,4 \\
\hline & 28,00 & 2 & 4,4 & 4,4 & 8,9 \\
\hline & 29,00 & 1 & 2,2 & 2,2 & 11,1 \\
\hline & 31,00 & 1 & 2,2 & 2,2 & 13,3 \\
\hline & 32,00 & 1 & 2,2 & 2,2 & 15,6 \\
\hline & 33,00 & 1 & 2,2 & 2,2 & 17,8 \\
\hline & 34,00 & 3 & 6,7 & 6,7 & 24,4 \\
\hline & 35,00 & 3 & 6,7 & 6,7 & 31,1 \\
\hline & 36,00 & 2 & 4,4 & 4,4 & 35,6 \\
\hline & 37,00 & 5 & 11,1 & 11,1 & 46,7 \\
\hline & 38,00 & 3 & 6,7 & 6,7 & 53,3 \\
\hline & 39,00 & 1 & 2,2 & 2,2 & 55,6 \\
\hline & 40,00 & 1 & 2,2 & 2,2 & 57,8 \\
\hline & 41,00 & 2 & 4,4 & 4,4 & 62,2 \\
\hline & 42,00 & 2 & 4,4 & 4,4 & 66,7 \\
\hline & 43,00 & 4 & 8,9 & 8,9 & 75,6 \\
\hline & 44,00 & 3 & 6,7 & 6,7 & 82,2 \\
\hline & 45,00 & 2 & 4,4 & 4,4 & 86,7 \\
\hline & 46,00 & 1 & 2,2 & 2,2 & 88,9 \\
\hline & 47,00 & 1 & 2,2 & 2,2 & 91,1 \\
\hline & 49,00 & 2 & 4,4 & 4,4 & 95,6 \\
\hline & 52,00 & 1 & 2,2 & 2,2 & 97,8 \\
\hline & 62,00 & 1 & 2,2 & 2,2 & 100,0 \\
\hline & Total & 45 & 100,0 & 100,0 & \\
\hline
\end{tabular}

Fuente: Información procesada por el autor.

Interpretación:

El docente de menor edad de esta muestra tiene 25 años, y el de mayor edad 62 años. 
Gráficamente observamos:

\section{GRÁFICO Nº 09}

RESULTADOS POR EDAD DEL GRUPO EXPERIMENTAL

DOCENTES DE LA IEP SALESIANO SANTA ROSA

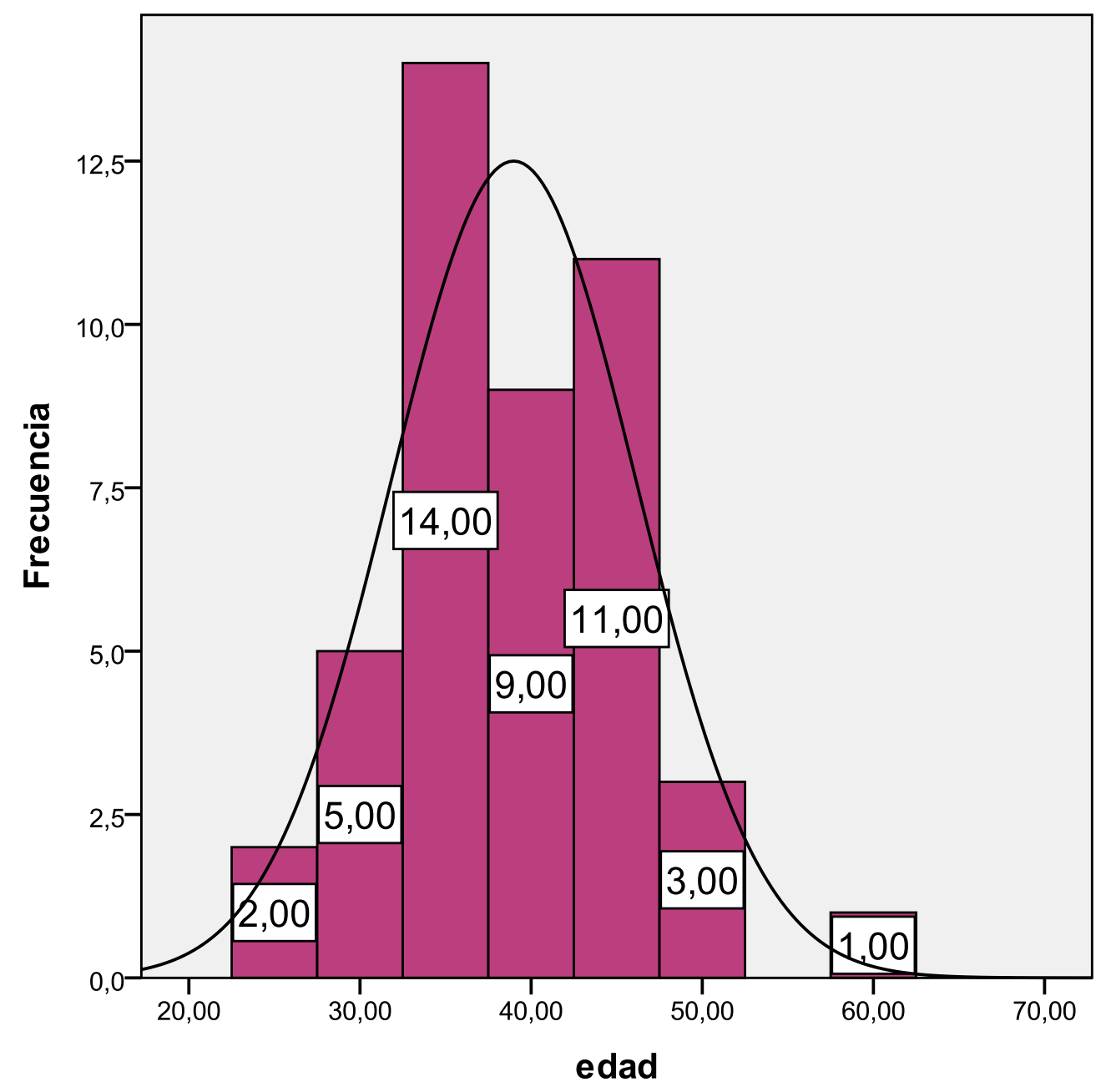




\section{CUADRO No 17 \\ RESULTADOS POR INSTITUCIÓN EDUCATIVA DEL GRUPO \\ EXPERIMENTAL \\ DOCENTES DE LA IEP SALESIANO SANTA ROSA}

\begin{tabular}{|c|c|c|c|c|}
\hline & $\mathrm{fi}$ & $\%$ & \% válido & $\%$ acumulado \\
\hline Válidos 2,00 & 45 & 100,0 & 100,0 & 100,0 \\
\hline
\end{tabular}

Fuente: Información procesada por el autor.

Interpretación:

Evidenciamos que el $100 \%$ pertenecen a la Institución

Educativa Salesiano Santa Rosa.

GRÁFICO No 10

RESULTADOS POR INSTITUCIÓN EDUCATIVA DEL GRUPO EXPERIMENTAL DOCENTES DE LA IEP SALESIANO SANTA ROSA

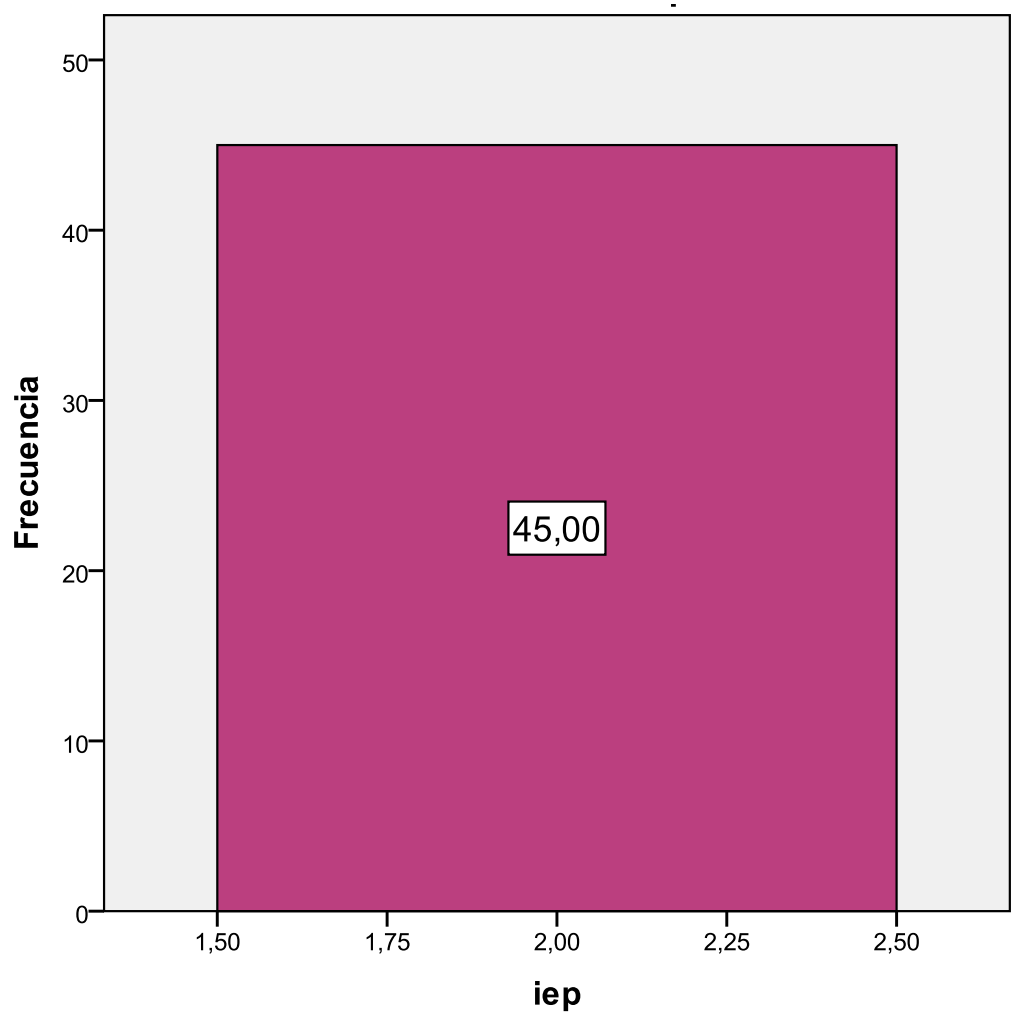




\section{CUADRO No 18}

RESULTADOS POR NIVEL EDUCATIVO DEL GRUPO EXPERIMENTAL DOCENTES DE LA IEP SALESIANO SANTA ROSA nivel

\begin{tabular}{|c|c|c|c|c|c|}
\hline & & fi & $\%$ & \% válido & $\%$ acumulado \\
\hline \multirow[t]{4}{*}{ Válidos } & 1,00 & 1 & 2,2 & 2,2 & 2,2 \\
\hline & 2,00 & 24 & 53,3 & 53,3 & 55,6 \\
\hline & 3,00 & 20 & 44,4 & 44,4 & 100,0 \\
\hline & Total & 45 & 100,0 & 100,0 & \\
\hline
\end{tabular}

Fuente: Información procesada por el autor.

Interpretación:

Podemos evidenciar como resultados del presente cuadro que 1 docente es del nivel inicial (2,2\%); 24 docentes son del nivel primario $(53,3 \%)$ y 20 docentes son del nivel secundario $(44,4 \%)$ de la IEP Salesiano Santa Rosa.

\section{GRÁFICO No 11}

RESULTADOS POR NIVEL EDUCATIVO DEL GRUPO EXPERIMENTAL DOCENTES DE LA IEP SALESIANO SANTA ROSA

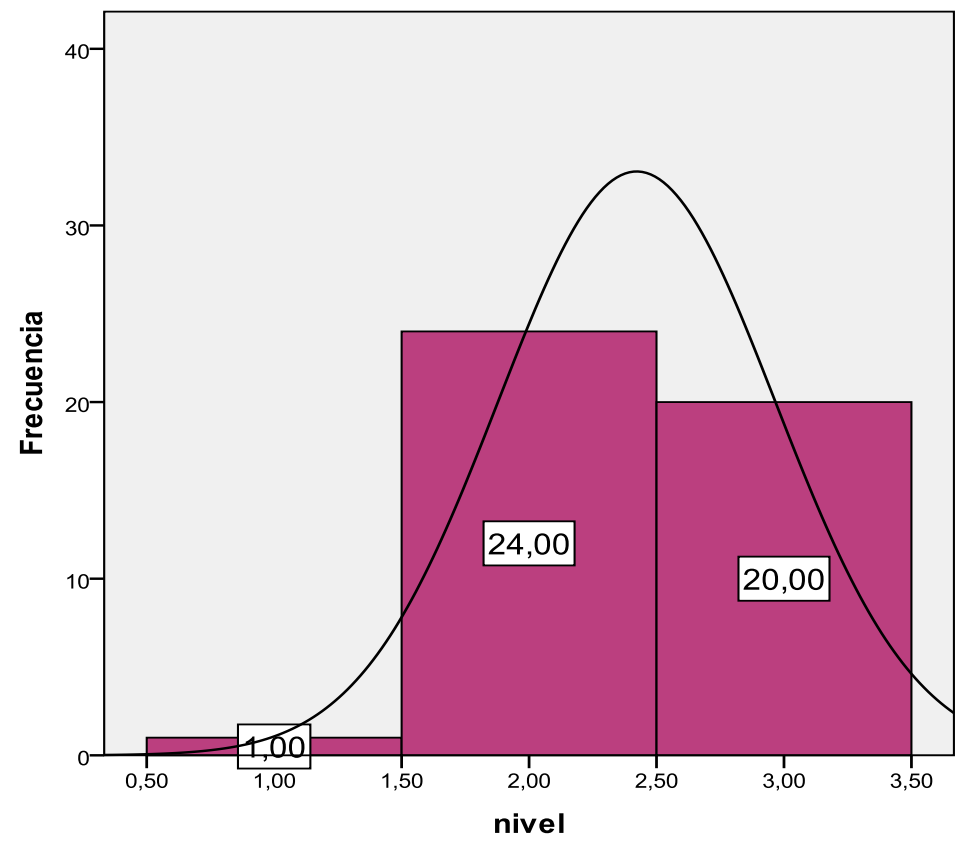


CUADRO No 19

RESULTADOS POR ÁREA DEL GRUPO EXPERIMENTAL DOCENTES DE LA IEP SALESIANO SANTA ROSA

\begin{tabular}{|c|c|c|c|c|c|}
\hline \multicolumn{6}{|c|}{ área } \\
\hline & & $\mathrm{fi}$ & $\%$ & \% válido & $\%$ acumulado \\
\hline Válidos & 1,00 & 10 & 22,2 & 22,2 & 22,2 \\
\hline & 2,00 & 7 & 15,6 & 15,6 & 37,8 \\
\hline & 3,00 & 6 & 13,3 & 13,3 & 51,1 \\
\hline & 4,00 & 2 & 4,4 & 4,4 & 55,6 \\
\hline & 5,00 & 5 & 11,1 & 11,1 & 66,7 \\
\hline & 6,00 & 1 & 2,2 & 2,2 & 68,9 \\
\hline & 7,00 & 1 & 2,2 & 2,2 & 71,1 \\
\hline & 8,00 & 3 & 6,7 & 6,7 & 77,8 \\
\hline & 9,00 & 3 & 6,7 & 6,7 & 84,4 \\
\hline & 10,00 & 5 & 11,1 & 11,1 & 95,6 \\
\hline & 11,00 & 2 & 4,4 & 4,4 & 100,0 \\
\hline & Total & 45 & 100,0 & 100,0 & \\
\hline
\end{tabular}

Fuente: Información procesada por el autor.

Interpretación:

Se logró la información siguiente, que:

- 10 profesores son del área de Matemática (22,2 \%).

- 7 profesores son del área de Comunicación (15,6 \%).

- 3 profesores son del área de Inglés (13,3\%).

- 2 profesores son del área de Arte (4,4\%).

- 5 profesores son del área de Historia, Geografía y Economía $(11,1$ $\%)$.

- 1 docente es del área de Formación Ciudadana y Cívica (2,2 \%).

- 1 docente es del área de Persona, Familia y Relaciones Humanas $(2,2 \%)$.

- 3 docentes son del área de Educación Física (6,7 \%). 
- 3 docentes son del área de Educación Religiosa (6,7 \%).

- 5 docentes son del área de Ciencia, Tecnología y Ambiente $(11,1 \%)$.

- 2 docentes son del área de Educación para el Trabajo (4,4 \%).

Gráficamente observamos:

\section{GRÁFICO No 12}

RESULTADOS POR ÁREA DEL GRUPO EXPERIMENTAL DOCENTES DE LA IEP SALESIANO SANTA ROSA

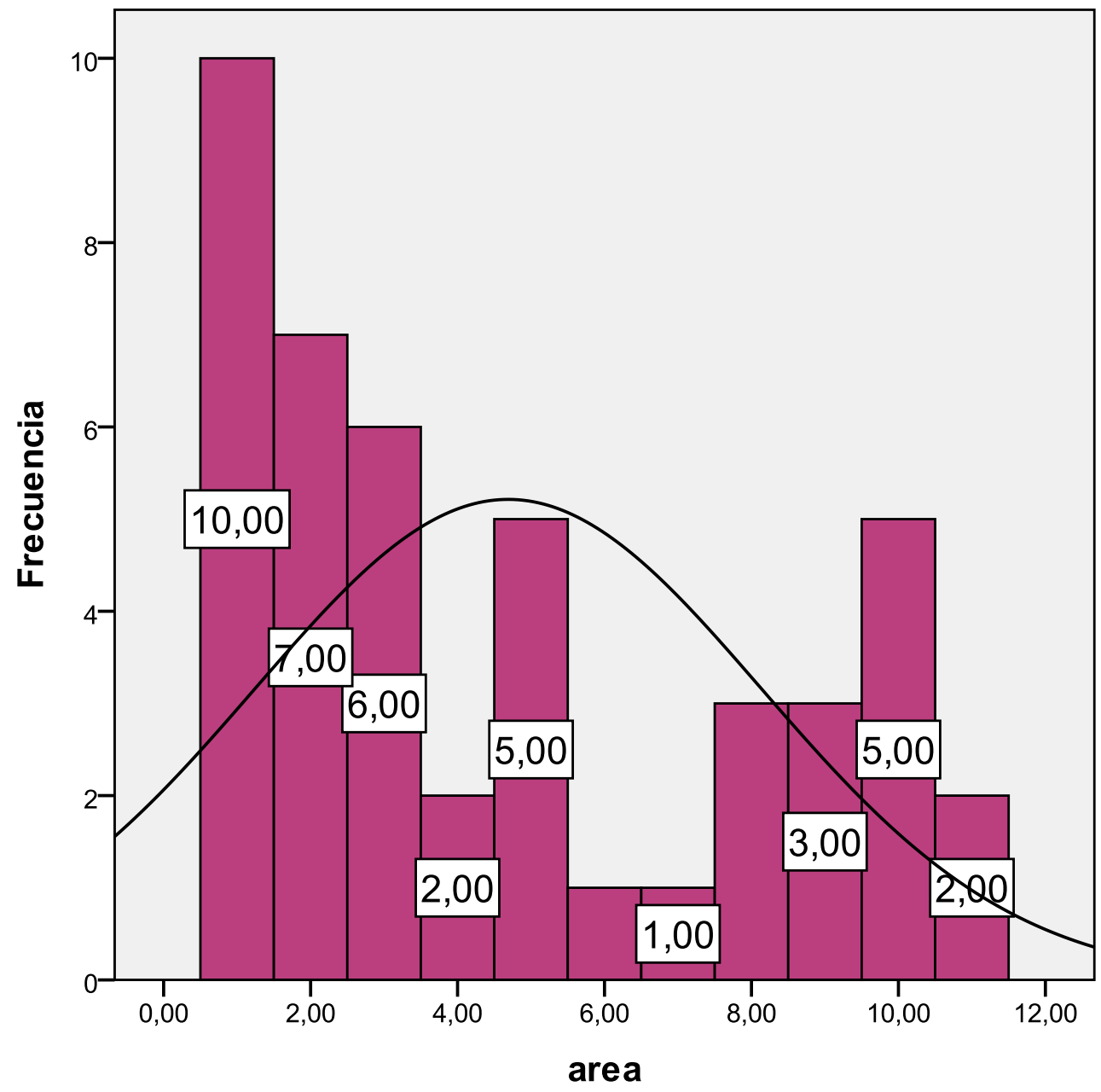




\section{CUADRO No 20 \\ RESULTADOS POR LA OBSERVACIÓN DE ENTRADA DEL GRUPO \\ EXPERIMENTAL \\ DOCENTES DE LA IEP SALESIANO SANTA ROSA}

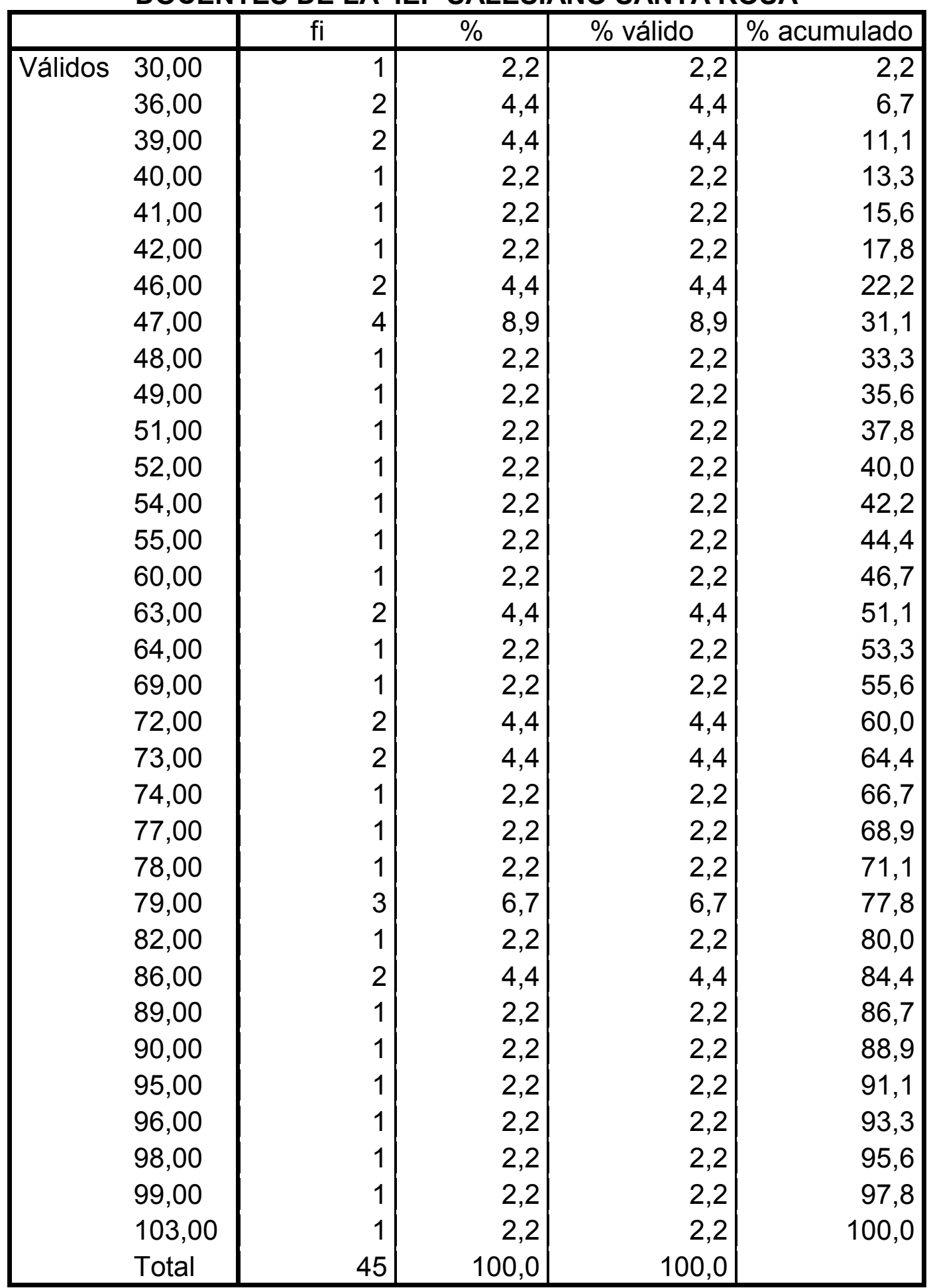

Fuente: Información procesada por el autor. 
Interpretación:

Producto de la tabulación de datos, en el cuadro se observa que:

- El puntaje mínimo logrado es de 30 puntos

- El máximo de 103 puntos en la prueba de entrada

- Existen además 4 docentes que lograron un puntaje de 47 puntos.

Gráficamente observamos:

\section{GRÁFICO No 13}

\section{OBSERVACIÓN DE ENTRADA DEL GRUPO EXPERIMENTAL DOCENTES DE LA IEP SALESIANO SANTA ROSA}

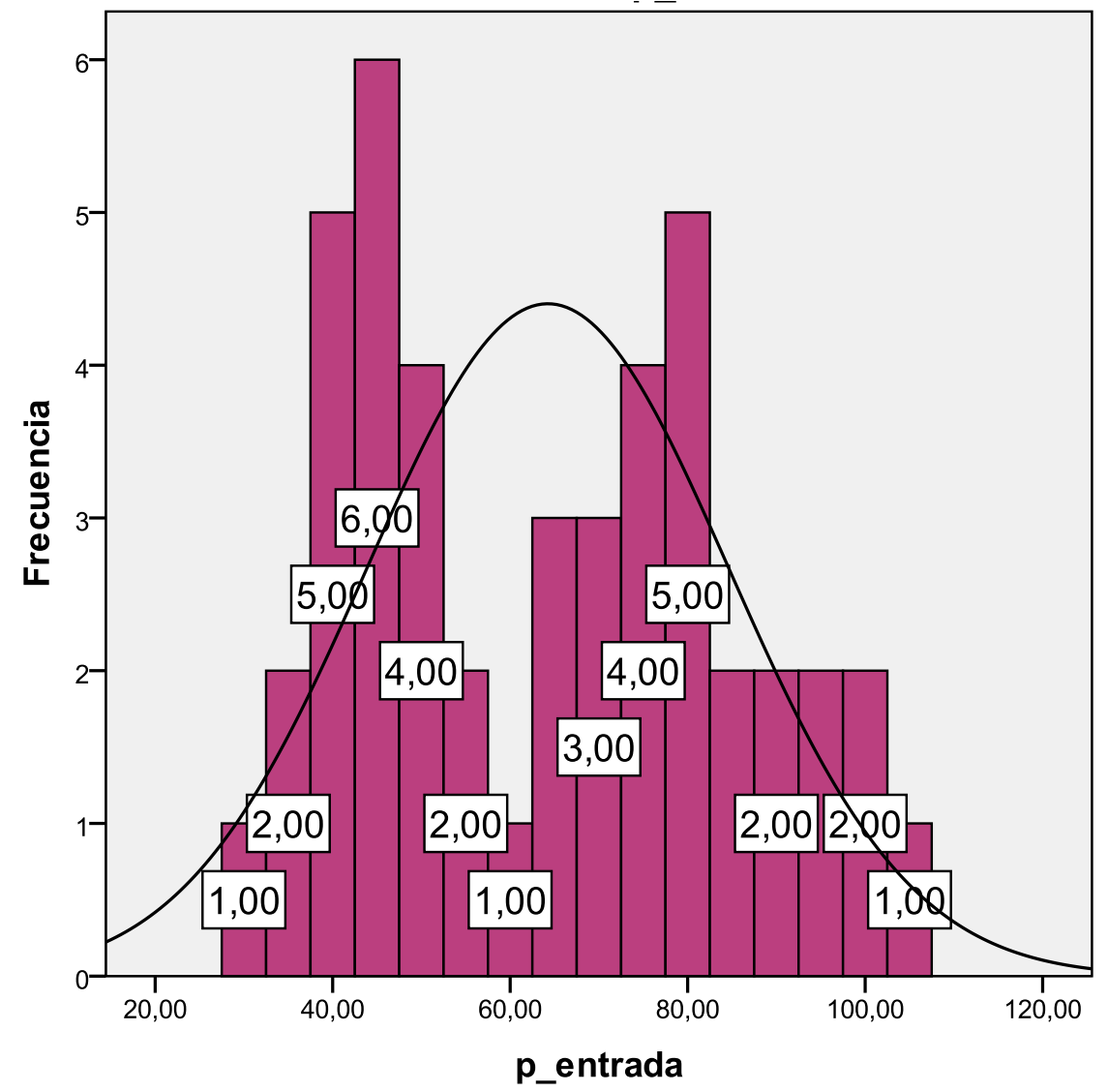




\section{CUADRO $\mathbf{N}^{\circ} 21$}

RESULTADOS POR LA OBSERVACIÓN DE SALIDA DEL GRUPO EXPERIMENTAL

DOCENTES DE LA IEP SALESIANO SANTA ROSA

\begin{tabular}{|c|c|c|c|c|c|}
\hline & & $\overline{\mathrm{fi}}$ & $\%$ & \% válido & $\%$ acumulado \\
\hline \multirow[t]{30}{*}{ Válidos } & 56,00 & 1 & 2,2 & 2,2 & 2,2 \\
\hline & 75,00 & 1 & 2,2 & 2,2 & 4,4 \\
\hline & 77,00 & 1 & 2,2 & 2,2 & 6,7 \\
\hline & 81,00 & 2 & 4,4 & 4,4 & 11,1 \\
\hline & 88,00 & 1 & 2,2 & 2,2 & 13,3 \\
\hline & 90,00 & 2 & 4,4 & 4,4 & 17,8 \\
\hline & 91,00 & 1 & 2,2 & 2,2 & 20,0 \\
\hline & 92,00 & 2 & 4,4 & 4,4 & 24,4 \\
\hline & 94,00 & 1 & 2,2 & 2,2 & 26,7 \\
\hline & 96,00 & 2 & 4,4 & 4,4 & 31,1 \\
\hline & 97,00 & 3 & 6,7 & 6,7 & 37,8 \\
\hline & 98,00 & 2 & 4,4 & 4,4 & 42,2 \\
\hline & 99,00 & 3 & 6,7 & 6,7 & 48,9 \\
\hline & 100,00 & 1 & 2,2 & 2,2 & 51,1 \\
\hline & 101,00 & 1 & 2,2 & 2,2 & 53,3 \\
\hline & 102,00 & 1 & 2,2 & 2,2 & 55,6 \\
\hline & 103,00 & 1 & 2,2 & 2,2 & 57,8 \\
\hline & 104,00 & 2 & 4,4 & 4,4 & 62,2 \\
\hline & 105,00 & 1 & 2,2 & 2,2 & 64,4 \\
\hline & 107,00 & 1 & 2,2 & 2,2 & 66,7 \\
\hline & 108,00 & 2 & 4,4 & 4,4 & 71,1 \\
\hline & 109,00 & 2 & 4,4 & 4,4 & 75,6 \\
\hline & 110,00 & 2 & 4,4 & 4,4 & 80,0 \\
\hline & 111,00 & 1 & 2,2 & 2,2 & 82,2 \\
\hline & 112,00 & 1 & 2,2 & 2,2 & 84,4 \\
\hline & 113,00 & 2 & 4,4 & 4,4 & 88,9 \\
\hline & 115,00 & 1 & 2,2 & 2,2 & 91,1 \\
\hline & 118,00 & 2 & 4,4 & 4,4 & 95,6 \\
\hline & 120,00 & 2 & 4,4 & 4,4 & 100,0 \\
\hline & Total & 45 & 100,0 & 100,0 & \\
\hline
\end{tabular}

Fuente: Información procesada por el autor. 
Interpretación:

Se puede evidenciar que:

- Existe un puntaje mínimo de 56 puntos.

- Existe un puntaje máximo de 120 puntos.

- Además 3 docentes lograron un puntaje de 97 puntos.

Gráficamente observamos:

\section{GRÁFICO N 14}

OBSERVACIÓN DE SALIDA DEL GRUPO EXPERIMENTAL DOCENTES DE LA IEP SALESIANO SANTA ROSA

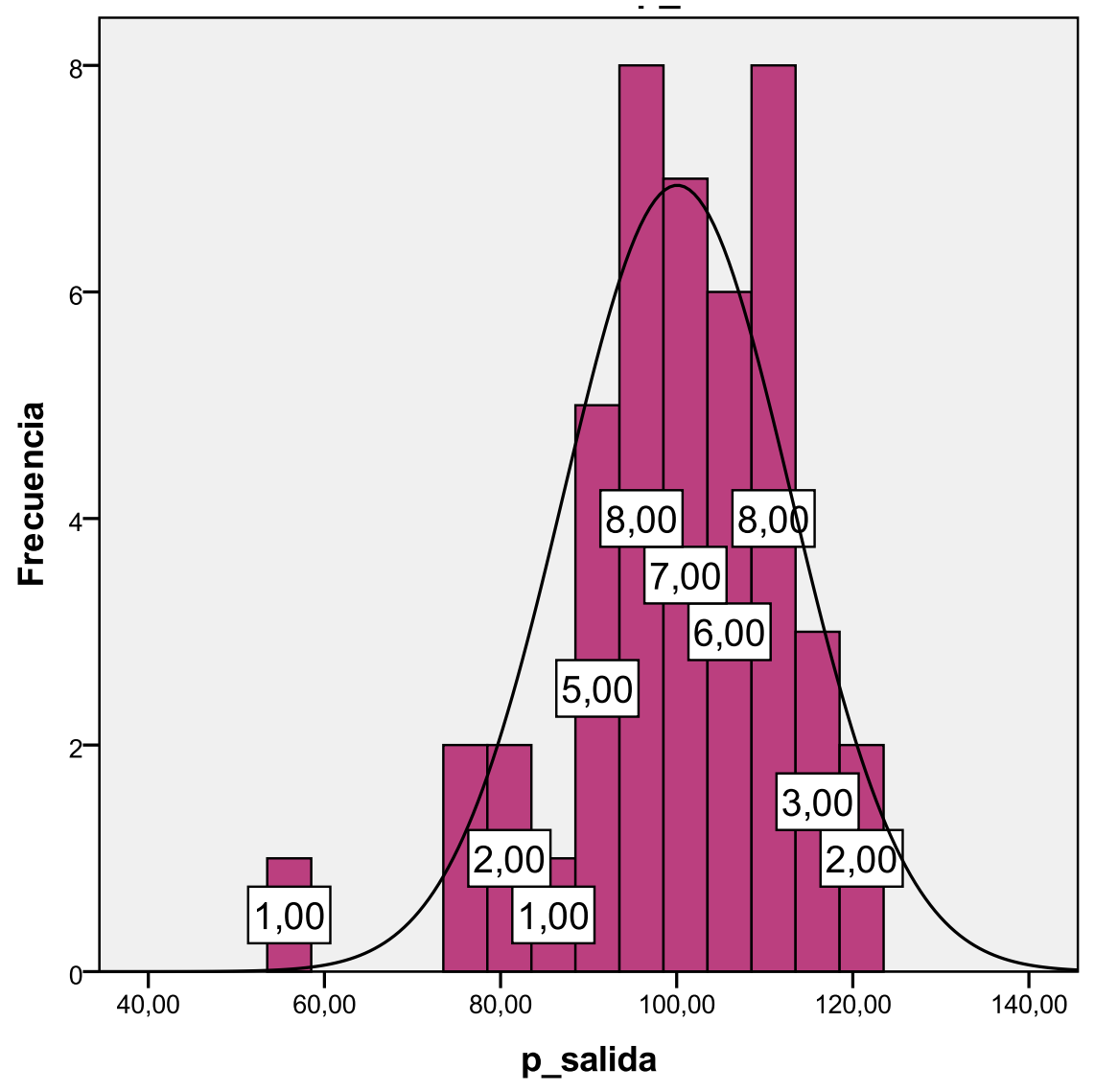




\section{CUADRO N 22}

\section{RESUMEN DE LOS RESULTADOS DEL GRUPO EXPERIMENTAL OBSERVACIÓN DE ENTRADA Y DE SALIDA DOCENTES DE LA IEP SALESIANO SANTA ROSA}

\begin{tabular}{|l|r|r|r|r|l|}
\hline & \multicolumn{1}{|c|}{$\#$} & Min & \multicolumn{1}{c|}{ Máx } & \multicolumn{1}{c|}{ X } & Desv. típ. \\
\hline p_entrada & 45 & 30,00 & 103,00 & 64,2444 & 20,38956 \\
p_salida & 45 & 56,00 & 120,00 & 100,0667 & 12,93058 \\
N válido (según & 45 & & & & \\
lista) & & & & & \\
\hline
\end{tabular}

Fuente: Información procesada por el autor.

\section{Interpretación:}

Podemos evidenciar en el siguiente cuadro el número de docentes conformantes de la muestra fueron 45, tanto para la observación de entrada como para el de salida; los puntajes mínimos logrados fueron, 30 y 56 puntos respectivamente; los puntajes máximos son 103 y 120 puntos; la media aritmética al inicio fue de 64,2444 puntos frente a los 100,0667 logrado y también tenemos una desviación típica de 20,38956 y 12,93058 respectivamente.

\subsection{PROCESO DE LA PRUEBA DE HIPÓTESIS.}

\subsubsection{Validación de hipótesis poblacional.}

a) Formulación de hipótesis.

Ho: No existe diferencia entre la varianza poblacional del grupo control y grupo experimental.

$\mathrm{H}_{1}$ : Existe diferencia entre la varianza poblacional del grupo control y grupo experimental. 
b) Hipótesis estadística.

$$
\begin{aligned}
& H_{0}: G c^{2}=G e^{2} \\
& H_{1}: G c^{2} \neq G e^{2}
\end{aligned}
$$

c) Nivel de significancia.

$$
\alpha=0,05 \text { es decir (5\%) }
$$

d) Estadígrafo pertinente.

$$
\text { Son } \mathrm{Sc}^{2} \text { y } \mathrm{Se}^{2} \text {. }
$$

e) Estadístico de prueba y su distribución.

$$
\text { R.V. }=\mathrm{Sc}^{2} / \mathrm{Se}^{2}
$$

R.V. : Región de varianza.

$$
\begin{aligned}
& \mathrm{GlC}=\mathrm{n}-1 \\
& \mathrm{GI}=\mathrm{n}-1
\end{aligned}
$$

f) Región de rechazo y aceptación.

- Valor superior.

$$
\mathrm{F}_{1-\alpha / 2}=\mathrm{F}_{\mathrm{o}, 975}=44
$$

$F_{0,975}=1,85$

- Valor inferior.

$$
F_{(0,025 ; 39,39)}=\frac{1}{F_{(0,925 ; 39,39)}}=\frac{1}{1,85}=0,01
$$




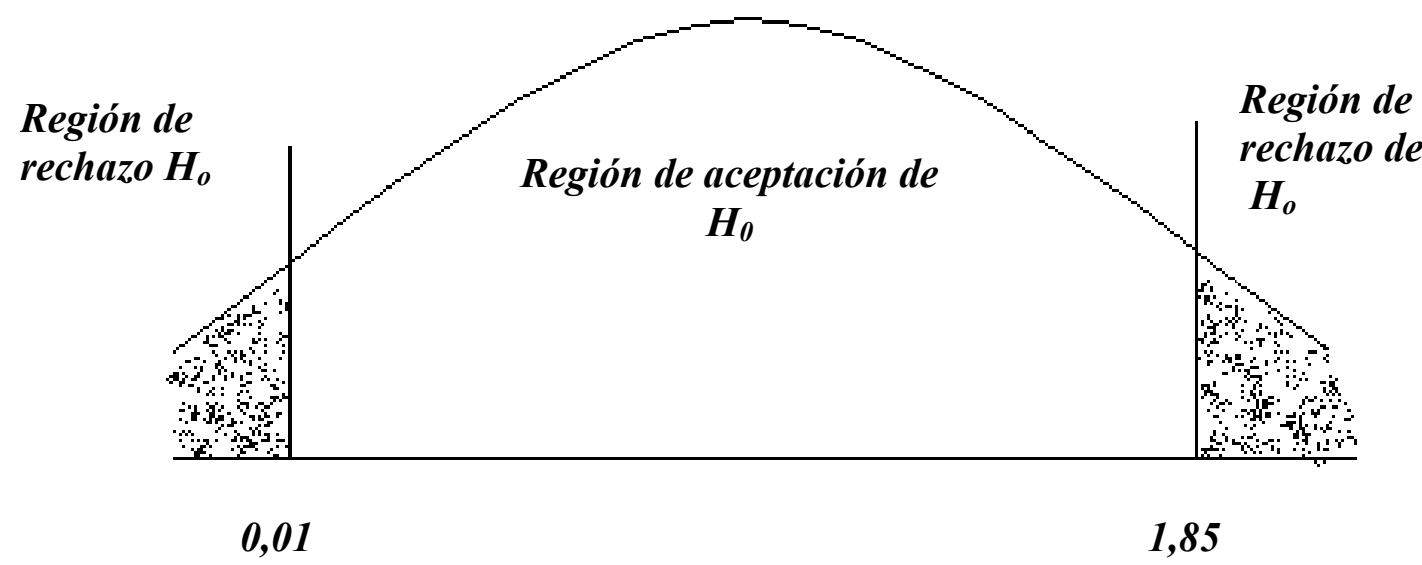

g) Recolección de datos y cálculos.

Las varianzas muestrales son las siguientes:

$$
\begin{aligned}
& \mathrm{Sc}^{2}=42,789 \\
& \mathrm{Se}^{2}=415,734 \\
& \mathrm{R} . \mathrm{V} .=\mathrm{Sc}^{2} / \mathrm{Se}^{2} \\
& \text { R.v. }=\frac{42,789}{415,734}=0.102923985
\end{aligned}
$$

h) Decisión estadística.

Como la R.V. es 0,102923985 y cae en la región de aceptación, en tal sentido se acepta $\mathrm{H}_{\circ}$ y se rechaza $\mathrm{H}_{1}$. Se concluye que las varianzas poblacionales no son diferentes.

\subsubsection{Validación.}

a) Formulación de hipótesis.

$\mathrm{H}_{\mathrm{o}}$ : No existe diferencia entre los promedios del grupo control y experimental en la aplicación del coaching en el 
desarrollo del desempeño docente en la provincia de Huancayo.

$\mathrm{H}_{1}$ : $\quad$ Existe diferencia entre los promedios del grupo control y experimental en la aplicación del coaching en el desarrollo del desempeño docente en la provincia de Huancayo.

b) Hipótesis estadística.

$\mathrm{H}_{\mathrm{o}}: \mathrm{Ue} \leq \mathrm{Uc}$

$\mathrm{H}_{1}: \mathrm{Ue}>\mathrm{Uc}$

c) Establecimiento de la prueba.

Es unilateral (cola derecha) por $\mathrm{H}_{1}$.

d) Nivel de significación.

$\alpha=0,05$

e) Esquema gráfico de la prueba.

$\alpha=0,05$

$g l=77$

$Z_{(0,05 ; 77)}=1,658$

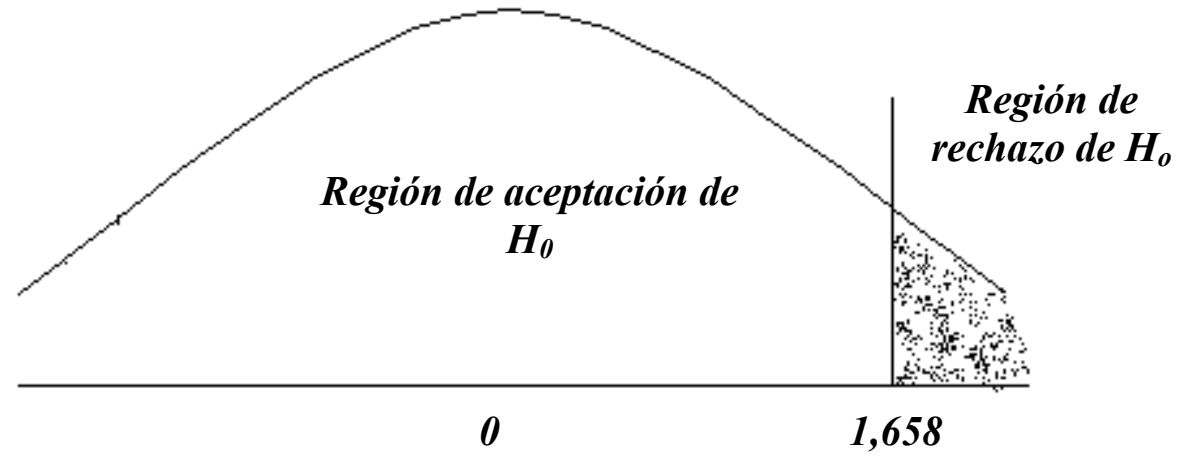


Aceptar Ho, si $Z_{c} \leq Z_{t}$

Rechazar $\mathrm{H}_{1}$, si $\mathrm{Z}_{\boldsymbol{c}}>\mathrm{Z}_{\boldsymbol{t}}$

f) Cálculo de estadígrado de la prueba.

$$
\begin{aligned}
& Z=\frac{42,789}{0,99} \\
& Z=\mathbf{4 3 , 2 2 1 2 1 2 1 2}
\end{aligned}
$$

g) Decisión estadística.

Como Zc es mayor que $\mathrm{Zt}$, se rechaza $\left(\mathrm{H}_{\mathrm{o}}\right)$ y se acepta $\mathrm{H}_{1}$, a un nivel de significación del $\alpha=0,05$.

h) Conclusión educativa.

Como $Z_{c}>Z_{t}$ en consecuencia concluimos que el promedio alcanzando por el grupo experimental mayor al del control en la aplicación del experimento.

\subsection{DISCUSIÓN DE RESULTADOS.}

Se puede evidenciar en los resultados estadísticos presentados que los datos obtenidos al finalizar el experimento son mayores en el grupo experimental que el grupo control, esto significa que se tuvo éxito y se consiguió lo que se esperaba,

Lo conseguido tiene un acercamiento y similitud con: Palma (2000), Cedeño (2008), Mendoza (2009), Adriano (2007), De La Cruz (2009), Montalvo (2008) y Salomé (2008). 
Los investigadores mencionados ratifican que la aplicación del coaching, por las características, funcionales, objetivos y manera de evaluar posee, tiene efectos significativos, debido a su versatilidad, manera de ayuda de un coach hacia un entrenante, logrando, gracias a ello, una mejora en el discípulo y su posterior potenciación de habilidades, destrezas y capacidades que pueda mostrar. Respecto al desempeño docente, los autores manifiestan también que mucho dependerá de cuán identificados se sienten respecto a la carrera docente, debido a que hay muchos factores que tienen que enfrentar y corregir. Uno de los estos factores es el amor por lo que hacen, la dedicación e identificación para con sus alumnos, conocer su contexto, dominar la metodología del área y/o curso a cargo, junto a un diálogo permanente con sus semejantes, en especial con sus pares y padres de familia.

Todo esto conjugado con un programa que evidencie y ratifique las expectativas de cambio en el diálogo, en la manera de cómo se debe trabajar, así como en el desarrollo de valores, harán que los docentes puedan desempeñarse mejor. Sin olvidar claro, que el estado tiene responsabilidades más grandes en este acápite para motivar al profesor y hacer que su carrera (digna, humilde y tolerante) pueda transformarse un una profesión que sea cada vez más aceptada por las grandes mayorías en todos los contextos de nuestra patria. El gobierno debe expresar su intención de mejorar los sueldos y salarios de los docentes que trabajan en zona de frontera, rurales o de difícil acceso, haciendo atractivo el pago y 
motivando a los docentes, de seguro se animarán para participar en esta carrera hermosa que es la educación.

Los gobiernos regionales de turno deben expresar también que, aun así puedan conocer los contextos de su entorno, los especialistas, directivos y profesores deben tener en claro que el conocimiento del contexto en sus diferentes esferas: económico, social, político, geográfico, sociocultural, artístico y en especial el educativo; les permitirá que cuando planifiquen sus planes de acción sea acorde a una realidad que conocen y muy bien. No debemos de caer en el facilismo de expresar con total frescura que estamos haciendo obras (desarrollo humano) solo en papeles, deben estar encargados de transformar con vehemencia y veracidad; motivando a cada docente de su región en aras de velar por el desarrollo pleno del estudiante.

Además se ha sincerado a nivel de los centros educativos que los directores, son los principales motivadores, las personas que deben hacer propias las aplicaciones metodológicas y de evaluación de acuerdo al ritmo y estilo de aprendizaje de sus alumnos; y esto garantizaría que motivarían a los profesores para que puedan ser capacitados en alto nivel de exigencia de acuerdo a su contexto, debido a que si una persona conoce los instrumentos de evaluación (y las puede elaborar con sus propias manos a partir del conocimiento y dominio del contexto en el que trabajará) logrará un resultado diferente; esto debe estar unido a la metodología que se empleará con los estudiantes debido a que el 
producto debe de ser evaluado de acuerdo a las expectativas que el mismo centro educativo ha establecido para tal fin, ello lo llevará a conseguir la gloria.

Por lo mencionado, manifestamos que coaching tiene influencia positiva en el desarrollo del desempeño docente en la provincia de Huancayo. 


\section{V \\ APORTES DE LA INVESTIGACIÓN}

\subsection{APORTES METODOLÓGICOS O TEÓRICOS.}

En este capítulo se podrá observar los aportes teóricos que tiene la variable independiente para el logro y consecución de la variable dependiente; es decir, cuán benéfico y correcto fue la aplicación del coaching para el logro y desarrollo del desempeño docente en el aula, con los profesores de la provincia de Huancayo, en especial con los centros educativos salesianos; motivo de nuestra muestra ejecutada.

Veamos:

El coaching permite desarrollar caracteres, personalidad, actitudes, metodologías; sólo si se está identificado con el cambio; no hay cambio si no existe interés.

Este interés debe partir desde los docentes, involucrados en la muestra e investigación. Deben apoderarse de la metodología que plantea esta variable y hacerla propia y de esta forma asegurar su verídica aplicación en el aula. 
Además se garantiza que aplicando esta variable (el coaching) en un conjunto de personajes, pasibles de cambio, se lograrán los resultados que esperamos alcanzar, debido a los siguientes factores:

La metodología de aplicación del experimento es activa, lo que significa que no hay coaching sin coach y sin coachee (entrenador y entrenante).

La dinámica es directa, interactiva debido a su cooperativismo entre los participantes, pues se plasma de manera directa, desarrollando el valor del respeto en los involucrados ya que se comparten las responsabilidades.

El coaching tiene varias ventajas: por ejemplo, permite el desarrollo de valores de quienes la practican; está orientada a alcanzar el resultado planeado y organizado; forma el carácter y la disciplina en el usuario; su aplicación cada vez más se retroalimenta y se mejoran las posibles fallas que pueda tener y existir en su desarrollo; ayuda al cooperativismo, no hay egoísmo, se persigue una meta común por la confianza y confidencialidad que tienen los entrenadores hacia los discípulos.

Claro que también evidenciaremos desventajas en el coaching y su aplicación en el aula o el centro educativo: Si no se toma en serio los resultados que se aspiran no se conseguirá lo planeado, debe verse reflejado en el respeto no en la improvisación; no debe ponerle barreras a los participantes pues el coach debe indicar de manera clara qué es lo que se persigue 
desde el momento a fin de que tenga que enfocar (el participante) sus objetivos a un logro inmediato.

Ahora, los aportes respecto al desempeño docente ha sido el mayor logro, pues se propone y entrega un instrumento que permitirá evaluar (observar) el profesor en el aula a través de: el planteamiento y organización de una sesión de clase; la rigurosidad en el contenido de su área; la aplicación de la metodología (estrategia, método, técnica, proceso y procedimiento) adecuado; un adecuado clima en el aula; utilizando materiales y recursos educativos acordes a la realidad del estudiante y finalmente con la elaboración de instrumentos de evaluación propios de su contexto.

\subsection{APORTES INSTITUCIONALES.}

La investigación se aplicó en colegios de varones, en especial pertenecientes al consorcio de colegios católicos del Perú con sede en la provincia de Huancayo y muy directamente con los centros educativos salesianos de varones: Salesiano Santa Rosa de Huancayo y Salesiano Técnico Don Bosco tiene influencia positiva.

Además, se propone una ficha de evaluación de la sesión de clase como aporte institucional. 


\section{CONCLUSIONES}

1. El coaching tiene influencia positiva en el desarrollo del desempeño docente en la Provincia de Huancayo.

2. Si existe un programa de aplicación del coaching en el desarrollo del desempeño docente en la provincia de Huancayo.

3. Las características que tiene el coaching está supeditada al desarrollo personal y profesional del docente.

4. Las ventajas que tiene el coaching ayuda a crecer al docente de manera personal y profesional; y las desventajas hacen que el coaching se convierta en una actividad repetitiva.

5. El nivel de desempeño docente es deficiente y después alto luego de aplicar el experimento. 
6. Los indicadores de desarrollo del desempeño docente están en función a las dimensiones que se pretende evaluar.

7. Los resultados obtenidos del desempeño docente son más favorables en el grupo experimental que en el grupo control antes y después del experimento. 


\section{SUGERENCIAS}

1. Para lograr un cambio significativo en el resultado académico y de formación y desarrollo de los alumnos de nuestra plantel, debemos utilizar el coaching con nuestros profesores, y esto ayudará al desarrollo del desempeño docente de los mismos; en todas las instituciones educativas posibles.

2. Los profesores; de los distintos planteles de Huancayo, deben aplicarse en cada uno de ellos el autocoaching, a fin de mejorar día a día aspectos profesionales y personales.

3. Si queremos resultados diferentes, apliquemos estrategias diferentes en nuestras aulas y ello garantizará el desarrollo pleno de lo que estábamos esperando realizar; es decir, aplicar estrategias modernas para alumnos modernos. 


\section{BIBLIOGRAFÍA}

1. Adriano, A. (2007). Clima organizacional y satisfacción laboral en las Instituciones Educativas del distrito de Satipo.

2. Calderón, J. (2007). Autoestima y liderazgo en directores de las Instituciones Educativas de la Provincia de Huancayo.

3. Cardó, A. (2010). Buen desempeño profesional docente: Lineamientos preliminares. Presidente del Consejo Nacional de Educación. Mejores aprendizajes con buen desempeño docente en nuevas escuelas. Del Primer Congreso Pedagógico Nacional organizado por el Consejo Nacional de Educación.

4. Cedeño, I. y otro (2008) El coaching como herramienta gerencial para optimizar el desempeño laboral del docente de la Universidad Nacional Experimental de las Fuerzas Armadas (UNEFA) Nucleo Barquisimeto, Estado Lara. Venezuela

5. De La Cruz, R. (2007). Clima laboral y Desempeño Docente.

6. Doyle, K. (1975). Student evaluation of instruction. Lexington, MA.: Lexington Books.

7. Hernández, R. y otros (1997) Metodología de la investigación. Editorial Mc Graw Hill. Interamericana. Editores S.A. de C.V. Segunda Edición. México.

8. Mateo, J. (2000) La evaluación educativa, su práctica y otras metáforas. Barcelona. Ed. Horsori. 
9. Mateo, J. (1998) La evaluación educativa. En Enciclopedia Generaı de la Educación, 532-586. Barcelona. Océano.

10. Mateo, J. y otros. (1996). "La Evaluación del profesorado. Un tema a debate". Revista de Investigación Educativa. 14, 2, 73-94.

11. Mendoza, R. (2009) El Coaching y su Aplicación en la Institución Educativa No 14344 Silahua - Frias Ayabaca - Piura. Universidad Nacional de Piura.

12. Montalvo, M. (2007) Motivación y Desempeño Docente, manifiesta que la motivación es el factor más importante del desempeño docente.

13. O'connor, J. y otro (2005) Coaching con PNL. Editorial Urano. Barcelona España.

14. Orellana, G. y Huamán L. (1999) Diseño y elaboración de proyectos de investigación pedagógica. Instituto Andino de Pedagogía INAP. Huancayo Perú. PP. 166.

15. Palma (2000) Variables de Diagnóstico organizacional. Madrid España.

16. Salomé, R. (2008), El liderazgo estratégico del director y su relación entre el desempeño docente en instituciones educativas del distrito de San Agustín de Cajas.

17. Sánchez, H. y Reyes, C. (2006) Metodología y diseños en la investigación científica. Lima Perú.

18. Whitmore, J. (2010) Coaching. El método para mejorar el rendimiento de las personas. Editorial Paidós. Argentina. 


\section{DIRECCIONES ELECTRÓNICAS}

Cambia de vida. Coaching personal on line http://www.cambiadevida.com/

Coach on line

http://coachenlinea.wordpress.com/

Consejería y coaching en línea. Psicología. Mediación. Arbitraje.

http://www.sipmapr.net/id41.htm

Escuela Europea. Líder en coaching en Español.

http://www.tisoc21sl.com/cursos-a-distancia-de-

coaching.php?gclid=CPTWrMvB9asCFQ475QodMVA7Mg

Programa de coaching en línea (FACEBOOK)

http://www.facebook.com/event.php?eid $=177061039002186$ 


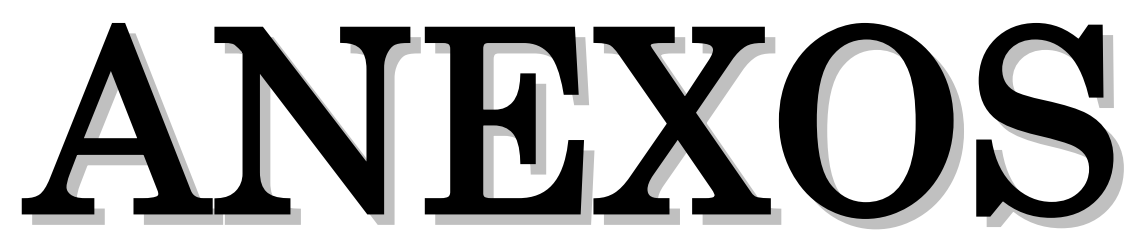

